\title{
CCDC186 controls dense-core vesicle cargo sorting by exit
}

Jérôme Cattin-Ortoláa ${ }^{a, t, \ddagger}$, Irini Topalidou ${ }^{a, \dagger}$, Ho-Tak Lau ${ }^{b}$, Blake Hummer ${ }^{c}$, Cedric S. Asensioc, Shao-En Ong ${ }^{\mathrm{b}}$ and Michael Ailion ${ }^{\mathrm{a}, *}$

${ }^{a}$ Department of Biochemistry, University of Washington, Seattle, United States

${ }^{b}$ Department of Pharmacology, University of Washington, Seattle, United States

${ }^{\mathrm{C} D e p a r t m e n t}$ of Biological Sciences, University of Denver, Denver, United States

${ }^{\dagger}$ These authors contributed equally to this work.

${ }^{\ddagger}$ Present address: MRC Laboratory of Molecular Biology, Cambridge, United Kingdom

*Correspondence: mailion@uw.edu

Running head: CCDC186 is a DCV cargo-sorting factor

\section{Abbreviations}

DCV: dense-core vesicle

TGN: trans-Golgi network

EARP: endosome-associated recycling protein

iDCV: immature dense-core vesicle

CPE: carboxypeptidase $\mathrm{E}$

PC1/3: proprotein convertase $1 / 3$

CgA: chromogranin A

MAO: monoamine oxidase

CPD: carboxypeptidase D

CD-MPR: cation-dependent mannose 6-phosphate receptor 


\section{ABSTRACT}

The regulated release of peptide hormones depends on their packaging into dense-core vesicles (DCVs). Two models have been proposed for DCV cargo sorting. The "sorting by entry" model proposes that DCV cargos selectively enter nascent DCVs at the trans-Golgi network (TGN). The "sorting by exit" model proposes that sorting occurs by the post-TGN removal of non-DCV cargos and retention of mature DCV cargos. Here we show that the coiled-coil protein CCDC186 controls sorting by exit. Ccdc186 KO insulinoma cells secrete less insulin, fail to retain insulin and carboxypeptidase $\mathrm{E}$ in mature DCVs at the cell periphery, and fail to remove carboxypeptidase D from immature DCVs. A mutation affecting the endosome-associated recycling protein (EARP) complex causes similar defects in DCV cargo retention and removal. CCDC186 and EARP may act together to control the post-Golgi retention of cargos in mature DCVs. 


\section{INTRODUCTION}

Neurons and endocrine cells contain specialized secretory vesicles called dense-core vesicles (DCVs) that undergo regulated secretion in response to external stimuli. DCVs contain neuropeptides, growth factors, biogenic amines, and peptide hormones that control numerous biological processes, ranging from growth and metabolism to mental state. DCVs are generated at the trans-Golgi network (TGN) as immature DCVs (iDCVs) and undergo a maturation process that includes vesicle acidification, proteolytic processing of cargos, and the acquisition of proper compartmental identity and release competency (Borgonovo et al., 2006; Gondré-Lewis et al., 2012; Kim et al., 2006; Tooze et al., 2001). Peptide precursors are processed in acidic iDCVs by several distinct processing enzymes. For example, the insulin precursor proinsulin is processed into mature insulin via two proprotein convertase enzymes (PC1/3 and PC2) and carboxypeptidase E (CPE) (Steiner et al., 2011).

Two models of DCV cargo sorting have been proposed. The 'sorting by entry' model proposes that cargos are sorted in the trans-Golgi and preferentially enter nascent DCVs as they bud off; the 'sorting by exit' model proposes that cargos are sorted in a post-Golgi step in which non-DCV cargos are removed from iDCVs while mature DCV cargos are retained (Arvan and Castle, 1998; Tooze, 1998). Both mechanisms likely contribute to DCV cargo sorting. Cargos removed from iDCVs include the transmembrane proteins carboxypeptidase $D$ (CPD) and the mannose 6-phosphate receptors (CD-MPR and CI-MPR) (Klumperman et al., 1998; Varlamov et al., 1999).

Genetic studies in the nematode $C$. elegans have identified several molecules that function in neuronal DCV biogenesis, including the small G protein RAB-2, the RAB-2 effector CCCP-1 (the C. elegans homolog of CCDC186/C10orf118), the endosome-associated recycling protein (EARP) complex (VPS-50, VPS-51, VPS-52, and VPS-53), and the EARP interactor EIPR-1 (Ailion et al., 2014; Edwards et al., 2009; Paquin et al., 2016; Sumakovic et al., 2009; Topalidou et al., 2016). Loss of any of these proteins causes a similar reduction in the levels of 
cargos in mature DCVs in axons, but it is unclear how RAB-2 and CCCP-1/CCDC186 are connected to EARP. In both C. elegans and in the rat insulinoma 832/13 cell line, RAB-2 and CCCP-1/CCDC186 colocalize near the TGN where the early steps of DCV biogenesis take place (Ailion et al., 2014; Cattin-Ortolá et al., 2017). EARP is localized to two distinct compartments in $832 / 13$ cells, a recycling endosome compartment and a compartment near the TGN where it colocalizes with CCDC186 (Topalidou, Cattin-Ortolá, et al., 2018). Additionally, Eipr1 knockout 832/13 cells have reduced insulin secretion and an altered distribution of insulin in the cell, with relatively more insulin near the TGN and less at the cell periphery (Topalidou, Cattin-Ortolá, et al., 2018). Thus, EARP and EIPR1 may be important for acting near the TGN to ensure the retention of processed cargos in mature DCVs.

Here we investigate the role of CCDC186 in DCV biogenesis, maturation, and cargo sorting in $832 / 13$ cells. Our results suggest that CCDC186 acts together with EARP to control several aspects of DCV cargo sorting, including the post-Golgi removal of some non-DCV cargos and retention of mature DCV cargos. 


\section{RESULTS}

\section{CCDC186 is required for normal insulin secretion and distribution of mature DCV cargos}

Our studies in C. elegans show that cccp-1 (the C. elegans homolog of

Ccdc186/C10orf118) and eipr-1 act in the same genetic pathway to control locomotion and neuronal DCV cargo levels (Figure S1). We recently found that EIPR1 is needed for proper insulin secretion and distribution of mature DCV cargos in rat insulinoma 832/13 cells

(Topalidou, Cattin-Ortolá, et al., 2018). CCDC186 is expressed in endocrine cell lines such as 832/13 and in multiple tissues in mice, including brain, heart, liver, kidney, and spleen (Figure S2A). To investigate the function of CCDC186 in 832/13 cells, we generated a Ccdc186 knockout $(\mathrm{KO})$ cell line and a $\mathrm{KO}$ line rescued by transgenic expression of a wild-type Ccdc186 cDNA (Figure S2B-D).

We found that Ccdc186 KO cells share many phenotypes with Eipr1 KO cells. In Ccdc186 KO cells, stimulated insulin secretion was significantly reduced (Figure 1A), but the total cellular insulin level was not changed (Figure 1B). Both proinsulin secretion and the cellular level of proinsulin were slightly increased in Ccdc186 KO cells, but the effects were not statistically significant (Figure S3A,B). Additionally, the ratio of total cellular proinsulin to insulin was unchanged in the Ccdc186 KO cells (Figure S3C) and there was no change in constitutive secretion (Figure S3D). These results suggest that CCDC186, like EIPR1, is required for normal levels of regulated secretion but is not required for the processing of proinsulin to insulin.

By measuring exocytotic events using NPY tagged with the $\mathrm{pH}$-sensitive GFP pHluorin, we found that Eipr1 $\mathrm{KO}$ cells have an apparent exocytosis defect that could contribute to their insulin secretion defect (Topalidou, Cattin-Ortolá, et al., 2019, manuscript submitted to MBoC). Similarly, we found that exocytotic events were strongly reduced in Ccdc186 KO cells under stimulating conditions (Figure S4), suggesting that Ccdc186 cells also have an exocytosis defect. However, a caveat to this experiment is that this assay may have underestimated the true exocytosis rate if it was not possible to detect DCVs carrying reduced amounts of 
NPY::pHluorin. As Ccdc186 KO cells appear to carry reduced amounts of cargos in mature DCVs (see below), it is possible that DCV exocytotic events in this mutant line were more difficult to detect.

The processing of proinsulin to insulin is mediated by several processing enzymes, including the proprotein convertases PC1/3 (PCSK1) and carboxypeptidase E (CPE) (Naggert et al., 1995; Smeekens et al., 1992). We recently found that EIPR1 is needed for the normal cellular levels of mature PC1/3 and CPE in 832/13 cells (Topalidou, Cattin-Ortolá, et al., 2019, manuscript submitted to $M B O C)$. Similarly, we found that loss of CCDC186 resulted in reduced levels of mature PC1/3 and CPE (Figure $1 \mathrm{C}$ and Figure S5A,B). By contrast, the level of the unprocessed pro form of CPE (pro-CPE) was not altered in Ccdc186 KO cells (Figure 1D), similar to Eipr1 KO cells (Topalidou, Cattin-Ortolá, et al., 2019, manuscript submitted to MBoC). These results suggest that CCDC186, like EIPR1, acts after the processing of pro-CPE.

We found that EIPR1 is required for the proper cellular distribution of mature CPE (CPEC) and insulin, but not of pro-CPE and proinsulin (Topalidou, Cattin-Ortolá, et al., 2019, manuscript submitted to $M B O C)$. In wild-type cells, insulin and mature CPE are found as colocalized puncta spread throughout the cytoplasm (Figure S5C). By contrast, in Ccdc186 KO cells, mature CPE and insulin are localized primarily to a perinuclear region that partially colocalizes with TGN38 (Figure 1E,F and Figure S6A,B). The redistribution of CPE and insulin in Ccdc186 KO cells appears to be due to decreased levels of mature CPE and insulin in vesicles in the cell periphery and increased retention of CPE and insulin in or near the TGN (Figure 1G,H and Figure S6C,D). In contrast to mature CPE and insulin, pro-CPE and proinsulin are localized near the TGN in WT and Ccdc186 KO cells (Figure S7). All of the CPE and insulin localization results of Ccdc186 KO cells are similar to those of Eipr1 KO cells (Topalidou, CattinOrtolá, et al., 2019, manuscript submitted to $M B o C)$. These results suggest that CCDC186, like EIPR1, acts at a post-Golgi level and that it is needed for the proper levels and cellular 
distribution of several mature DCV cargos, including insulin and the insulin processing enzymes PC1/3 and CPE.

One possible explanation for the increased colocalization of insulin and mature CPE with TGN38 is that there might be increased acidification of the Golgi in the Ccdc186 KO cells that allows proteolytic processing of DCV cargos. However, there was little change in the $\mathrm{pH}$ of the Golgi in Ccdc186 KO cells and if anything a slight increase (Figure S8). Additionally, pulsechase experiments show that DCV cargo is not stuck in the Golgi in Ccdc186 KO cells, but does exit the TGN and move out to the periphery (Figure S9). These results are consistent with CCDC186 acting in a post-Golgi step in the DCV biogenesis pathway.

\section{CCDC186 localizes to a ring-like compartment around proinsulin}

We previously reported that EARP localizes to two distinct compartments: an endosomal recycling compartment and a CCDC186-positive compartment relevant to DCV biogenesis (Topalidou et al., 2018). In C. elegans neurons and 832/13 cells, CCCP-1 localizes at or close to the TGN and immature DCVs (Ailion et al., 2014; Cattin-Ortolá et al., 2017). These data were based largely on overexpressed GFP-tagged constructs. To more specifically define the localization of endogenous CCDC186 in 832/13 cells, we performed costaining of CCDC186 with a number of compartmental markers. Endogenous CCDC186 is localized to an area immediately adjacent to but not tightly overlapping with the TGN marker TGN38 (Figure 2A and Figure S10). By contrast, CCDC186 colocalized most closely with the SNARE protein syntaxin 6, and the iDCV cargos chromogranin $\mathrm{A}(\mathrm{CgA})$ and proinsulin (Figure $2 \mathrm{~A}$ and Figure $\mathrm{S} 10$ ). Syntaxin 6 and proinsulin are localized to the TGN and iDCVs, but are excluded from mature DCVs (Klumperman et al., 1998; Wendler et al., 2001). CgA is localized mainly to a perinuclear area, but also to some puncta throughout the cytoplasm and the cell periphery (Figure S10), suggesting that $\mathrm{CgA}$ is present at the TGN, iDCVs, and some mature DCVs. CCDC186 does not colocalize tightly with markers of the ERGIC (ERGIC53), cis-Golgi (GM130), early 
endosome (EEA1), or lysosome (LAMP1) (Figure 2A and Figure S10). We conclude that CCDC186 is localized at or close to the TGN and iDCVs.

To determine the localization of CCDC186 at higher resolution, we used structured illumination microscopy (SIM, Figure 2B) and stimulated emission depletion microscopy (STED, Figure S11). With both techniques, we found that endogenous CCDC186 is localized to ring-like structures of variable size ( 200-500 nm diameter) rather than the puncta seen by conventional confocal microscopy. Interestingly, the rings of CCDC186 often surrounded proinsulin, suggesting that CCDC186 localizes at or close to iDCV membranes, or to a subdomain of the TGN carrying DCV cargos.

\section{The CCDC186 C-terminal domain is in close proximity to carboxypeptidase D}

To further characterize the compartment where CCDC186 localizes, we used the proximity biotinylation BiolD approach to investigate the protein composition of CCDC186positive membranes (Roux et al., 2012). To increase the specificity of labeling the membranes bound by CCDC186, we used a mitochondrial relocation strategy because it should give a background composed of mitochondrial proteins that we could easily discard (Shin, Gillingham, et al., 2017).

CCDC186 was ectopically expressed and localized to mitochondria through attachment to the mitochondrially-localized transmembrane domain of monoamine oxidase (MAO) (Wong and Munro, 2014) (Figure S12A). We generated constructs with full-length CCDC186 and the CCDC186 C-terminal domain CC3, each fused at their C-terminus to an HA tag and to MAO (Figure S12B). CC3 binds RAB2 and membranes and is both necessary and sufficient for localization of CCDC186 to the compartment near the TGN (Cattin-Ortolá et al., 2017). Experiments using the full-length CCDC186 protein fused to MAO resulted in low expression of the construct and high toxicity in $832 / 13$ cells, so we did not pursue further. We showed by immunofluorescence that CC3::HA::MAO colocalized well with the mitochondrial marker 
MitoTracker but not with the TGN marker TGN38 (Figure S12C). We also observed that CC3::HA::MAO colocalized with constitutively active forms of both RAB2A and RAB2B (Figure S12D,E). Thus, the mitochondrial relocation experiment recapitulates the known interaction of the CC3 domain with RAB2.

For BioID, we fused the promiscuous biotin ligase BirA* to the $\mathrm{C}$ terminus of $\mathrm{CC} 3$ (CC3:: BirA*::HA::MAO) (Figure 3A,B). BirA*::HA::MAO was used as a negative control. We generated PC12 cell lines that stably expressed these constructs instead of 832/13 cells for technical reasons (see Material and Methods) and performed mass spectrometry on the biotinylated material pulled down by streptavidin beads. Many peptides for CCDC186 were found in the CC3 sample but few were found in the negative control, demonstrating the efficiency of the labeling (Figure 3C and Table S1). Comparison of CC3::HA::MAO with the negative control also gave carboxypeptidase D (CPD) as a possible specific hit (Figure 3C, Figure S13, and Table S1). Immunoblotting of streptavidin-purified biotinylated proteins from cells expressing the different BirA* constructs using an anti-CPD antibody validated the mass spectrometry result (Figure 3D). We also verified that expression of CC3::HA::MAO resulted in partial relocation of CPD to the mitochondria (Figure 3E). CPD belongs to the family of metallocarboxypeptidases that remove arginine or lysine residues from the C-terminus of peptides, but its targets and cellular function are unclear (Fricker, 2013). CPD localizes mainly to the TGN but also traffics to the plasma membrane and endosomes (Varlamov and Fricker, 1998), and CPD also localizes to iDCVs (Varlamov et al., 1999). Because CPD is a transmembrane protein (Kuroki et al., 1995; Xin, Varlamov, et al., 1997), CCDC186 might interact with a membrane carrying CPD, such as the TGN or vesicles that bud from the TGN.

\section{CCDC186 is required for the removal of carboxypeptidase D from dense-core vesicles}

Studies in AtT-20 cells have shown that although CPD localizes to iDCVs, it is mostly absent from mature DCVs, indicating that CPD is removed from iDCVs during maturation 
(Varlamov et al., 1999). We found that CCDC186 and CPD partially colocalized in a perinuclear area (Figure 4A). Importantly, although CPD colocalized with the TGN marker TGN38 in WT cells (Figure 4B), CPD was largely mislocalized to puncta distributed throughout the cytoplasm in Ccdc186 KO cells and this phenotype was rescued by expression of Ccdc186(+) (Figure 4B). Because EIPR1 and CCDC186 function in the same pathway in DCV biogenesis (Figure S1), we tested whether CPD localization also depends on EIPR1. We found that CPD was localized to puncta distributed throughout the cytoplasm in Eipr1 $\mathrm{KO}$ cells, but to a lesser extent than in the Ccdc186 KO cells (Figure 4B). Thus, CCDC186 and EIPR1 are required to restrict CPD localization to the TGN.

We reasoned that the punctate cytoplasmic pattern of CPD in Ccdc186 KO cells and Eipr1 $\mathrm{KO}$ cells could be the result of defective CPD removal from iDCVs. Consistent with this possibility, most CPD-positive cytoplasmic puncta colocalized with insulin in Ccdc186 KO cells and Eipr1 KO cells (78 +/- $10 \%$ of CPD cytoplasmic puncta in Ccdc186 KO cells are insulin positive), suggesting that these CPD-positive puncta represent mature DCVs (Figure 4C).

To further test whether CPD is mislocalized to mature DCVs in the Ccdc186 and Eipr1 mutants, we performed cellular fractionation experiments by equilibrium sedimentation through a sucrose gradient to separate the Golgi and DCV compartments (Figure 5). The absence of CCDC186 or EIPR1 did not have a significant effect on the sedimentation profile of PC1/3, indicating that the density of DCVs is not significantly altered in either knock-out cell line. However, we found that some of the CPD shifted to a heavier fraction that comigrated with the DCV marker PC1/3 in both Ccdc186 and Eipr1 KO cells (Figure 5), consistent with the model that CPD is retained in mature DCVs in these mutants. Together, these immunofluorescence and biochemical data indicate that CCDC186 and EIPR1 are required for the removal of CPD from iDCVs.

Similar to CPD, other proteins such as the cation-dependent mannose 6-phosphate receptor (CD-MPR) are removed from mature DCVs (Klumperman et al., 1998). Interestingly, 
bioRxiv preprint doi: https://doi.org/10.1101/616458; this version posted November 6, 2019. The copyright holder for this preprint (which was not certified by peer review) is the author/funder, who has granted bioRxiv a license to display the preprint in perpetuity. It is made available under aCC-BY 4.0 International license.

although the CD-MPR is a transmembrane protein with similar cytosolic sorting motifs as CPD (Bonifacino and Traub, 2003; Eng et al., 1999), its removal from iDCVs is not dependent on CCDC186 or EIPR1 (Figure S14). Thus, different mechanisms are needed for the removal of CPD and the CD-MPR from immature DCVs. 


\section{DISCUSSION}

In this study we investigated the role of CCDC186 in DCV function in the rat pancreatic beta-cell line 832/13. Using CRISPR knock-outs and rescuing experiments, we found that CCDC186 acts in the post-Golgi maturation of DCVs to control the retention of mature cargos such as insulin and CPE, and the removal of cargos such as CPD. We propose that CCDC186 acts as a regulator of DCV maturation by ensuring that mature DCVs carry the proper type and amount of cargo.

\section{CCDC186 controls retention of cargos in mature DCVs}

C. elegans mutants in rab-2, cccp-1 (the C. elegans homolog of Ccdc186), eipr-1, and the EARP complex subunits have reduced levels of DCV cargo (Ailion et al., 2014; Edwards et al., 2009; Paquin et al., 2016; Sumakovic et al., 2009; Topalidou et al., 2016). This conclusion was based mainly on assays using exogenous DCV cargos overexpressed in neurons. In this study, we used the rat insulin-secreting insulinoma cell line $832 / 13$ to investigate the secretion, localization, and processing of endogenous DCV cargos. We found that cells lacking CCDC186 remain responsive to stimulated secretion, but secrete reduced levels of insulin and have reduced levels of insulin and other luminal cargos in mature DCVs at the cell periphery. Our data are most consistent with a model in which CCDC186 acts in a post-Golgi step to control retention of DCV cargos (Figure 6), rather than acting in the TGN to control sorting of cargos by entry or having a direct effect on peptide processing. First, Ccdc186 KO cells show no defect in the levels or localization of immature DCV cargos such as proinsulin and pro-CPE, but have reduced levels of mature cargos such as CPE. Second, the exogenous DCV cargo ANF-GFP was not stuck in the TGN in Ccdc186 KO cells, but moved to the periphery following release of a low-temperature block. Third, there is not increased acidity of the TGN in Ccdc186 KO cells. Fourth, there is no apparent defect in processing of proinsulin to insulin in Ccdc186 KO cells. These data suggest that early steps in the sorting and processing of pro-proteins occur normally 
in the absence of CCDC186, but that mature DCV cargos are lost in a post-Golgi step. Eipr1 KO cells have similar defects (Topalidou, Cattin-Ortolá, et al., 2018, and this study), supporting the genetic data indicating that CCDC186 and EIPR1/EARP act in the same pathway to regulate DCV maturation.

\section{CCDC186 controls the removal of CPD from immature DCVs}

In a proximity biotinylation screen, we identified CPD as being in close proximity to the C-terminal CC3 domain of CCDC186. CPD is a transmembrane protein with a short cytosolic tail ( 60 amino acids) and a longer N-terminal intraluminal domain (Kuroki et al., 1995; Xin, Varlamov, et al., 1997). CPD is an ubiquitously expressed member of the metallocarboxypeptidase family, but its role in the processing of peptides destined to the regulated secretory pathway remains unclear (Fricker, 2013).

The basis of the interaction between CCDC186 and CPD-positive membranes is not clear. In coimmunoprecipitation experiments from 832/13 detergent lysates, we did not detect an interaction between GFP-tagged CCDC186 and either endogenous CPD or overexpressed mCherry-tagged CPD cytosolic tail (data not shown), indicating that CCDC186 and CPD do not interact directly or their interaction is too weak to detect by this method. CCDC186 might bind to CPD-positive membranes via interaction with another protein or by directly binding to membranes. The CC3 domain of CCDC186 is capable of direct association with synthetic membrane liposomes and is both necessary and sufficient for CCDC186 localization to TGN/iDCV membranes (Cattin-Ortolá et al., 2017).

Studies in AtT-20 cells have shown that CPD localizes to the TGN and to iDCVs but is mostly absent from mature DCVs (Varlamov et al., 1999). We show here that in the absence of CCDC186 or EIPR1, CPD remains in mature, insulin-positive DCVs. Thus, we propose that CCDC186 and EIPR1 ensure the removal of CPD from DCVs during maturation. Similar to CPD, other proteins such as the cation-independent and the cation-dependent mannose 6- 
phosphate receptors (CI-MPR and CD-MPR) are removed from iDCVs by a pathway that depends on AP-1 and clathrin (Dittie et al., 1999; Klumperman et al., 1998). The fate of these proteins once removed is unknown, but it has been proposed that they follow the endosomal route (Arvan and Halban, 2004; Feng and Arvan, 2003). Strikingly, although the CD-MPR is also a transmembrane protein with similar cytosolic sorting motifs as CPD (Bonifacino and Traub, 2003; Eng et al., 1999), its removal from iDCVs was not affected by the absence of CCDC186 or EIPR1, suggesting that different cargos may be removed from immature DCVs by different mechanisms. Our data suggest that CCDC186 and EIPR1 ensure the removal of CPD from DCVs (Figure 6).

\section{What is the role of CCDC186 in DCV biogenesis?}

Our data suggest that CCDC186 is important for both the retention of mature DCV cargos and the removal of some non-DCV cargos from immature DCVs. These are both postGolgi processes, but it is unclear whether they are independent or controlled coordinately by a single action of CCDC186. Here we propose that CCDC186 serves a role in ensuring that the proper amount and type of cargo remains in mature DCVs.

Our data suggest that CCDC186 acts after the processing of peptide cargos. This distinguishes CCDC186 from other proteins important for DCV biogenesis such as PICK1, ICA69, and HID1. Like CCDC186, these proteins are also required for normal levels of mature DCV cargos (Cao, Mao, et al., 2013; Du, Zhou, Zhao, Cheng, et al., 2016; Holst, Madsen, et al., 2013; Hummer et al., 2017), but in contrast to CCDC186, loss of PICK1, ICA69, or HID1 leads to a defect in the processing of proinsulin to insulin (Cao, Mao, et al., 2013; Du, Zhou, Zhao, Cheng, et al., 2016). PICK1, ICA69, and HID1 have been proposed to act at an early step of DCV biogenesis during budding of immature DCVs from the TGN; our data suggest that CCDC186 and EIPR1 act at a post-Golgi step during DCV maturation. 
The connection between CCDC186 and the EARP complex suggests there may be trafficking between EARP-positive endosomes and CCDC186-positive TGN/iDCV membranes. Such a trafficking step may be involved in the removal of CPD from iDCVs. Trafficking from endosomes to iDCVs may also be involved in the retrieval of DCV membrane proteins following exocytosis. It has been shown that after DCV exocytosis, transmembrane proteins such as phogrin and PAM are recycled and traffic through endosomes before reaching newly-generated DCVs (Bäck et al., 2010; Vo et al., 2004). CCDC186 and EARP could mediate the recycling of DCV proteins from endosomes to iDCVs; disrupting this recycling pathway could also indirectly impair the proper trafficking of sorting receptors required for retention of luminal DCV cargos. Similar to loss of CCDC186 or EIPR1, loss of other proteins such as BAIAP3 and Vti1a/Vti1b that are involved in retrograde trafficking from endosomes to Golgi also leads to reduced levels of DCV cargos (Emperador-Melero et al., 2018; Zhang et al., 2017). However, BAIAP3 and Vti1a/b appear to affect endosome to Golgi trafficking more generally because their loss also affects non-DCV cargos and perturbs Golgi morphology (Emperador-Melero et al., 2018; Zhang et al., 2017), whereas loss of CCDC186 or EIPR1 does not affect non-DCV cargos and has no apparent effect on Golgi morphology as assayed by TGN38 staining. CCDC186 and EARP may be specifically involved in endosomal trafficking of DCV-related factors or cargos.

The idea that CCDC186 and EARP affect DCV cargo levels by regulating trafficking to or from endosomes is supported by experiments in C. elegans that found that disrupting trafficking to the endolysosomal system could restore levels of DCV cargo in rab-2 mutants, suggesting that cargo is lost via an endolysosomal route (Edwards et al., 2009; Sumakovic et al., 2009). Given that CCDC186/CCCP-1 and EARP act in the same genetic pathway as RAB-2 (Ailion et al., 2014; Topalidou et al., 2016), it is likely that they also act to retain cargos in mature DCVs by preventing the loss of cargos to the endolysosomal system. Interestingly, a recent study showed that cholesterol-deficient DCVs are lost through lysosomal degradation, leading to a reduction in insulin secretion (Hussain, Harris, et al., 2018). This observation raises the 
intriguing possibility that CCDC186 and EARP may be involved not only in protein trafficking,

but also in cholesterol transfer to DCVs. Supporting this possibility, the EARP complex

associates with Rab11-positive recycling endosomes (Schindler, Chen, et al., 2015), and Rab11

and its effector RELCH act to promote cholesterol transfer from recycling endosomes to the

TGN (Sobajima et al., 2018). Perhaps CCDC186 and EARP are also involved in this process. 


\section{MATERIALS \& METHODS}

\section{C. elegans strains, molecular biology, and plasmids}

C. elegans strains were cultured using standard methods (Brenner, 1974). A complete list of strains used is provided in the Strain List (Table S2). A complete list of constructs is provided in the plasmid list (Table S3). Vector backbones and PCR-amplified fragments containing 20-30 bp overlapping ends were combined by Gibson cloning (Gibson et al., 2009).

\section{Locomotion assays}

To measure C. elegans locomotion, first-day adults were picked to 2 to 3 -day-old lawns of OP50 bacteria, stimulated by touching their tail using a worm pick, and body bends were then counted for one minute. A body bend was defined as the movement of the worm from maximum to minimum amplitude of the sine wave.

\section{C. elegans imaging and image analysis}

Young adult worms were placed in $8 \mu \mathrm{l}$ of $50 \mathrm{mM}$ sodium azide on $2 \%$ agarose pads and anesthetized for $10 \mathrm{~min}$. Images of animals with dorsal side up were obtained using a Nikon Eclipse 80i wide-field compound microscope. The same region of the dorsal cord around the vulva was imaged in all worms. All strains in an experiment were imaged on the same day and the microscope settings were kept constant. Maximum-intensity projections were quantified using ImageJ. For each animal, the total fluorescence in five regions of interest including the dorsal cord was measured and the background fluorescence of a region of the same size adjacent to the dorsal cord was subtracted from each. The final fluorescence intensity for each animal was calculated as the average total fluorescence of the five regions.

\section{Cell culture}


The $832 / 13$ cell line is an INS-1-derived clone that was isolated by Dr. Christopher Newgard (Duke University School of Medicine) and obtained by Dr. Duk-Su Koh (via Dr. Ian Sweet, both at University of Washington), who provided it to us. The Eipr1 KO and EIPR1(+) rescued 832/13 cell lines were generated as described (Topalidou, Cattin-Ortolá, et al., 2018). The 832/13 and 832/13-derived cell lines were grown in RPMI 1640-GlutaMAX (GIBCO) medium supplemented with 10\% FBS (RMBIO), 1 mM sodium pyruvate (GIBCO), $10 \mathrm{mM}$ HEPES (GIBCO), 1X Pen/Strep (GIBCO), and $0.0005 \%$ beta-mercaptoethanol at $5 \% \mathrm{CO}_{2}$ and $37^{\circ} \mathrm{C}$. The PC12 cell line was obtained from Dr. Duk-Su Koh (University of Washington) and was grown in DMEM-GlutaMAX (GIBCO) medium supplemented with $10 \%$ horse serum (RMBIO), $5 \%$ FBS (RMBIO), and $1 \mathrm{X}$ Pen/Strep (GIBCO) at $5 \% \mathrm{CO}_{2}$ and $37^{\circ} \mathrm{C}$. All cell lines were shown to be mycoplasma-free by DAPI staining and PCR test (ABM, G238).

\section{Protein extraction from mouse tissues}

Tissues were dissected from an adult female mouse. Bigger organs such as the liver and brain were placed in $3 \mathrm{ml}$ of lysis buffer, and smaller organs such as the heart and intestine were placed in $1.5 \mathrm{ml}$ of lysis buffer (Tissue-PE LB ${ }^{\mathrm{TM}}$, G-Biosciences \#786-181). These organs were then frozen in liquid nitrogen and kept at $-80^{\circ} \mathrm{C}$ for 1 hour. Tissues were dissolved with the use of a homogenizer until they became liquid and then were further homogenized with mechanical breakage using a 22-gauge needle, applying 12-15 strokes. The tissues were then spun down at 20,000g in a microcentrifuge for 15 minutes, and the supernatant was collected and spun again for 5 more minutes. The supernatant was finally collected and stored at $-80^{\circ} \mathrm{C}$.

\section{Immunoblotting}

Protein extracts were loaded on 8,10 , or $12 \%$ SDS-PAGE gels and transferred onto PVDF membranes. For the blots shown in Figure S2A,B, membranes were blocked in $3 \%$ milk in TBST (50 mM Tris pH 7.4, $150 \mathrm{mM} \mathrm{NaCl}, 0.1 \%$ Tween 20) for 1 hour at room temperature 
(RT) and stained with the relevant primary and secondary antibodies in $3 \%$ milk in TBST for 1 hour at RT or overnight at $4^{\circ} \mathrm{C}$, followed by three 5 -minute washes in TBST. For the blots shown in Figure 1C,D, Figure 3D, Figure 5A, and Figure S5A,B, membranes were blocked with Odyssey ${ }^{\circledR}$ Blocking Buffer (PBS) (\#927-4000), incubated overnight at $4^{\circ} \mathrm{C}$ with primary antibody diluted in Odyssey® Blocking Buffer (PBS) supplemented with $0.2 \%$ Tween 20, washed with PBST (PBS + 0.1\% Tween 20), incubated for 1 hour at room temperature in secondary antibody diluted in Odyssey® Blocking Buffer (PBS) supplemented with 0.2\% Tween 20 and 0.01\% SDS, and washed with PBST. A LI-COR processor was used to image the membranes. The antibodies used are listed in Tables S4 and S5.

\section{Generation of Ccdc186 KO by CRISPR}

We performed Cas9-mediated genome editing in 832/13 cells as described (Ran, Hsu, et al., 2013). We designed guide RNAs using the online CRISPR design tool (Ran, Hsu, et al., 2013) and selected a guide RNA that recognizes a sequence in the first exon of rat Ccdc186: 5'- GCGTGAGTCGTCCTTCAACTCGG -3'.

The guide RNA was cloned into the pSpCas9(BB)-2A-GFP vector as described (Ran, Hsu, et al., 2013). The efficiency of the cloned guide RNA was tested using the SURVEYOR nuclease assay according to the manufacturer's instructions (Surveyor Mutation Detection kit, Transgenomic). We designed a homology-directed repair (HDR) template using the pPUR vector (Clontech) as a backbone and cloned approximately $1.5 \mathrm{~kb}$ Ccdc186 homology arms upstream and downstream of the puromycin selection cassette. The HDR template was assembled using Gibson cloning.

To cotransfect the CRISPR plasmid and HDR template into 832/13 cells, 832/13 cells were grown in two $10-\mathrm{cm}$ petri dishes to near confluency. Cells were cotransfected with $7 \mu \mathrm{g}$ CRISPR plasmid and $7 \mu \mathrm{g}$ non-linearized HDR template using Lipofectamine 3000 according to the instructions (ThermoFisher). 48 hours after transfection, we removed the culture 
medium and replaced with new medium containing $1 \mu \mathrm{g} / \mathrm{ml}$ puromycin. The puromycin selection was kept until individual clones could be picked, grown in individual dishes, and tested for Ccdc186 KO. These clones were screened for Ccdc186 KO by immunofluorescence and subsequently by RT-PCR and Western blot.

\section{Lentiviral production, infection of cells, and selection of stable lines}

The following method was used to create a Ccdc186 KO cell line rescued by expression of the Ccdc186 cDNA. Platinum-E (PlatE) retroviral packaging cells (a gift from Suzanne Hoppins) were grown for a couple of generations in DMEM-GlutaMAX (GIBCO) medium supplemented with 10\% FBS (RMBIO), 1 X Pen/Strep (GIBCO), $1 \mu \mathrm{g} / \mathrm{ml}$ puromycin, and 10 $\mu \mathrm{g} / \mathrm{ml}$ blastocidin at $5 \% \mathrm{CO}_{2}$ and $37^{\circ} \mathrm{C}$. On day one, approximately $3.6 \times 10^{5}$ PlatE cells per well were plated in a six-well dish in DMEM-GlutaMAX medium supplemented with $10 \%$ FBS and $1 \mathrm{X}$ Pen/Strep. On day two, a mix of $152 \mu$ l Opti-MEM (ThermoFisher), $3 \mu \mathrm{g}$ CCDC186_pBabehygro DNA, and $9 \mu$ Fugene HD transfection reagent (Promega) was incubated for 10 minutes at room temperature and transfected into each well. On day three, we removed the medium and replaced with new PlatE medium. On day four, approximately $1.5 \times 10^{5}$ Ccdc186 KO 832/13 cells per well were plated in a six-well dish in RPMI 1640-GlutaMAX, supplemented with $10 \%$ FBS, $1 \mathrm{mM}$ sodium pyruvate, $10 \mathrm{mM}$ HEPES, $1 \mathrm{X}$ Pen/Strep, and $0.0005 \%$ betamercaptoethanol. $3 \mu \mathrm{l}$ of $8 \mathrm{mg} / \mathrm{ml}$ hexadimethrine bromide (Sigma) was added to each well. The supernatant of the PlatE cells (48-hour viral supernatant) was collected with a sterile syringe, passed through a 0.45 micron filter, and added to the Ccdc186 KO cells. The Ccdc186 KO cells were incubated for $5-8$ hours at $5 \% \mathrm{CO}_{2}$ and $37^{\circ} \mathrm{C}$, then the medium was changed and replaced with new medium and the cells were incubated overnight at $5 \% \mathrm{CO}_{2}$ and $37^{\circ} \mathrm{C}$. On day five, the supernatant was removed from the Ccdc186 KO cells and replaced with the supernatant from the PlatE cells (72-hour viral supernatant) after passing through a 0.45 micron filter. $3 \mu$ of 8 $\mathrm{mg} / \mathrm{ml}$ hexadimethrine bromide was added to each well and the cells were incubated for 5-8 
hours. The medium was replaced with new $832 / 13$ cell medium. On day six, the Ccdc186 KO cells were collected, transferred into a $10-\mathrm{cm}$ petri dish, and $200 \mu \mathrm{g} / \mathrm{ml}$ hygromycin was added. The cells were grown under hygromycin selection until individual clones could be picked and tested for CCDC186 expression.

\section{RT-PCR}

WT and Ccdc186 KO cells were grown in 10-cm tissue-culture dishes, washed twice with ice-cold PBS, and harvested in $1 \mathrm{ml}$ of TRIzol (Invitrogen). Total RNA was isolated following the manufacturer's protocol and cDNA was synthesized from $1 \mu \mathrm{g}$ total RNA using the QuantiTekt Reverse Transcription kit (Qiagen). The primers used for detecting Ccdc186 cDNA were:

\section{F: 5'-ATGAAGATCAGGAGCAGATTTGAAG-3'}

\section{R: 5'-GGCCTTCTTCGTCCTCTGCTC-3'}

\section{Immunofluorescence}

Cells were seeded onto cover slips (Thomas Scientific \#121N79) placed in 24-well cell culture plates. For GFP or epitope-tagged constructs, cells were transfected at least 24 hours after seeding with 500-800 ng of plasmid using Lipofectamine 2000 (ThermoFisher), according to the manufacturer's instructions, for 24 to 48 hours. When indicated, cells were incubated for 25 minutes with $50 \mu \mathrm{g} / \mathrm{ml}$ Alexa488- or Alexa568-transferrin (Invitrogen \#T12242 or \# T23365) diluted in serum-free RPMI medium + 25 mM HEPES + 1\% BSA before fixation. When indicated, cells were incubated with MitoTracker deep red FM (Thermofisher \#M22426) at a final concentration of $300 \mathrm{nM}$ for 15 minutes in complete medium at $37^{\circ} \mathrm{C}$.

For antibody staining, cells were rinsed twice with PBS and fixed with $4 \%$ paraformaldehyde (made in PBS) for 20 minutes at room temperature, then rinsed twice with PBS and permeabilized with $0.1 \%$ Triton X-100 in PBS for 20 minutes or $0.5 \%$ Triton X-100 in 
PBS for 5 minutes at room temperature, and finally rinsed twice with PBS and placed in $5 \%$ milk in PBS for 1 hour at room temperature. Cells were stained with primary antibodies in $0.5 \%$ milk in PBS at room temperature for 1 hour, washed three times with PBS, and incubated in secondary antibody for 1 hour at room temperature. The cells were washed with PBS three times, mounted onto glass slides using Vectashield (Vector laboratories H1000) or Prolong Diamond (Life Technologies P36965), sealed with transparent nail polish and examined by fluorescence microscopy. Antibodies and their working dilutions are listed in Tables S4 and S5.

Most images were obtained using an Olympus Fluoview FV1200 confocal microscope with a 60X UPlanSApo oil objective (numerical aperture $=1.35$ ). The acquisition software was Olympus Fluoview v4.2. When indicated, a Nikon Eclipse 80i wide-field compound microscope was used. For the quantification of the insulin, proinsulin, CPE, and pro-CPE distributions in Ccdc186 KO cells (Figure 1F, S6B, S7B and S7D), Pearson's correlation coefficients were determined from confocal images using Fiji and the coloc-2 plugin by taking maximum-intensity projections of whole cells and drawing a line around each individual cell. For the quantification shown in Figures $1 \mathrm{G}$ and S6C, z-stack images were obtained using a Nikon Eclipse 80i widefield compound microscope. Maximum-intensity projections were quantified using Fiji. The final fluorescence intensity is the total fluorescence in a region of interest around the Golgi divided by the fluorescence of a region of the same size in the cytoplasm of the cell (Golgi/Cytoplasm). For the quantification shown in Figures $1 \mathrm{H}$ and S6D, z-stack images were obtained using an Olympus Fluoview FV1200 confocal microscope. Maximum-intensity projections were obtained by only keeping the slices that had TGN38 signal so insulin or CPE signal coming from the top and the bottom of the cell would not impact the quantification. A line was drawn around the TGN38 marker and Pearson's correlation coefficients were obtained using FIJI and the coloc-2 plugin. For the quantification of colocalization with CCDC186 (Figure 2A), a square was drawn around the perinuclear area where CCDC186 is localized, and Pearson's correlation coefficients were determined using Fiji and the JACOP plugin. 
For super-resolution imaging, cells were prepared as described above. For SIM imaging, coverslips were mounted with DAPI-free Vectashield and imaged with a 3D SIM OMX SR microscope (GE Healthcare). For STED microscopy, secondary antibodies were used at higher concentration (see Table S5). Coverslips were mounted in DAPI-free fresh Prolong Diamond, sealed with twinsil囚 22, and imaged with a Leica SP8 STED microscope.

\section{Insulin and proinsulin secretion assays}

Cells were grown in 24-well plates to near confluency. Cells were washed twice with PBS and incubated for 1 hour in $200 \mu$ per well resting buffer $(5 \mathrm{mM} \mathrm{KCl}, 120 \mathrm{mM} \mathrm{NaCl}, 24 \mathrm{mM}$ $\mathrm{NaHCO}_{3}, 1 \mathrm{mM} \mathrm{MgCl} 2,15 \mathrm{mM}$ HEPES $\mathrm{pH}$ 7.4). The medium was collected, cleared by centrifugation, and stored at $-80^{\circ} \mathrm{C}$. The cells were incubated for 1 hour in $200 \mu \mathrm{l}$ per well stimulating buffer (55 mM KCl, $25 \mathrm{mM}$ glucose, $70 \mathrm{mM} \mathrm{NaCl}, 24 \mathrm{mM} \mathrm{NaHCO}, 1 \mathrm{mM} \mathrm{MgCl}, 2$ $\mathrm{mM} \mathrm{CaCl}_{2}, 15 \mathrm{mM}$ HEPES $\mathrm{pH}$ 7.4). After stimulation, the medium was cleared by centrifugation and stored at $-80^{\circ} \mathrm{C}$. The cells were washed once with PBS, harvested in PBS, and extracted in $100 \mu$ per well acid-ethanol solution (absolute ethanol: $\mathrm{H}_{2} \mathrm{O}: \mathrm{HCl}, 150: 47: 3$ ). The $\mathrm{pH}$ of the acidethanol solution was neutralized by addition of $20 \mu \mathrm{l}$ of $1 \mathrm{M}$ Tris base per $100 \mu \mathrm{l}$ of acid ethanol and the samples were stored at $-80^{\circ} \mathrm{C}$.

Samples were assayed for insulin or proinsulin content using ELISA according to the instructions of the manufacturers (Rat/Mouse insulin ELISA, Millipore, \#EZRMI-13K; Rat/Mouse proinsulin ELISA, Mercodia, \#10-1232-01). Secreted insulin and proinsulin levels were normalized against total cellular protein concentration and were presented as fraction of the wild type under stimulating conditions (Figure 1A and S3A).

\section{Constitutive secretion assay}

WT and Ccdc186 KO cells were seeded on 12-well plates and grown to subconfluency. Cells were transfected with a plasmid expressing GFP fused to a signal peptide at its $\mathrm{N}$ - 
terminus (ssGFP) (Hummer et al., 2017). 36-48 hours later, cells were incubated for 1 hour at $37^{\circ} \mathrm{C}$ in the cell culture incubator with resting medium $(114 \mathrm{mM} \mathrm{NaCl}, 4.7 \mathrm{mM} \mathrm{KCl}, 1.2 \mathrm{mM}$ $\mathrm{KH}_{2} \mathrm{PO}_{4}, 1.16 \mathrm{mM} \mathrm{MgSO}_{4}, 20 \mathrm{mM}$ HEPES, $2.5 \mathrm{mM} \mathrm{CaCl}_{2}, 25.5 \mathrm{mM} \mathrm{NaHCO}_{3}, 3 \mathrm{mM}$ glucose).

The 12-well plate was transferred to ice and the secretion medium was collected and centrifuged at $20,000 \mathrm{~g}$ for 10 minutes at $4^{\circ} \mathrm{C}$ to remove the cell debris. The supernatant was collected in a separate tube. The pelleted cells were lysed on ice with $50 \mathrm{mM}$ Tris- $\mathrm{HCl}, \mathrm{pH} 8.0$, $150 \mathrm{mM} \mathrm{NaCl}, 1 \%$ Triton X-100, $1 \mathrm{mM}$ EDTA, protease inhibitor cocktail without EDTA (Pierce). The lysate was clarified by centrifugation at $20,000 \mathrm{~g}$ at $4^{\circ} \mathrm{C}$ for 10 minutes and the supernatant was collected to a new tube. The fluorescence of the medium (secreted GFP) and the lysate (cellular GFP) were measured using a plate reader (Molecular Devices Spectramax Gemini XPS, excitation $=485 \mathrm{~nm}$, emission $=525 \mathrm{~nm}$, cutoff $=515 \mathrm{~nm})$. Background fluorescence was determined using the medium and lysate from cells that were not transfected. The data are presented as the ratio of fluorescence in the medium to the fluorescence in the cell lysate.

\section{Exocytosis assay}

832/13 cells stably expressing NPY-pHluorin were transfected (FuGene, Promega) with NPY-mCherry. At $1 \mathrm{~d}$ after transfection, cells were washed once with PBS, dislodged using media, and transferred onto poly-L-lysine coated $22 \mathrm{~mm}$ glass coverslips. After an additional 2 $\mathrm{d}$, cells were reset for $2 \mathrm{hrs}$ in low $\mathrm{K}+$ Krebs-Ringer buffer with $1.5 \mathrm{mM}$ glucose, washed once with low $\mathrm{K}+$ Krebs-Ringer buffer with $1.5 \mathrm{mM}$ glucose, and coverslips were transferred to an open imaging chamber (Life Technologies). Cells were imaged close to the coverslips, focusing on the plasma membrane (determined by the presence of NPY-mCherry-positive plasma membrane docked vesicles), using a custom-built Nikon spinning disk confocal micrscope at a resolution of $512 \times 512$ pixels. Images were collected for $100 \mathrm{~ms}$ at $10 \mathrm{~Hz}$ at room temperature with a 63X objective (Oil Plan Apo NA 1.49) and an ImageEM X2 EM-CCD camera (Hamamatsu, Japan). Following baseline data collection (15 s), an equal volume of Krebs- 
Ringer buffer containing $110 \mathrm{mM} \mathrm{KCl}$ and $30.4 \mathrm{mM}$ glucose was added to stimulate secretion and cells were imaged for an additional $80 \mathrm{~s}$. At the end of the experiment, cells were incubated with Krebs-Ringer buffer containing $50 \mathrm{mM} \mathrm{NH}_{4} \mathrm{Cl}, \mathrm{pH} 7.4$, to reveal total fluorescence and to confirm that the imaged cells were indeed transfected. Movies were acquired in MicroManager (UCSF) and exported as tiff files. Movies were analyzed using ImageJ software by counting events and measuring cell area.

\section{pH measurement of the late-Golgi compartment}

WT and Ccdc186 KO cells stably expressing the 17-residue transmembrane domain of beta-galactoside alpha 2,6-sialyltransferase tagged to pHluorin (St6Gal1::pHluorin) were generated as follows. HEK293T cells were maintained in DMEM with $10 \%$ fetal bovine serum under $5 \% \mathrm{CO}_{2}$ at $37^{\circ} \mathrm{C}$. Lentivirus was produced by transfecting HEK293T cells with FUGW, psPAX2, and pVSVG using Fugene HD according to the manufacturer's instructions. Two days after transfection, the medium was collected and filtered $(0.45 \mu \mathrm{m})$. Medium containing the lentivirus was then applied to $832 / 13$ cells in suspension at varying ratios. Transduction efficiency was screened using an epifluorescence microscope. The protocol to measure the $\mathrm{pH}$ of the late-Golgi compartment (Hummer et al., 2017) was adapted to a plate-reader format. An equal number of WT and Ccdc186 KO 832/13 cells stably expressing St6Gal1::pHluorin were plated on clear-bottom black-wall 96-well plates and grown to confluence. Cells were washed once with Tyrode buffer (119 mM NaCl, $2.5 \mathrm{mM} \mathrm{KCl,} 2 \mathrm{mM} \mathrm{CaCl}$, $2 \mathrm{mM} \mathrm{MgCl}$, $25 \mathrm{mM} \mathrm{HEPES}$, $30 \mathrm{mM}$ glucose, $\mathrm{pH}$ 7.4) and incubated for 10 minutes either in Tyrode buffer or in $\mathrm{KCl}$-enriched buffer at different pHs $\left(125 \mathrm{mM} \mathrm{KCl}, 20 \mathrm{mM} \mathrm{NaCl}, 0.5 \mathrm{mM} \mathrm{CaCl}_{2}, 0.5 \mathrm{mM} \mathrm{MgCl}_{2}\right.$, and $25 \mathrm{mM}$ MES (at pH 5.5 or 6 ) or 25 mM HEPES (at pH 6.5, 7, 7.5, 8, or 8.5). The KCl-enriched buffer was supplemented with $5 \mu \mathrm{M}$ nigericin (Sigma Aldrich) and $5 \mathrm{nM}$ monensin (Sigma Aldrich). The fluorescence of each well was measured using a Varioskan Lux plate reader (Thermo Scientific) (Excitation=485 nm, Emission=520 nm). For each buffer, cell type, and independent biological 
replicate, the reading was repeated three times. Calibration curves were generated for each cell type and each independent repetition. The absolute $\mathrm{pH}$ values were extrapolated from the calibration curve using the fluorescence of the cells incubated with Tyrode buffer.

\section{ANF-GFP pulse-chase experiment}

To monitor the exit of DCV cargo from the TGN, we used a protocol similar to the one described (Kögel et al., 2013; Kögel, Rudolf, et al., 2010). WT and Ccdc186 KO 832/13 cells were seeded on glass coverslips in 24-well plates and after at least 24 hours, $100 \mathrm{ng}$ of ANF::GFP plasmid was transfected in each well with Lipofectamine 2000 for $12-16$ hours at $37^{\circ} \mathrm{C}$ in complete medium. Subsequently, cells were incubated at $20^{\circ} \mathrm{C}$ in PBS for 2 hours in a conventional incubator (pulse) to block protein exit from the TGN. 30 minutes before the end of the low temperature block, $10 \mu \mathrm{g} / \mathrm{ml}$ of cycloheximide was added to the medium to block the synthesis of new ANF::GFP. The PBS was then exchanged for growth medium and the cells were shifted to $37^{\circ} \mathrm{C}$ for the indicated times, then fixed with $4 \%$ PFA, and stained with an antiGFP antibody as described (see Immunofluorescence section). Cells were scored in three categories: those that had most of the ANF::GFP concentrated at the TGN ("Golgi-like"), those that had ANF::GFP both at the TGN-region and at the cell periphery ("Intermediate") and those where the ANF::GFP was excluded from the TGN ("Periphery"). 50 to 100 cells per time point and per genotype were imaged and counted using a Nikon Eclipse 80i wide-field compound microscope. The experimenter was blind to the genotypes of the cell lines used and to the time point. The experiment was repeated three times with similar results.

\section{Generation of PC12 cell lines for the mitochondria relocation assays}

For the mitochondria relocation assay, PC12 cells were used instead of $832 / 13$ cells for drug selection compatibility reasons. Moreover, toxicity of the mitochondria relocation constructs appeared to be less in PC12 cells. A 6-well plate was transfected with $4 \mu \mathrm{g}$ of the appropriate 
plasmid using Lipofectamine 2000 (ThermoFisher) according to the manufacturer's instructions. After 48 hours, the cell culture medium was replaced with Pen/Strep-free selection medium (DMEM-GlutaMAX (GIBCO) supplemented with 5\% FBS (RMBIO), 10\% horse serum (RMBIO), and $700 \mu \mathrm{g} / \mathrm{ml} \mathrm{G418).} \mathrm{The} \mathrm{selection} \mathrm{medium} \mathrm{was} \mathrm{changed} \mathrm{every} \mathrm{2-3} \mathrm{days} \mathrm{until} \mathrm{large} \mathrm{single}$ colonies could be seen. Colonies were transferred to a 96-well plate and expanded in selection medium and then to 24 -well and 6-cm plates before being frozen in 10\% DMSO. Individual clones were screened by immunostaining using an anti-HA antibody. Highly expressing clones were used for the BiolD experiment.

\section{BiolD experiment and sample preparation for mass spectrometry}

The protocol for isolating proteins biotinylated by BirA* was adapted from (Shin, Gillingham, et al., 2017). PC12 stable lines expressing the BirA* constructs (BirA*::HA::MAO and CC3::BirA*::HA::MAO) were grown to confluence in three $175-\mathrm{cm}^{2}$ flasks in complete PC12 DMEM medium (DMEM-GlutaMAX (GIBCO) supplemented with 5\% FBS (RMBIO) and 10\% horse serum (RMBIO)). 24 hours before harvest, cells were incubated with $50 \mu \mathrm{M}$ biotin (10 $\mathrm{mg} / \mathrm{ml}$ stock in DMSO). Cells were transferred on ice, washed $2 \mathrm{x}$ with ice-cold PBS, and harvested by gentle pipetting. Cells were pelleted by centrifugation (10 minutes, 1850g) and resuspended in lysis buffer $(50 \mathrm{mM}$ Tris $\mathrm{pH} 7.4,0.1 \mathrm{M} \mathrm{NaCl}, 1 \mathrm{mM}$ EDTA, $1 \%$ Triton X-100, 1 mM PMSF, protease inhibitor cocktail (Pierce)), vortexed briefly, incubated on ice for 20 min, and vortexed again. Lysates were clarified by centrifugation at $20,000 \mathrm{~g}$ for 10 minutes at $4^{\circ} \mathrm{C}$ and supernatants were mixed with an equal volume of $50 \mathrm{mM}$ Tris $\mathrm{pH} 7.4$. The total protein content was about $30 \mathrm{mg}$ as measured by a BCA assay. The supernatant was incubated with $250 \mu \mathrm{l}$ Dynabeads MyOne Streptavidin C1 beads (Invitrogen \# 65002) that had been prewashed twice in the same buffer. The beads were incubated at $4^{\circ} \mathrm{C}$ overnight on a Nutator, washed twice for 8 minutes in $2 \%$ SDS-PAGE and protease inhibitor cocktail (Pierce), then three times for $8 \mathrm{~min}$ in $1 \%$ Triton $\mathrm{X}-100,0.1 \%$ deoxycholate, $500 \mathrm{mM} \mathrm{NaCl}, 1 \mathrm{mM}$ EDTA, 50 
mM HEPES, and protease inhibitor cocktail at $\mathrm{pH} 7.5$, and three times for 8 minutes in $50 \mathrm{mM}$

Tris $\mathrm{pH} 7.4,50 \mathrm{mM} \mathrm{NaCl}$, and protease inhibitor cocktail. Finally, the beads were incubated for 5 minutes at $98^{\circ} \mathrm{C}$ with $50 \mu \mathrm{l} 1 \mathrm{X}$ lithium dodecyl sulfate (LDS) sample buffer (Invitrogen NuPAGE® \#NP0007) containing 10\% beta-mercaptoethanol and $3 \mathrm{mM}$ biotin. The supernatant was collected and the beads were discarded.

The samples were then prepared for mass spectrometry as follows. The eluted proteins in $1 \mathrm{X}$ LDS were reduced with $1 \mathrm{mM}$ Tris(2-carboxyethyl)phosphine (TCEP) at $37^{\circ} \mathrm{C}$ for 20 minutes on a shaker and alkylated with $2 \mathrm{mM}$ chloroacetamide for 20 minutes at $37^{\circ} \mathrm{C}$. The reaction was quenched by incubation with $1 \mathrm{mM}$ TCEP for 20 minutes at $37^{\circ} \mathrm{C}$ and $60 \%$ of the eluate was run on an SDS-PAGE gel (Mini-Protean TGX, 4-15\%, Bio-Rad \#4561084). The gel was stained with colloidal Coomassie (Bio-Rad \#1610803) overnight at room temperature and destained with Milli-Q water. Gel slices (4-5 slices per lane) were excised and destained by two 10-minute washes with a 50/50 solution of high-grade ethanol/100 mM triethylammonium bicarbonate (TEAB). The gel was dehydrated with two washes of high-grade ethanol. Gel slices were rehydrated with a solution of $12.5 \mathrm{ng} / \mu \mathrm{l}$ trypsin (Promega Trypsin Gold, Mass Spectrometry Grade, \#PRV5280) diluted in 100 mM TEAB. Once rehydrated, 2-3 volumes of $100 \mathrm{mM}$ TEAB were added and the sample was incubated overnight at $37^{\circ} \mathrm{C}$ in a shaking thermomixer at $1,400 \mathrm{rpm}$. The reaction was quenched by addition of $1 / 510 \%$ trifluoroacetic acid (TFA) and digested peptides were purified by StageTips (Rappsilber et al., 2007). StageTips were washed with $50 \mu \mathrm{l}$ methanol, $50 \mu$ l reaction buffer B $(0.1 \%$ TFA, $80 \%$ acetonitrile $(\mathrm{ACN}))$, and equilibrated with $50 \mu \mathrm{l}$ of buffer $\mathrm{A}(5 \% \mathrm{ACN}, 0.1 \%$ TFA in water) by centrifugation at 2,000g at room temperature. The samples were loaded onto StageTips that were then washed once with $50 \mu \mathrm{l}$ buffer $\mathrm{A}$ and kept at $4^{\circ} \mathrm{C}$ until mass spectrometry analysis.

\section{Liquid chromatography mass spectrometry (LC/MS) analysis.}


Peptides were eluted from StageTips using elution buffer ( $50 \%$ acetonitrile, $0.1 \%$ TFA) and then loaded on a self-pulled $360 \mu$ m outer diameter (OD) x $100 \mu \mathrm{m}$ inner diameter (ID) 20 cm column with a 7- $\mu \mathrm{m}$ tip packed with $3 \mu \mathrm{m}$ Reprosil C18 resin (Dr. Maisch, Germany). Peptides were analyzed by nanoLC-MS in a 120 minutes, $5 \%$ to $35 \%$ acetonitrile gradient in $0.1 \%$ acetic acid at $300 \mathrm{nl} / \mathrm{min}$ (Thermo Dionex RSLCnano) on an Orbitrap Elite. Orbitrap Fourier Transform Mass Spectrometry (FTMS) spectra $(R=30,000$ at $400 \mathrm{~m} / \mathrm{z} ; \mathrm{m} / \mathrm{z} 350-1600$; 3e6 target; max 500 ms ion injection time) and Top15 data dependent collision-induced dissociation (CID) MS/MS spectra (1e4 target; max 100 ms injection time) were collected with dynamic exclusion for $20 \mathrm{sec}$ and an exclusion list size of 500 . The normalized collision energy applied for CID was $35 \%$ for $10 \mathrm{msec}$.

\section{Data analysis}

Mass spectra were searched against the Uniprot rat reference proteome downloaded on Feburary 12, 2017 using MaxQuant v1.5.7.4. Detailed MaxQuant settings used were "LFQ mode" with "Fast LFQ"; and "Match between runs" mode was enabled. Other settings were kept as default.

Data analysis was carried out in R. Briefly, label-free quantification (LFQ, (Cox et al., 2014) intensities calculated by MaxQuant were $\log _{2}$ and Z-score transformed; only proteins present in at least two out of three replicates were selected for further analysis; missing values were replaced by random numbers drawn from a distribution with mean of -3.51 and a standard deviation of 0.3 to represent protein abundance below the detection limit; a two-sided Student's t-test was used to determine the $p$-values and the results are presented in the form of a volcano plot (Figure S13). Proteins with ratios $\left(\log _{2} \mathrm{CCDC} 186 \mathrm{CC} 3-\log _{2} \mathrm{Bir} \mathrm{A}^{*}\right)$ higher than 1.8 are labeled. The data for all mass spectrometry experiments are shown in Tables S6 and S7.

\section{Equilibrium sedimentation}


Wild type, Ccdc186 KO, and Eipr1 KO 832/13 cells were grown in 15-cm tissue culture plates. Cells were washed twice with ice-cold PBS, transferred to $15 \mathrm{ml}$ conical tubes, and centrifuged at $300 \mathrm{~g}$ for 10 minutes at $4^{\circ} \mathrm{C}$. Cells were washed once with $5 \mathrm{ml}$ of SH buffer (10 mM HEPES pH 7.2, 0.3 M sucrose, $1 \mathrm{mM}$ PMSF and protease inhibitor cocktail (SIGMAFAST)) and resuspended in $1 \mathrm{ml} \mathrm{SH}$ buffer, passed through a 21-gauge needle, and homogenized using a ball bearing device (Isobiotec, $18 \mu \mathrm{m}$ clearance). The lysate was collected and centrifuged at $1000 \mathrm{~g}$ for 8 minutes. A 0.6-1.9 M continuous sucrose gradient was prepared in 10 mM HEPES pH 7.2 in ultracentrifuge tubes (Beckman Coulter) that were coated with Sigmacote (Sigma \#SL2). The post-nuclear supernatant was loaded onto the gradient and centrifuged at $30,000 \mathrm{rpm}$ in an SW41 rotor for $14-16$ hours at $4^{\circ} \mathrm{C}$. Fractions $(750 \mu \mathrm{l}$ each) were collected from top to bottom. The sucrose concentration for each fraction was determined by measuring the Brix using a Misco palm abbe digital refractometer. Fractions were analyzed by immunoblotting using antibodies to PC1/3 and CPD (see above and Tables S4 and S5). Band intensity was quantified using FIJI and plotted against the sucrose concentration of the fraction.

\section{Statistics}

Data were tested for normality by a Shapiro-Wilk test. When data did not pass the normality test, we tested for statistical significance between groups by the Kruskal-Wallis test followed by Dunn's test when making comparisons among groups of three or more, and the Mann-Whitney test for comparisons between groups of two. When data passed the normality test, we tested for statistical significance by a one-way ANOVA test with Bonferroni correction when making comparisons among groups of three or more, and an unpaired t-test for comparisons between groups of two.

\section{ACKNOWLEDGEMENTS}


We thank Alex Merz for mentoring and sharing equipment; Christopher Newgard, Ian Sweet, and Duk-Su Koh for the 832/13 cell line; Suzanne Hoppins for the pBabe vector, platE cells, protocol for lentiviral production and infection, help with cell culture, and sharing equipment; Richard Palmiter for the pPUR vector; Sean Munro and John Shin for the mitochondrial relocation and BirA* plasmids, advice, and protocols for BiolD; Lloyd Fricker for the anti-CPD and anti-CPE antibodies; Joshua Vaughan and Aaron Halpern for secondary antibodies used in STED microscopy; Patrina Pellett and David Castaneda-Castellanos for assistance with SIM and STED microscopy, respectively; Ngoc-Han Thi Nguyen and Donna Prunkard from the UW Pathology Flow Cytometry Core Facility; Ken Miller and Joshua Kaplan for worm strains with integrated transgenes; and Kelly Duong for the mouse tissues and protocol for protein extraction. This work used an EASY-nLC1200 UHPLC and Thermo Scientific Orbitrap Fusion Lumos Tribrid mass spectrometer purchased with funding from a National Institutes of Health SIG grant S10OD021502 (S-E.O.). Some worm strains were provided by the CGC, which is funded by NIH Office of Research Infrastructure Programs (P40 OD010440). This work was supported by American Diabetes Association grant \#1-17-JDF-064 and by NIH grant R01 GM124035 to CSA, and by a University of Washington Diabetes Research Center Pilot and Feasibility Award (NIH grant P30 DK017047) and by NIH grant R01 GM121481 to MA. 


\section{REFERENCES}

Ailion, M., Hannemann, M., Dalton, S., Pappas, A., Watanabe, S., Hegermann, J., Liu, Q., Han, H.-F., Gu, M., Goulding, M.Q., et al. (2014). Two Rab2 Interactors Regulate Dense-Core Vesicle Maturation. Neuron 82, 167-180.

Arvan, P., and Castle, D. (1998). Sorting and storage during secretory granule biogenesis: looking backward and looking forward. Biochem. J. 332, 593-610.

Arvan, P., and Halban, P.A. (2004). Sorting Ourselves Out: Seeking Consensus on Trafficking in the Beta-Cell. Traffic 5, 53-61.

Bäck, N., Rajagopal, C., Mains, R.E., and Eipper, B.A. (2010). Secretory Granule Membrane Protein Recycles through Multivesicular Bodies. Traffic 11, 972-986.

Bonifacino, J.S., and Traub, L.M. (2003). Signals for Sorting of Transmembrane Proteins to Endosomes and Lysosomes. Annu. Rev. Biochem. 72, 395-447.

Borgonovo, B., Ouwendijk, J., and Solimena, M. (2006). Biogenesis of secretory granules. Curr. Opin. Cell Biol. 18, 365-370.

Brenner, S. (1974). The Genetics of Caenorhabditis Elegans. Genetics 77, 71-94.

Cao, M., Mao, Z., Kam, C., Xiao, N., Cao, X., Shen, C., Cheng, K.K.Y., Xu, A., Lee, K.M., Jiang, L., et al. (2013). PICK1 and ICA69 Control Insulin Granule Trafficking and Their Deficiencies Lead to Impaired Glucose Tolerance. PLoS Biol 11, e1001541. 
Cattin-Ortolá, J., Topalidou, I., Dosey, A., Merz, A.J., and Ailion, M. (2017). The densecore vesicle maturation protein $\mathrm{CCCP}-1$ binds $\mathrm{RAB}-2$ and membranes through its $\mathrm{C}$ terminal domain. Traffic 18, 720-732.

Cox, J., Hein, M.Y., Luber, C.A., Paron, I., Nagaraj, N., and Mann, M. (2014). Accurate proteome-wide label-free quantification by delayed normalization and maximal peptide ratio extraction, termed MaxLFQ. Mol. Cell. Proteomics 13, 2513-2526.

Davidson, H.W., Rhodes, C.J., and Hutton, J.C. (1988). Intraorganellar calcium and pH control proinsulin cleavage in the pancreatic $\beta$ cell via two distinct site-specific endopeptidases. Nature 333, 93-96.

Dittie, A.S., Klumperman, J., and Tooze, S.A. (1999). Differential distribution of mannose-6-phosphate receptors and furin in immature secretory granules. J. Cell Sci. 112, 3955-3966.

Du, W., Zhou, M., Zhao, W., Cheng, D., Wang, L., Lu, J., Song, E., Feng, W., Xue, Y., Xu, P., et al. (2016). HID-1 is required for homotypic fusion of immature secretory granules during maturation. eLife 5, e18134.

Edwards, S.L., Charlie, N.K., Richmond, J.E., Hegermann, J., Eimer, S., and Miller, K.G. (2009). Impaired dense core vesicle maturation in Caenorhabditis elegans mutants lacking Rab2. J. Cell Biol. 186, 881-895.

Emperador-Melero, J., Huson, V., Weering, J. van, Bollmann, C., Mollard, G.F. von, Toonen, R.F., and Verhage, M. (2018). Vti1a/b regulate synaptic vesicle and dense core vesicle secretion via protein sorting at the Golgi. Nat. Commun. 9, 3421. 
Eng, F.J., Varlamov, O., and Fricker, L.D. (1999). Sequences within the Cytoplasmic Domain of Gp180/Carboxypeptidase D Mediate Localization to the Trans-Golgi Network. Mol. Biol. Cell 10, 35-46.

Feng, L., and Arvan, P. (2003). The Trafficking of a1-Antitrypsin, a Post-Golgi Secretory Pathway Marker, in INS-1 Pancreatic Beta Cells. J. Biol. Chem. 278, 31486-31494.

Fricker, L.D. (2013). Chapter 235 - Carboxypeptidases E and D. In Handbook of Biologically Active Peptides (Second Edition), A.J. Kastin, ed. (Boston: Academic Press), pp. 1715-1720.

Fricker, L.D., and Devi, L. (1993). Posttranslational processing of carboxypeptidase E, a neuropeptide-processing enzyme, in AtT-20 cells and bovine pituitary secretory granules. J. Neurochem. 61, 1404-1415.

Fricker, L.D., Das, B., and Angeletti, R.H. (1990). Identification of the pH-dependent membrane anchor of carboxypeptidase E (EC 3.4.17.10). J. Biol. Chem. 265, 24762482.

Fricker, L.D., Berman, Y.L., Leiter, E.H., and Devi, L.A. (1996). Carboxypeptidase E Activity Is Deficient in Mice with the fat Mutation Effect on Peptide Processing. J. Biol. Chem. 271, 30619-30624.

Gershlick, D.C., Schindler, C., Chen, Y., and Bonifacino, J.S. (2016). TSSC1 is novel component of the endosomal retrieval machinery. Mol. Biol. Cell 27, 2867-2878. 
Gibson, D.G., Young, L., Chuang, R.-Y., Venter, J.C., Hutchison, C.A., and Smith, H.O. (2009). Enzymatic assembly of DNA molecules up to several hundred kilobases. Nat. Methods 6, 343-345.

Gillingham, A.K., Sinka, R., Torres, I.L., Lilley, K.S., and Munro, S. (2014). Toward a Comprehensive Map of the Effectors of Rab GTPases. Dev. Cell 31, 358-373.

Gondré-Lewis, M.C., Park, J.J., and Loh, Y.P. (2012). Cellular mechanisms for the biogenesis and transport of synaptic and dense-core vesicles. Int. Rev. Cell Mol. Biol. $299,27-115$.

Holst, B., Madsen, K.L., Jansen, A.M., Jin, C., Rickhag, M., Lund, V.K., Jensen, M., Bhatia, V., Sørensen, G., Madsen, A.N., et al. (2013). PICK1 Deficiency Impairs Secretory Vesicle Biogenesis and Leads to Growth Retardation and Decreased Glucose Tolerance. PLoS Biol 11, e1001542.

Hummer, B.H., Leeuw, N.F. de, Burns, C., Chen, L., Joens, M.S., Hosford, B., Fitzpatrick, J.A.J., and Asensio, C.S. (2017). HID-1 controls formation of large dense core vesicles by influencing cargo sorting and trans-Golgi network acidification. Mol. Biol. Cell 28, 3870-3880.

Hussain, S.S., Harris, M.T., Kreutzberger, A.J.B., Inouye, C.M., Doyle, C.A., Castle, A.M., Arvan, P., and Castle, J.D. (2018). Control of insulin granule formation and function by the $A B C$ transporters $A B C G 1$ and $A B C A 1$ and by oxysterol binding protein OSBP. Mol. Biol. Cell 29, 1238-1257. 
Kim, T., Gondré-Lewis, M.C., Arnaoutova, I., and Loh, Y.P. (2006). Dense-Core

Secretory Granule Biogenesis. Physiology 21, 124-133.

Klumperman, J., Kuliawat, R., Griffith, J.M., Geuze, H.J., and Arvan, P. (1998).

Mannose 6-Phosphate Receptors Are Sorted from Immature Secretory Granules via Adaptor Protein AP-1, Clathrin, and Syntaxin 6-positive Vesicles. J. Cell Biol. 141, 359371.

Kögel, T., Rudolf, R., Hodneland, E., Copier, J., Regazzi, R., Tooze, S.A., and Gerdes, H.-H. (2013). Rab3D Is Critical for Secretory Granule Maturation in PC12 Cells. PLoS ONE 8, e57321.

Kögel, T., Rudolf, R., Hodneland, E., Hellwig, A., Kuznetsov, S., Seiler, F., Söllner T.H., Barroso, J., and Gerdes, H.-H. (2010). Distinct Roles of Myosin Va in Membrane Remodeling and Exocytosis of Secretory Granules. Traffic 11, 637-650.

Kuroki, K., Eng, F., Ishikawa, T., Turck, C., Harada, F., and Ganem, D. (1995). gp180, a host cell glycoprotein that binds duck hepatitis B virus particles, is encoded by a member of the carboxypeptidase gene family. J. Biol. Chem. 270, 15022-15028.

Naggert, J.K., Fricker, L.D., Varlamov, O., Nishina, P.M., Rouille, Y., Steiner, D.F., Carroll, R.J., Paigen, B.J., and Leiter, E.H. (1995). Hyperproinsulinaemia in obese fat/fat mice associated with a carboxypeptidase $E$ mutation which reduces enzyme activity. Nat. Genet. 10, 135-142. 
Orci, L., Ravazzola, M., Amherdt, M., Madsen, O., Perrelet, A., Vassalli, J.D., and Anderson, R.G. (1986). Conversion of proinsulin to insulin occurs coordinately with acidification of maturing secretory vesicles. J. Cell Biol. 103, 2273-2281.

Orci, L., Ravazzola, M., Storch, M.J., Anderson, R.G., Vassalli, J.D., and Perrelet, A. (1987). Proteolytic maturation of insulin is a post-Golgi event which occurs in acidifying clathrin-coated secretory vesicles. Cell 49, 865-868.

Paquin, N., Murata, Y., Froehlich, A., Omura, D.T., Ailion, M., Pender, C.L., Constantine-Paton, M., and Horvitz, H.R. (2016). The Conserved VPS-50 Protein Functions in Dense-Core Vesicle Maturation and Acidification and Controls Animal Behavior. Curr. Biol. 26, 862-871.

Ran, F.A., Hsu, P.D., Wright, J., Agarwala, V., Scott, D.A., and Zhang, F. (2013). Genome engineering using the CRISPR-Cas9 system. Nat. Protoc. 8, 2281-2308.

Rappsilber, J., Mann, M., and Ishihama, Y. (2007). Protocol for micro-purification, enrichment, pre-fractionation and storage of peptides for proteomics using StageTips.

Nat. Protoc. 2, 1896-1906.

Roux, K.J., Kim, D.I., Raida, M., and Burke, B. (2012). A promiscuous biotin ligase fusion protein identifies proximal and interacting proteins in mammalian cells. J. Cell Biol. 196, 801-810.

Schindler, C., Chen, Y., Pu, J., Guo, X., and Bonifacino, J.S. (2015). EARP is a multisubunit tethering complex involved in endocytic recycling. Nat. Cell Biol. 17, 639650. 
Shin, J.J.H., Gillingham, A.K., Begum, F., Chadwick, J., and Munro, S. (2017).

TBC1D23 is a bridging factor for endosomal vesicle capture by golgins at the trans-

Golgi. Nat. Cell Biol. 19, 1424-1432.

Smeekens, S.P., and Steiner, D.F. (1990). Identification of a human insulinoma cDNA encoding a novel mammalian protein structurally related to the yeast dibasic processing protease Kex2. J. Biol. Chem. 265, 2997-3000.

Smeekens, S.P., Montag, A.G., Thomas, G., Albiges-Rizo, C., Carroll, R., Benig, M., Phillips, L.A., Martin, S., Ohagi, S., and Gardner, P. (1992). Proinsulin processing by the subtilisin-related proprotein convertases furin, PC2, and PC3. Proc. Natl. Acad. Sci. 89, $8822-8826$.

Sobajima, T., Yoshimura, S., Maeda, T., Miyata, H., Miyoshi, E., and Harada, A. (2018).

The Rab11-binding protein RELCH/KIAA1468 controls intracellular cholesterol distribution. J. Cell Biol. 217, 1777-1796.

Song, L., and Fricker, L. (1995). Processing of procarboxypeptidase E into carboxypeptidase E occurs in secretory vesicles. J. Neurochem. 65, 444-453.

Song, L., and Fricker, L.D. (1996). Tissue Distribution and Characterization of Soluble and Membrane-bound Forms of Metallocarboxypeptidase D. J. Biol. Chem. 271, 28884-28889.

Steiner, D. F., Chan, S. J. and Rubenstein, A. H. (2011). Biosynthesis of Insulin. In Comprehensive Physiology, R. Terjung (Ed.). doi:10.1002/cphy.cp070203 
Sumakovic, M., Hegermann, J., Luo, L., Husson, S.J., Schwarze, K., Olendrowitz, C., Schoofs, L., Richmond, J., and Eimer, S. (2009). UNC-108/RAB-2 and its effector RIC19 are involved in dense core vesicle maturation in Caenorhabditis elegans. J. Cell Biol. 186, 897-914.

Tooze, S.A. (1998). Biogenesis of secretory granules in the trans-Golgi network of neuroendocrine and endocrine cells. Biochim. Biophys. Acta - Mol. Cell Res. 1404, $231-244$.

Tooze, S.A., Martens, G.J.M., and Huttner, W.B. (2001). Secretory granule biogenesis: rafting to the SNARE. Trends Cell Biol. 11, 116-122.

Topalidou, I., Cattin-Ortolá, J., Pappas, A.L., Cooper, K., Merrihew, G.E., MacCoss, M.J., and Ailion, M. (2016). The EARP Complex and Its Interactor EIPR-1 Are Required for Cargo Sorting to Dense-Core Vesicles. PLOS Genet. 12, e1006074.

Topalidou, I., Cattin-Ortolá, J., and Ailion, M. (2018). EIPR1 controls dense-core vesicle cargo sorting and EARP complex localization in insulinoma cells. bioRxiv 374488. https://doi.org/10.1101/374488

Varlamov, O., and Fricker, L.D. (1998). Intracellular trafficking of metallocarboxypeptidase D in AtT-20 cells: localization to the trans-Golgi network and recycling from the cell surface. J. Cell Sci. 111, 877-885. 
Varlamov, O., Eng, F.J., Novikova, E.G., and Fricker, L.D. (1999). Localization of Metallocarboxypeptidase D in AtT-20 Cells. Potential Role in Prohormone Processing. J. Biol. Chem. 274, 14759-14767.

Vindrola, O., and Lindberg, I. (1992). Biosynthesis of the prohormone convertase mPC1 in AtT-20 cells. Mol. Endocrinol. 6, 1088-1094.

Vo, Y.P., Hutton, J.C., and Angleson, J.K. (2004). Recycling of the dense-core vesicle membrane protein phogrin in Min6 $\beta$-cells. Biochem. Biophys. Res. Commun. 324, 1004-1010.

Wendler, F., Page, L., Urbé, S., and Tooze, S.A. (2001). Homotypic Fusion of Immature Secretory Granules During Maturation Requires Syntaxin 6. Mol. Biol. Cell 12, 16991709.

Wong, M., and Munro, S. (2014). The specificity of vesicle traffic to the Golgi is encoded in the golgin coiled-coil proteins. Science 346, 1256898.

Wong, S.H., Low, S.H., and Hong, W. (1992). The 17-residue transmembrane domain of beta-galactoside alpha 2,6-sialyltransferase is sufficient for Golgi retention. J. Cell Biol. 117, 245-258.

Xin, X., Varlamov, O., Day, R., Dong, W., Bridgett, M.M., Leiter, E.H., and Fricker, L.D. (1997). Cloning and Sequence Analysis of cDNA Encoding Rat Carboxypeptidase D. DNA Cell Biol. 16, 897-909. 
Zhang, X., Jiang, S., Mitok, K.A., Li, L., Attie, A.D., and Martin, T.F.J. (2017). BAIAP3, a C2 domain-containing Munc13 protein, controls the fate of dense-core vesicles in neuroendocrine cells. J Cell Biol 216, 2151-2166.

Zhou, Y., and Lindberg, I. (1993). Purification and characterization of the prohormone convertase PC1(PC3). J. Biol. Chem. 268, 5615-5623. 


\section{FIGURE LEGENDS}

\section{Figure 1. Ccdc186 knock-out cells have defective insulin secretion and distribution of} mature DCV cargos

A. Insulin secretion from WT, Ccdc186 KO, and Ccdc186(+) rescued 832/13 cells under resting conditions (no glucose, $5 \mathrm{mM} \mathrm{KCl}$, white bars) and stimulating conditions ( $25 \mathrm{mM}$ glucose, 55 $\mathrm{mM} \mathrm{KCl}$, black bars). All values were normalized to the WT value in stimulating conditions (WT high Glu). $n=8 ;{ }^{*} p<0.05,{ }^{* *} p<0.01$, ns $p>0.05$, error bars $=$ SEM.

B. Total insulin content in WT, Ccdc186 KO, and Ccdc186(+) rescued 832/13 cells. All values were normalized to WT. $n=8$; ns $p>0.05$, error bars $=$ SEM.

We performed three biological replicates. For each replicate, the same cells were used to determine the amount of insulin secreted under resting conditions, stimulating conditions, and the amount of total cellular insulin.

C. Ccdc186 KO cells have reduced levels of the processed form of CPE. Detergent lysates from WT, Ccdc186 KO, and Ccdc186(+) rescued 832/13 cells were blotted with an antibody to the Cterminus of CPE (CPE-C). $\beta$-tubulin was used as a loading control. The experiment was repeated three times.

D. The levels of the unprocessed form of CPE (pro-CPE) are not affected by the loss of CCDC186. Detergent lysates from WT, Ccdc186 KO, and Ccdc186(+) rescued 832/13 cells were blotted with an antibody to pro-CPE. $\beta$-tubulin was used as a loading control. The experiment was repeated three times with similar results. The data shown for the WT are the same shown in Figure 3B of (Topalidou, Cattin-Ortolá, et al., 2019, manuscript submitted to $M B O C$ ) since these experiments were run in parallel with the same WT control.

E. The mature processed form of CPE is localized at or near the TGN in Ccdc186 KO cells. Representative confocal images of WT, Ccdc186 KO, and Ccdc186(+) rescued 832/13 cells 
costained with the CPE C-terminal antibody (CPE-C) and TGN38. Maximum-intensity projections. Scale bars: $5 \mu \mathrm{m}$. The experiment was repeated three times with similar results. F. Quantification of the colocalization between the mature form of CPE and the TGN marker TGN38. Maximum-intensity projection images were obtained and Pearson's correlation coefficients were determined by drawing a line around each cell. The data shown are from one

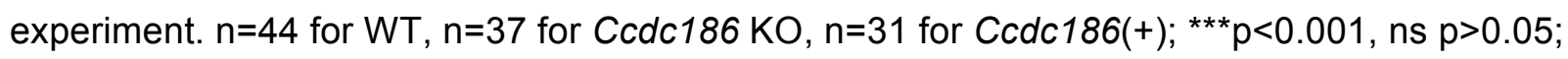
error bars $=$ SEM.

G. Ccdc186 KO cells have an increased proportion of CPE localized near the TGN.

Fluorescence of a region of interest around the TGN divided by the fluorescence of a region of the same size in the cytoplasm. The data shown are from one experiment. $n=30$ for WT and

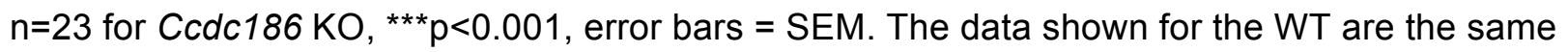
shown in Figure $3 G$ of (Topalidou, Cattin-Ortolá, et al., 2019, manuscript submitted to MBoC) since these experiments were run in parallel with the same WT control.

H. Ccdc186 KO cells have an increased amount of CPE localized at or near the TGN. Maximum-intensity projection images of z-stacks encompassing the TGN38 signal were obtained and Pearson's correlation coefficients were determined by drawing a line around the TGN38 positive signal. The data shown are from one experiment. $n=28$ for $W T, n=27$ for Ccdc186 KO, n=24 for Ccdc186(+); ${ }^{*} p<0.05,{ }^{* *} p<0.001$; error bars $=$ SEM.

Figure 2. Endogenous CCDC186 localizes to ring-like structures around proinsulin. A. Pearson's correlation coefficient was measured using confocal images (Figure S10) to quantify the colocalization between endogenous CCDC186 and markers of the different cell compartments (ERGIC53 for the ERGIC; GM130 for the cis-Golgi; EEA1 for early-endosomes; LAMP1 for lysosomes; TGN38 for the TGN; and Syntaxin 6 (Syn6), chromogranin A (CgA) and proinsulin for the TGN and immature DCVs). $n=12$ cells for TGN38 and $n=9$ cells for every other marker, ${ }^{* *} \mathrm{p}<0.001$, error bars $=$ SEM. 
B. Representative structured illumination microscopy (SIM) images of 832/13 cells costained for endogenous CCDC186 and proinsulin. Maximum-intensity projections. Upper panels, scale bars: $2 \mu \mathrm{m}$. Lower panels, scale bars: $200 \mathrm{~nm}$.

Figure 3. The CCDC186 C-terminal domain CC3 is in close proximity to carboxypeptidase D (CPD).

A. Schematic of the BiolD experiment. The promiscuous biotin ligase BirA* biotinylates proteins that are in close proximity (approximately $<10 \mathrm{~nm}$ ).

B. Domain structure of CCDC186. The CC3 fragment was fused to the mitochondria-targeting domain MAO (in black) and to the promiscuous biotin ligase BirA* (in green). The predicted coiled-coil domains are marked with different shades of red. CC=coiled-coil.

C. Mass-spectrometric (MS) analysis of biotinylated proteins from PC12 cells stably expressing CC3::BirA*::HA::MAO or the negative control BirA*::HA::MAO. The plot compares the number of unique peptides between $\mathrm{CC} 3:: B i r A^{*}:: \mathrm{HA}:: \mathrm{MAO}$ and the negative control. The data shown are from one out of three independent experiments.

D. CPD is biotinylated by CC3::BirA*::HA::MAO. Biotinylated proteins from PC12 cell extracts stably expressing BirA*::HA::MAO or CC3::BirA*::HA::MAO were purified with streptavidincoated beads and immunoblotted for CPD. IN: input. CPD was found enriched in all three independent pulldowns by MS, but it could only be detected by Western blotting in the sample that showed the highest enrichment in MS.

E. CPD is partially relocated to the mitochondria by CC3::HA::MAO. Representative confocal images of $832 / 13$ cells transiently transfected with CC3::HA::MAO, incubated with MitoTracker, and costained for HA and CPD. Single slices. Scale bars: $5 \mu \mathrm{m}$.

Figure 4. CPD is mislocalized to mature DCVs in Ccdc186 KO and Eipr1 KO 832/13 cells. 
A. CPD partially colocalizes with CCDC186::GFP. Representative confocal images of 832/13 cells transiently transfected with CCDC186::GFP and costained for endogenous CPD and GFP. Single slices. Scale bars: $5 \mu \mathrm{m}$.

B. CCDC186 and EIPR1 are required to restrict CPD localization to the TGN. Representative confocal images of WT, Ccdc186 KO, Ccdc186(+) rescued, Eipr1 KO and Eipr1(+) rescued 832/13 cells costained for endogenous CPD and the TGN marker TGN38. The white arrows indicate puncta in Eipr1 KO cells. Single slices. Scale bars: $5 \mu \mathrm{m}$. The experiment was repeated three times with similar results.

C. In the absence of CCDC186 or EIPR1, CPD is mislocalized to insulin-positive vesicles. Representative confocal images of WT, Ccdc186 KO, and Eipr1 KO 832/13 cells costained for endogenous CPD and insulin. The intensity of CPD signal in WT cells was increased to show the occasional presence of low intensity CPD-positive puncta that do not overlap with insulin. The white arrows indicate CPD-positive puncta that colocalize with insulin in Eipr1 KO cells. Single slices. Scale bars: $5 \mu \mathrm{m}$. The experiment was repeated three times.

Figure 5. CPD cosediments with mature DCV cargos in Ccdc186 KO and Eipr1 KO cells. A. Post-nuclear supernatants from WT, Ccdc186 KO, and Eipr1 KO cells were separated by equilibrium sedimentation through $0.6-1.9 \mathrm{M}$ sucrose. Fractions were collected from the top of the gradient and blotted with antibodies against PC1/3 (mature DCV marker) and CPD. The intensity and contrast of each blot was adjusted to show similar band intensities between cell types. The data shown are from one representative experiment of three independent experiments with similar results.

B. Band intensity for each fraction was quantified using FIJI, presented as a percentage of total band intensity, and plotted against the sucrose concentration of the fraction. The data shown are from one representative experiment of three independent experiments with similar results. 


\section{Figure 6. Model for CCDC186 and EIPR1 function in DCV maturation.}

In Ccdc186 KO cells, insulin and other luminal DCV cargos are reduced in mature DCVs in the cell periphery and mildly retained near the TGN. Proinsulin and other unprocessed cargos are not affected. Thus, CCDC186 is required for the retention of mature DCV cargos. Additionally, CPD is retained in mature DCVs in Ccdc186 KO cells, suggesting that CCDC186 is also required for the removal of unwanted cargo from immature DCVs. Eipr1 KO cells have similar phenotypes to Ccdc186 KO cells, suggesting that CCDC186 and EIPR1/EARP act together to control the post-Golgi retention and removal of DCV cargos. 


\section{SUPPLEMENTARY FIGURE LEGENDS}

Figure S1. cccp-1 functions in the same pathway as eipr-1 and vps-50 to control locomotion and dense-core vesicle cargo sorting in C. elegans.

A. $c c c p-1$ acts in the same pathway as eipr-1 and vps-50 to control locomotion. The cccp1(ox334) mutation does not enhance the slow locomotion phenotype of either eipr-1(tm4790) or vps-50(ok2627) mutants. Error bars = SEM; $\mathrm{n}=12-22$.

B. $\operatorname{ccp}-1$ acts in the same genetic pathway as eipr-1 and vps-50 to control DCV cargo trafficking. Representative images of NLP-21::Venus fluorescence in motor neuron axons of the dorsal nerve cord. Maximum-intensity projections. Scale bar: $10 \mu \mathrm{m}$.

C. Quantification of NLP-21::Venus fluorescence levels in the dorsal nerve cord. Double mutants of $c c c p-1(o x 334)$ with eipr-1(tm4790) or vps-50(ok2627) are not significantly different from the single mutants ${ }^{* * *}, p<0.001 ; n s$, not significant, $\left.p>0.05\right)$. Error bars $=$ SEM; $n=10-15$.

\section{Figure S2. Generation of a Ccdc186 KO 832/13 beta-cell line.}

A. CCDC186 is expressed in multiple mouse tissues. Protein extracts from different mouse tissues were blotted for CCDC186 using a commercial antibody. $\beta$-tubulin was used as a loading control. In two independent blots run from the same protein samples, we saw the same small differences in the size of the CCDC186 band in different tissues.

B. Ccdc186 KO cells do not express CCDC186. Protein extracts from WT, Ccdc186 KO, and Ccdc186 KO 832/13 cells stably expressing wild type CCDC186 (Ccdc186(+)) were blotted with anti-CCDC186 antibody. The faint band of slightly larger size in the Ccdc186 KO sample was not seen in other repetitions of this experiment and is presumed to be a nonspecific band. $\beta$ tubulin was used as a loading control.

C. Total cDNA from WT $832 / 13$ and Ccdc186 KO cells was PCR amplified using primers that detect the Ccdc186 cDNA. 
D. WT, Ccdc186 KO, and Ccdc186(+) rescued cells were stained with anti-CCDC186 antibody. Single slices. Wide-field fluorescence compound microscopy. Scale bars: $10 \mu \mathrm{m}$.

Figure S3. Proinsulin secretion and constitutive secretion are not affected in Ccdc186 knock-out cells.

A. Proinsulin secretion from WT, Ccdc186 KO and Ccdc186(+) rescued 832/13 cells under resting and stimulating conditions. All values were normalized to the WT value in stimulating conditions (WT high Glu). $n=6 ; n s ~ p>0.05$, error bars $=$ SEM.

B. Total proinsulin content in WT, Ccdc186 KO, and Ccdc186(+) rescued 832/13 cells. All values were normalized to WT. $n=6 ;{ }^{*} p<0.05, n s p>0.05$, error bars $=$ SEM.

We performed three biological replicates. For each replicate, the same cells were used to determine the amount of proinsulin secreted under resting conditions, stimulating conditions, and the amount of total cellular proinsulin.

C. CCDC186 is not required for proinsulin processing. Ratio of the cellular proinsulin content to the total cellular insulin content in WT, Ccdc186 KO, and Ccdc186(+) rescued 832/13 cells. We performed two biological replicates. For each replicate, the amounts of total cellular proinsulin and total cellular insulin were determined from the same cells. $n=6$, error bars $=$ SEM.

D. Ccdc186 KO cells have normal constitutive secretion. Secretion of ssGFP (GFP fused at its $\mathrm{N}$-terminus to the signal peptide of rat ANF). The data shown are combined from two independent experiments with similar results. $n=6$, error bars $=$ SEM. The data shown for the WT are the same shown in Figure 1F of (Topalidou, Cattin-Ortolá, et al., 2019, manuscript submitted to $M B O C$ ) since these experiments were run in parallel with the same WT control.

\section{Figure S4. Ccdc186 knock-out cells have exocytosis defects.}

WT and Ccdc186 KO 832/13 cells stably expressing NPY-pHluorin were reset for 2 hrs in low $\mathrm{K}+$ Krebs-Ringer buffer with $1.5 \mathrm{mM}$ glucose. Cells were then imaged in low $\mathrm{K}+\mathrm{Krebs}-\mathrm{Ringer}$ 
buffer with $1.5 \mathrm{mM}$ glucose for $15 \mathrm{~s}$ using spinning-disk confocal microscopy. Cells were then stimulated with $60 \mathrm{mM} \mathrm{K}+$ and $16.7 \mathrm{mM}$ glucose for $80 \mathrm{~s}$ and imaged again. Images (100 ms exposure) were collected at $10 \mathrm{~Hz}$. Exocytotic events were hand-counted. Bar graphs show the number of exocytotic events per second normalized to cell surface area. $n s<>0.05,{ }^{*} p<0.05$. Three experiments were performed on different days and plotted separately. The Ccdc186 KO showed reduced stimulated exocytosis on days 1 and 2, but no significant difference from WT on day 3. However, very few events were observed on day 3, even for WT (note the scale of the y-axis), suggesting problems on that day with the stimulation protocol or ability to detect events. On day $1, n=47$ cells for WT (four coverslips imaged separately with $20,12,7$, and 8 cells);

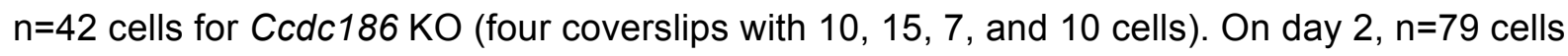
for WT (four coverslips with 26, 13, 22, and 18 cells); $\mathrm{n}=28$ cells for Ccdc186 KO (two coverslips with 10 and 18 cells). On day $3, n=30$ cells for WT (two coverslips with 12 and 18 cells); $n=21$ cells for Ccdc186 KO (two coverslips with 15 and 6 cells). The data shown for the WT are the same shown in Figure S3 of (Topalidou, Cattin-Ortolá, et al., 2019, manuscript submitted to $M B O C$ ) since these experiments were run in parallel with the same WT control.

\section{Figure S5. The levels of mature PC1/3 and CPE are decreased in Ccdc186 KO cells and mature CPE colocalizes with insulin in WT cells.}

A. Ccdc186 KO cells have reduced levels of the processed form of the proprotein convertase PC1/3. Detergent lysates from WT, Ccdc186 KO, and Ccdc186(+) rescued 832/13 cells were blotted with an antibody to PC1/3. $\beta$-tubulin was used as a loading control. The experiment was repeated four times with similar results.

B. Ccdc186 KO cells have reduced levels of the processed form of CPE. Detergent lysates from WT, Ccdc186 KO, and Ccdc186(+) rescued 832/13 cells were blotted with an antibody to the Nterminus of CPE (CPE-N). $\beta$-tubulin was used as a loading control. The experiment was 
repeated three times. The data shown for the WT are the same shown in Figure $3 \mathrm{C}$ of

(Topalidou, Cattin-Ortolá, et al., 2019, manuscript submitted to MBoC) since these experiments were run in parallel with the same WT control.

C. CPE and insulin almost fully colocalize. Representative confocal images of $832 / 13$ cells costained for endogenous insulin and endogenous CPE using the CPE-C antibody. Maximumintensity projections. Scale bars: $5 \mu \mathrm{m}$.

\section{Figure S6. Ccdc186 knock-out cells have defective distribution of insulin.}

A. Insulin is localized less in the periphery and more at or near the TGN in Ccdc186 KO cells. Representative confocal images of WT, Ccdc186 KO, and Ccdc186(+) rescued 832/13 cells costained for insulin and TGN38. Maximum-intensity projections. Scale bars: $5 \mu \mathrm{m}$. We performed three biological replicates.

B. Quantification of the colocalization between insulin and the TGN marker TGN38. Maximumintensity projection images were obtained and Pearson's correlation coefficients were determined by drawing a line around each cell. The data shown are from one representative experiment of three biological replicates with similar results. $n=12$ for WT and Ccdc186 KO; $\mathrm{n}=11$ for $\operatorname{Ccdc186}(+),{ }^{* *} \mathrm{p}<0.01,{ }^{* * *} \mathrm{p}<0.001, \mathrm{~ns} \mathrm{p}>0.05$, error bars $=$ SEM.

C. Ccdc186 KO cells have an increased proportion of insulin localized near the TGN.

Fluorescence of a region of interest around the TGN divided by the fluorescence of a region of the same size in the cytoplasm. The data shown are from one experiment. $n=25$ for WT and Ccdc186 KO, ${ }^{* * *} \mathrm{p}<0.001$, error bars $=$ SEM. The data shown for the WT are the same shown in Figure 2C of (Topalidou, Cattin-Ortolá, et al., 2019, manuscript submitted to $M B \circ C$ ) since these experiments were run in parallel with the same WT control.

D. Quantification of insulin localized at or near the TGN. Maximum-intensity projection images of z-stacks encompassing the TGN38 signal were obtained and Pearson's correlation coefficients were determined by drawing a line around the TGN38 positive signal. The data shown are from 
one representative experiment of three biological replicates with similar results. $n=20$ for WT and Ccdc186 KO, n=15 for Ccdc186(+); ns p>0.05; error bars = SEM.

\section{Figure S7. Ccdc186 knock-out cells have normal distributions of proinsulin and} unprocessed CPE.

A. The localization of proinsulin is not affected by the absence of CCDC186. Representative images of WT and Ccdc186 KO 832/13 cells costained for endogenous proinsulin and TGN38. Single slices. Scale bars: $5 \mu \mathrm{m}$. We performed three biological replicates.

B. Quantification of the colocalization between proinsulin and the TGN marker TGN38. The data shown are from one representative experiment of three biological replicates with similar results. $\mathrm{n}=18$ for WT and $\mathrm{n}=16$ for Ccdc186 KO, ns $\mathrm{p}>0.05$, error bars = SEM. The data shown for the WT are the same shown in Figure 2G of (Topalidou, Cattin-Ortolá, et al., 2019, manuscript submitted to $M B O C$ ) since these experiments were run in parallel with the same WT control. C. The unprocessed form of CPE (pro-CPE) is localized at or near the TGN in both WT and Ccdc186 KO cells. Representative confocal images of WT and Ccdc186 KO cells costained for pro-CPE antibody and TGN38. Single slices. Scale bars: $5 \mu \mathrm{m}$. The experiment was repeated twice.

D. Quantification of the colocalization between pro-CPE and the TGN marker TGN38. The data shown are from one experiment. $\mathrm{n}=20$ for both WT and Ccdc186 KO, ns $p>0.05$, error bars $=$ SEM.

Figure S8. The acidity of the Golgi does not significantly change in Ccdc186 KO cells. A. Example calibration curve for Golgi pH measurements based on measuring the fluorescence of TGN-targeted pHluorin in solutions of defined $\mathrm{pH}$. For each biological replicate of WT and Ccdc186 KO 832/13 cells tested for $\mathrm{pH}$, an individual calibration curve such as the one shown was obtained from WT and Ccdc186 KO cells grown in the same 96-well plate as the test 
samples and exposed to buffers of decreasing $\mathrm{pH}(8.5-5.5)$ in the presence of nigericin and monensin (see Materials and Methods). Each data point shows the mean of the fluorescent measurements (in arbitrary units (AU)) from cells in three different wells. Error bars=SEM. B. The late-Golgi compartment is not more acidic in Ccdc186 KO 832/13 cells. The fluorescence of TGN-targeted pHluorin was measured in WT and Ccdc186 KO cells. The absolute pH value of each sample was extrapolated from a paired calibration curve (as in A). The data show mean \pm SEM; $n=8$ for WT and Ccdc186 KO. The data shown for the WT are the same shown in Figure S4B of (Topalidou, Cattin-Ortolá, et al., 2019, manuscript submitted to MBoC) since these experiments were run in parallel with the same WT control.

\section{Figure S9. DCV cargo exit the TGN in Ccdc186 KO cells.}

A. The exogenous DCV cargo ANF::GFP is mostly localized near the TGN in Ccdc186 KO cells at steady state. Representative images of WT and Ccdc186 KO 832/13 cells transfected with ANF::GFP and costained for GFP and TGN38. Maximum-intensity projections. Scale bars: 10 $\mu \mathrm{m}$.

B. Experimental set up. Cells were transiently transfected with ANF::GFP. Incubation at $20^{\circ} \mathrm{C}$ for 2 hours resulted in blocking ANF::GFP from exiting the TGN (pulse). 30 minutes before the end of the low temperature incubation, cycloheximide was added to inhibit synthesis of new ANF::GFP. Following the low temperature block, cells were incubated at $37^{\circ} \mathrm{C}$ (chase) before fixation and imaging.

C. Representative images of the three cell categories used for qualitative assessment of TGN exit: those with most of the fluorescence concentrated at the TGN (Golgi-like), those where the TGN was still apparent but a large portion of the fluorescence was at the cell periphery (Intermediate), and those where the TGN was no longer apparent (Periphery). Single slices. Scale bar: $5 \mu \mathrm{m}$. 
D. 70 cells for each time point and genotype were imaged blindly. The data are plotted as percentage of each phenotype at each time point. The experiment was repeated three times with similar results. Error bars $=$ SEM. The data shown for the WT are the same shown in Figure 4D of (Topalidou, Cattin-Ortolá, et al., 2019, manuscript submitted to MBoC) since these experiments were run in parallel with the same WT control.

Figure S10. Endogenous CCDC186 localizes to a perinuclear area near the TGN and immature DCVs.

Representative confocal images of $832 / 13$ cells costained for endogenous CCDC186 and markers for different cell compartments: the ERGIC marker ERGIC53; the cis-Golgi marker GM130; the early-endosome marker EEA1; the lysosomal marker LAMP1; the TGN marker TGN38; the TGN/iDCV markers syntaxin 6 (Syn6), proinsulin, and chromogranin A (CgA); and the mature DCV marker insulin. Single slices. Scale bars: $5 \mu \mathrm{m}$.

Figure S11. Endogenous CCDC186 localizes to ring-like structures around proinsulin. Representative stimulated emission depletion (STED) microscopy images of 832/13 cells costained for endogenous CCDC186 and endogenous proinsulin. Maximum-intensity projections. Scale bars: $2 \mu \mathrm{m}$.

Figure S12. Mitochondria relocation of CCDC186 fragments.

A. Schematic of the CCDC186 mitochondria relocation experiment.

B. Domain structure of CCDC186 and CC3 fragment fused at their C-terminus to the transmembrane domain of monoamine oxidase (MAO, black). The domains marked with different shades of red are predicted coiled-coil domains (CC).

C. The CC3 fragment fused to MAO is relocated to the mitochondria. Representative confocal images of $832 / 13$ cells transiently transfected with CC3::HA::MAO, incubated with MitoTracker, 
and costained for HA and TGN38. The intensity and contrast of the image showing MitoTracker staining was adjusted to remove the high background. Of note, we observed that overexpression of CC3::HA::MAO caused clustering of mitochondria in a perinuclear region adjacent to the TGN marker TGN38. Single slices. Scale bars: $5 \mu \mathrm{m}$. The experiment was repeated twice.

$D, E$. The CCDC186 fragment CC3 fused to MAO relocates the GTP-bound forms of RAB2A and RAB2B to mitochondria. Representative confocal images of $832 / 13$ cells transiently cotransfected with CC3::HA::MAO and GFP::RAB2A(Q65L) or GFP::RAB2B(Q65L), and costained for HA and GFP. Single slices. Scale bars: $5 \mu \mathrm{m}$. The experiment was repeated twice.

\section{Figure S13. Volcano plot representation of the CC3 BiolD experiment.}

Volcano plot showing the Student's t-test p-value for each protein as a measure of that protein's enrichment in CC3::BirA*::HA::MAO streptavidin pulldowns compared to the negative control BirA*::HA::MAO. Lysates from cells overexpressing CC3::BirA*::HA::MAO and BirA*::HA::MAO were subjected to affinity enrichment using streptavidin. Proteins with a Log2 ratio (CC3::BirA*::HA::MAO / BirA*::HA::MAO) larger than 1.8 are labeled.

\section{Figure S14. CCDC186 and EIPR1 are not required for CD-MPR trafficking.}

Representative confocal images of WT, Ccdc186 KO, and Eipr1 KO 832/13 cells transiently transfected with CD-MPR::GFP and costained for insulin and GFP. Single slices. Scale bars: 5 $\mu \mathrm{m}$. The experiment was repeated twice. 


\section{Figure 1}

A

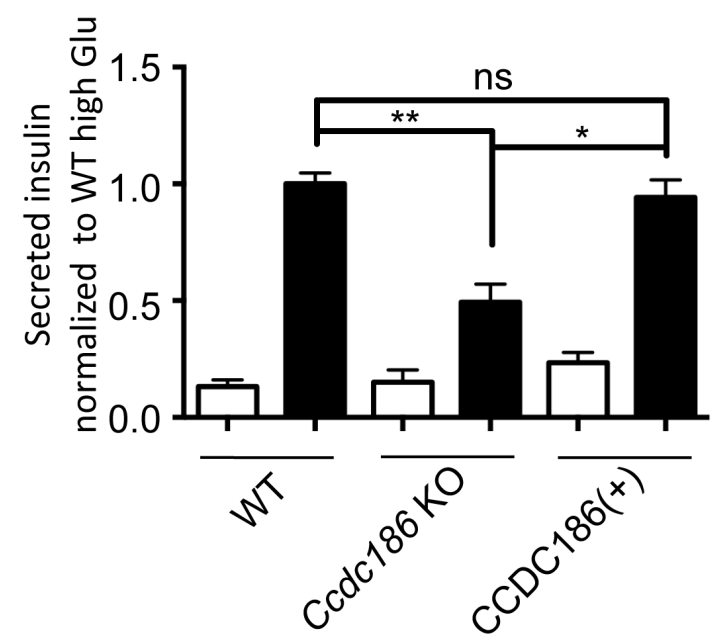

E
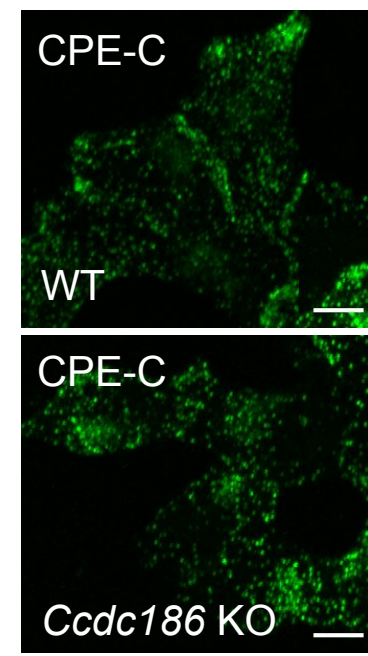

$$
\text { CPE-C }
$$

$\square 5 \mathrm{mM} \mathrm{KCl}, 0 \mathrm{mM}$ Glucose

$55 \mathrm{mM} \mathrm{KCl}, 25 \mathrm{mM}$ Glucose
B

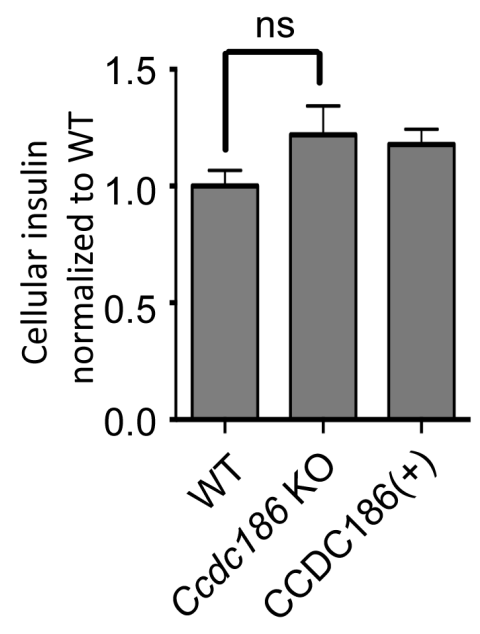

C

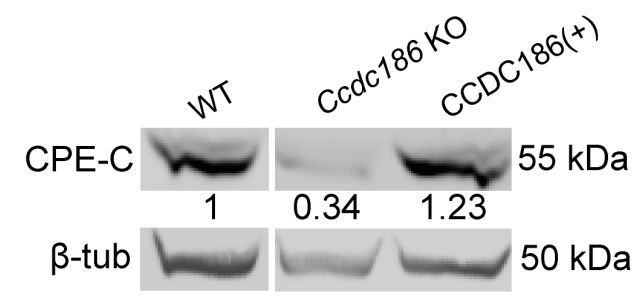

D

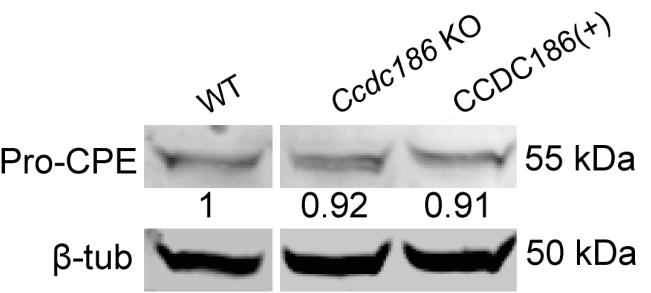

$\mathbf{F}$

Total CPE-C - TGN38
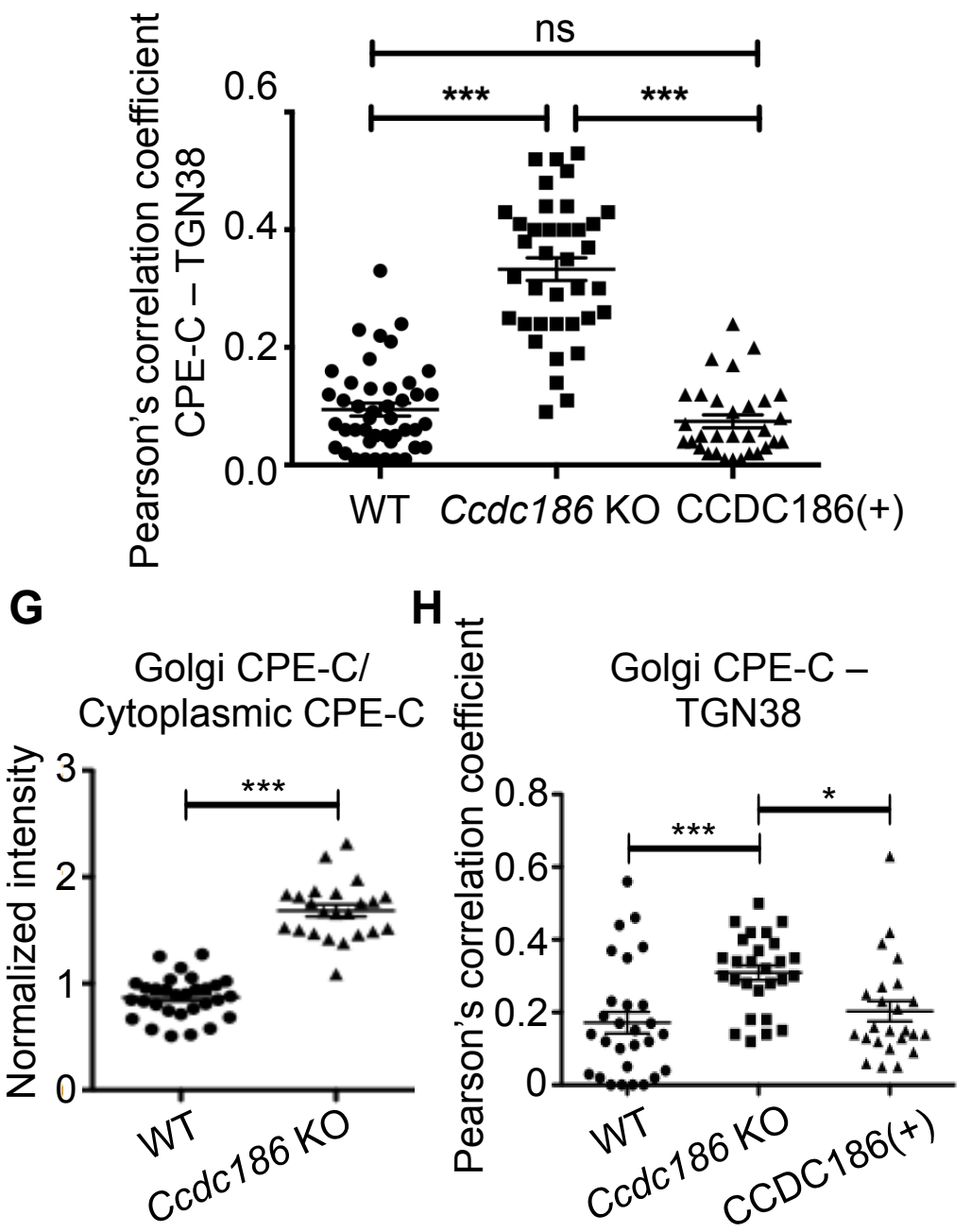
Figure 2

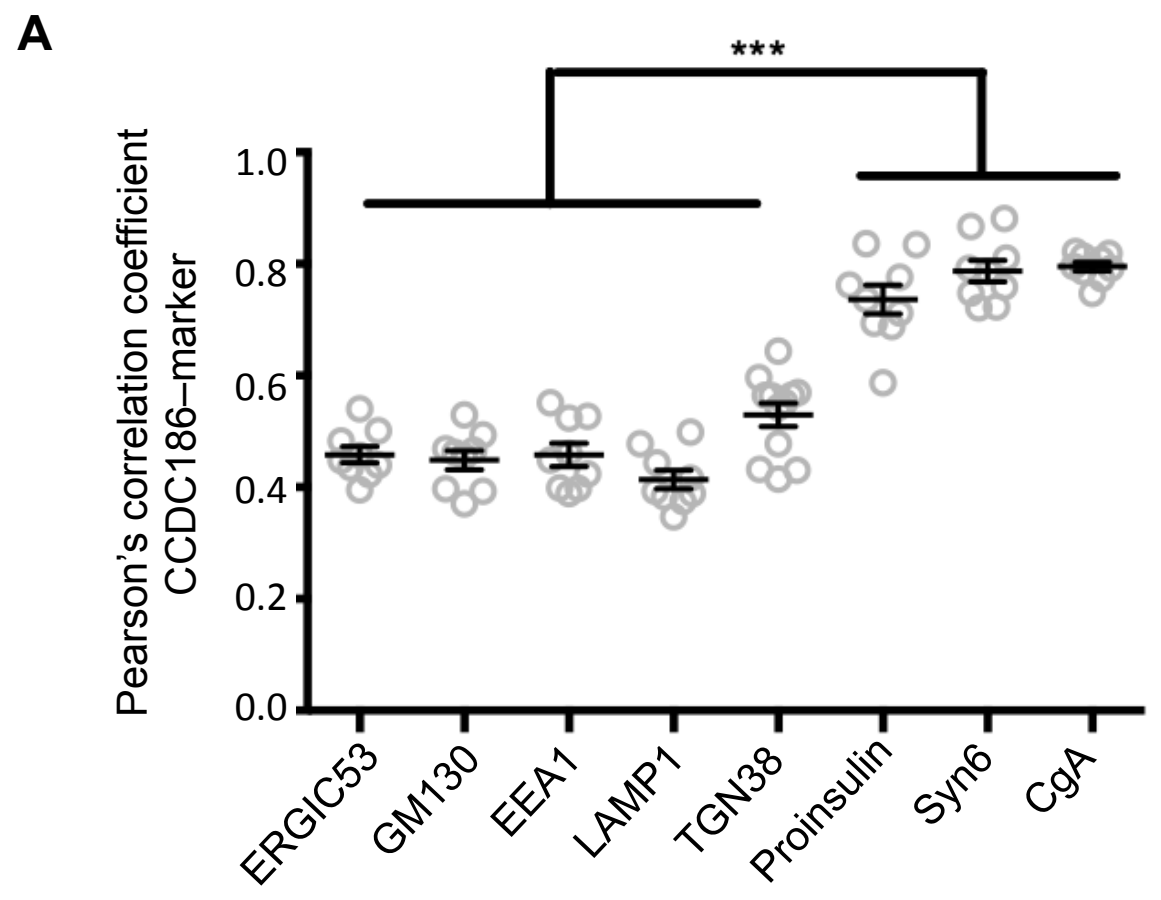

B
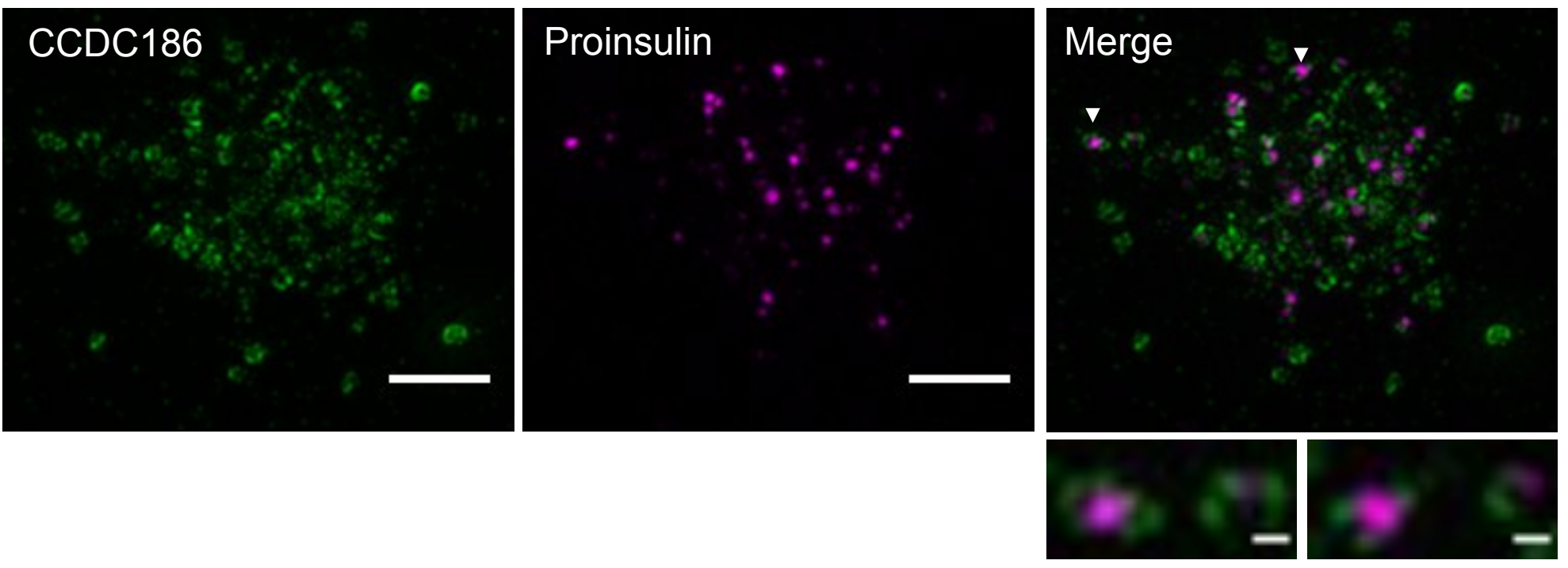


\section{Figure 3} under aCC-BY 4.0 International license.

A

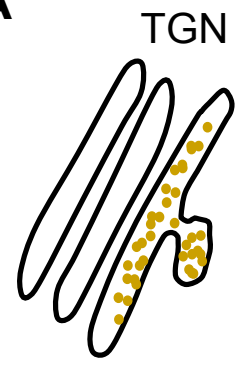

B

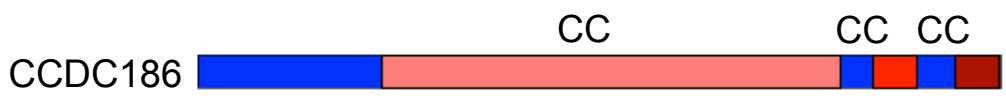

CC3::BirA*::HA::MAO

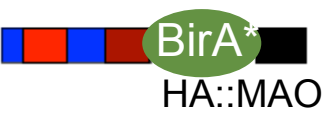

$\mathrm{CC}=$ coiled-coil
Interactors?
Vesicle?

CC3::BirA*::HA::MAO

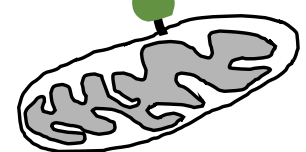

Mitochondria
C

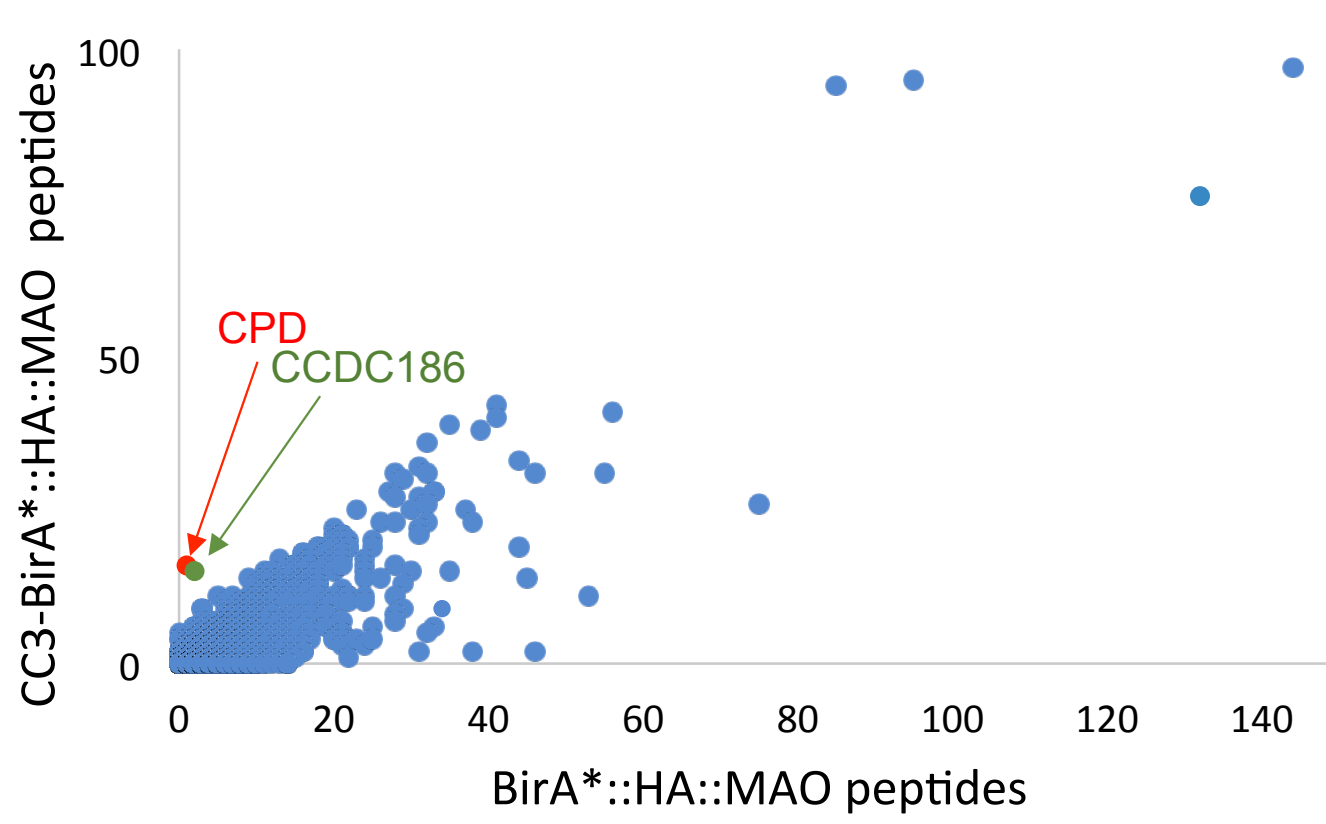

E

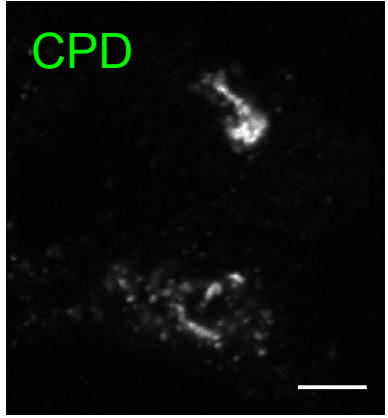

D

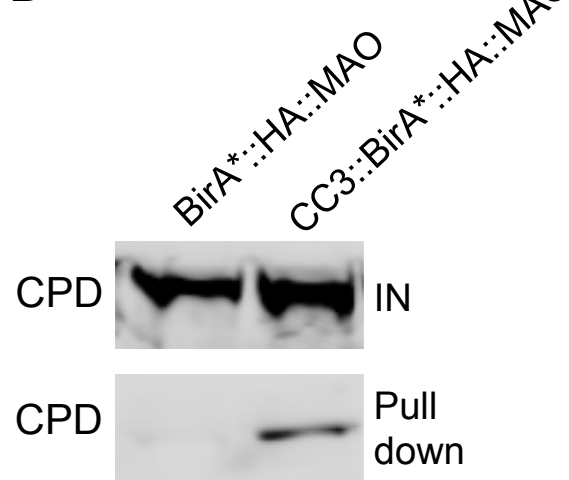


Figure 4

A

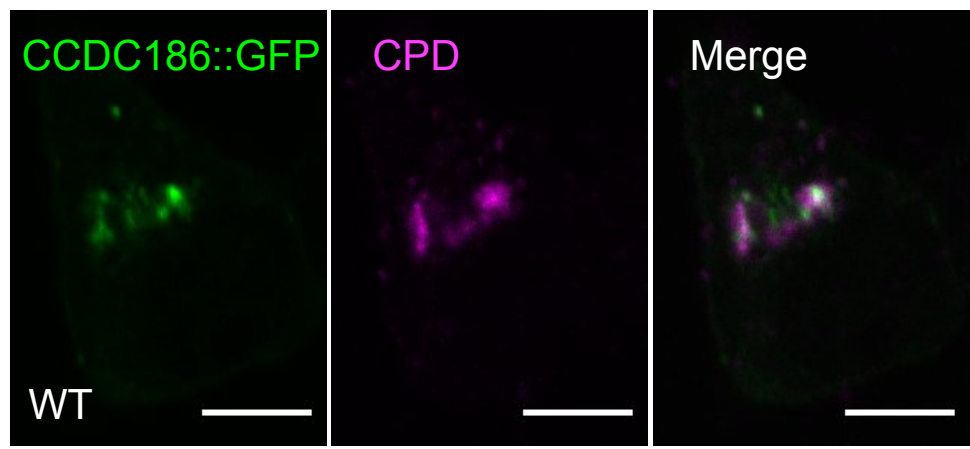

C
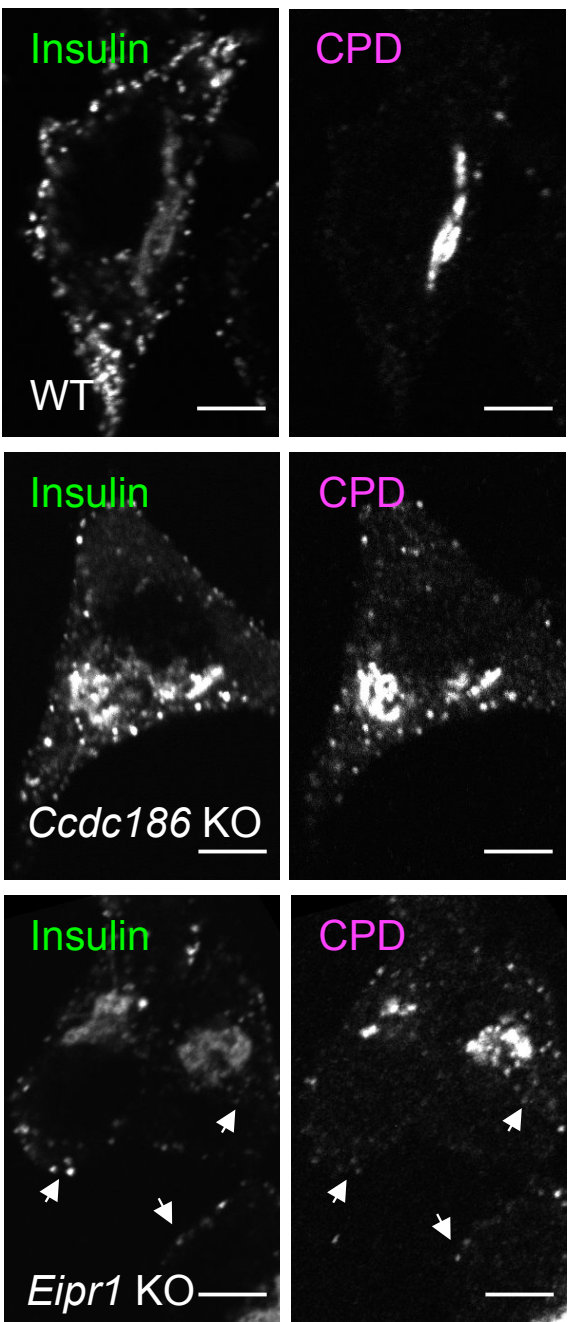

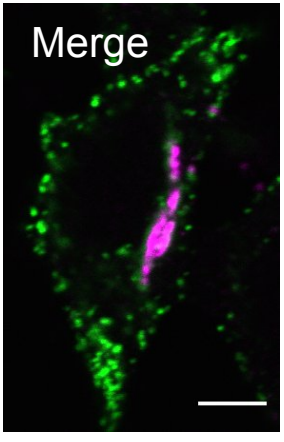

\section{Merge}

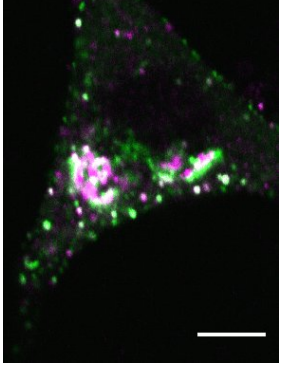

Merge :

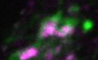

B

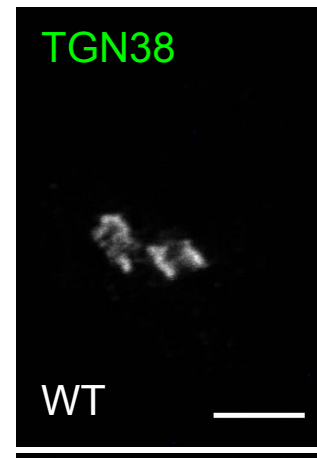

\section{TGN38}
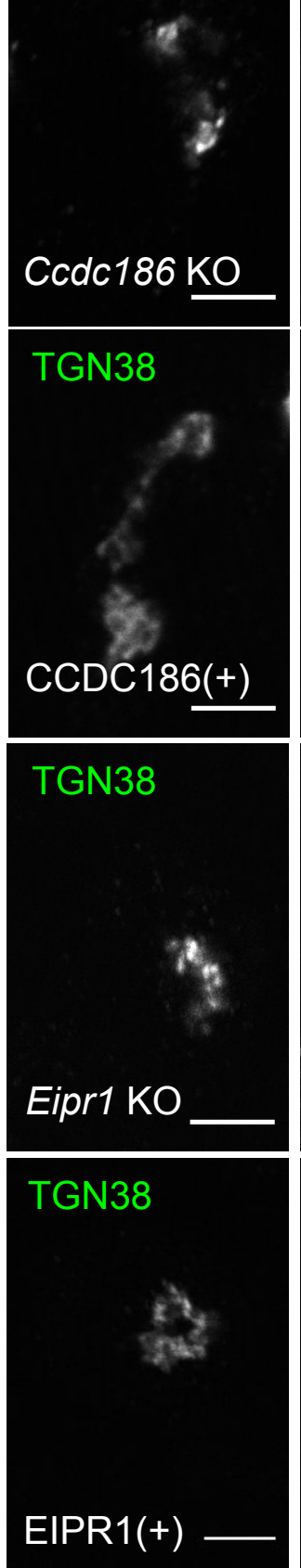

$$
\text { CPD }
$$

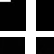
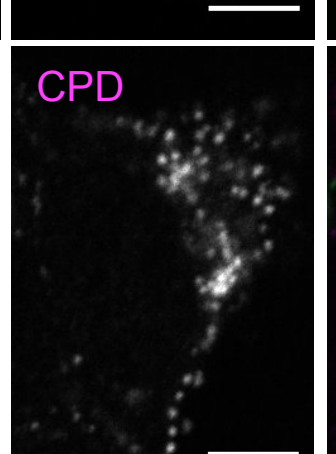

Merge
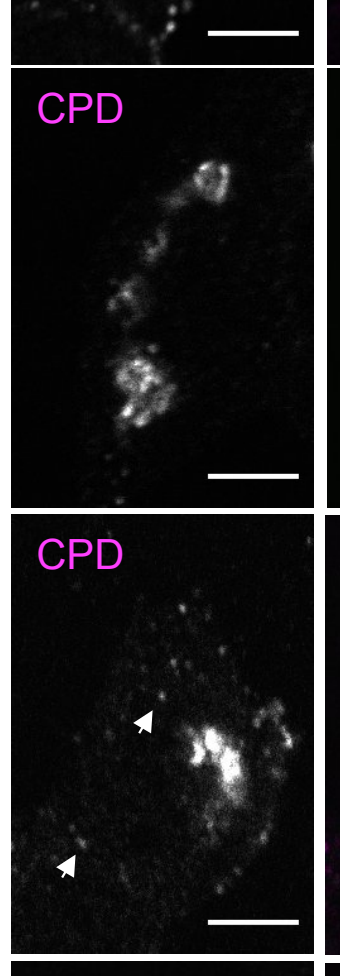

CPD

\section{Merge}

Merge

Merge

Merge

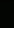




\section{Figure 5}

A

Sucrose: $0.6 \mathrm{M}$

$1.9 \mathrm{M}$

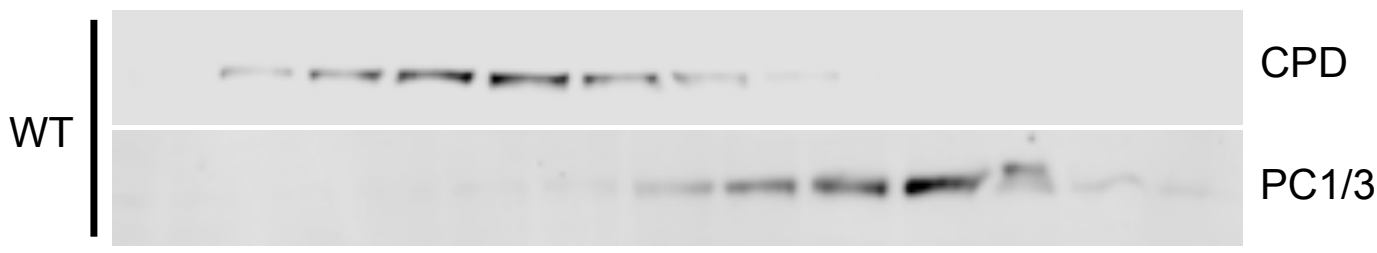

\begin{tabular}{l|ll}
$\operatorname{Ccdc186\mathrm {KO}} \mid+\frac{\mathrm{CPD}}{\mathrm{PC} 1 / 3}$ & $\mathrm{P}$
\end{tabular}

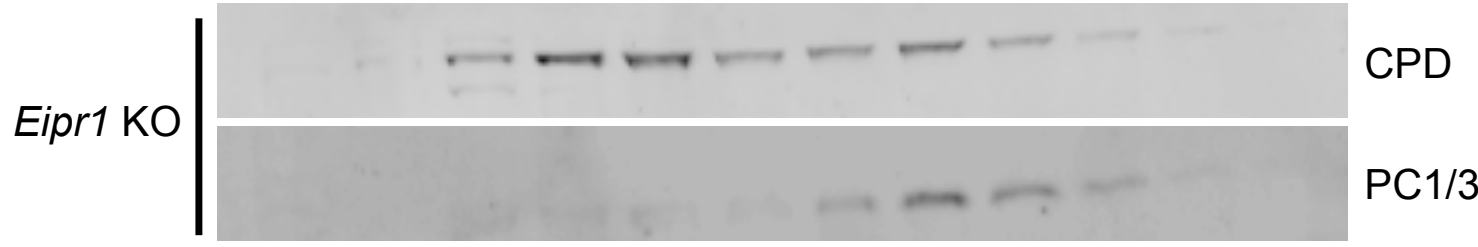

B

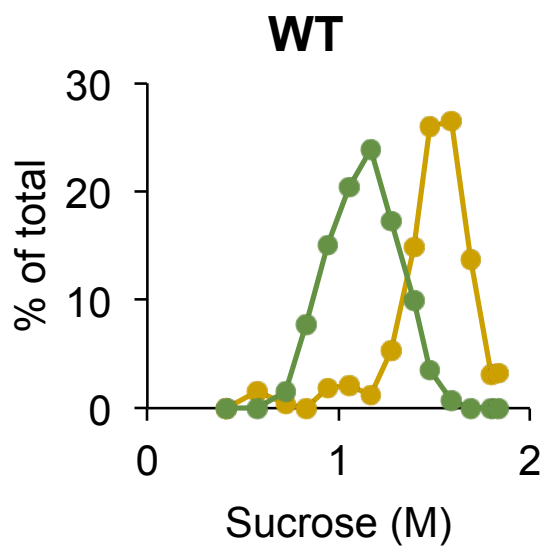

Ccdc186 KO

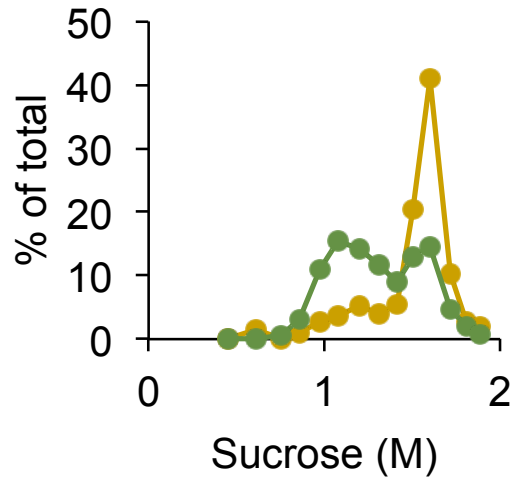

Eipr1 KO

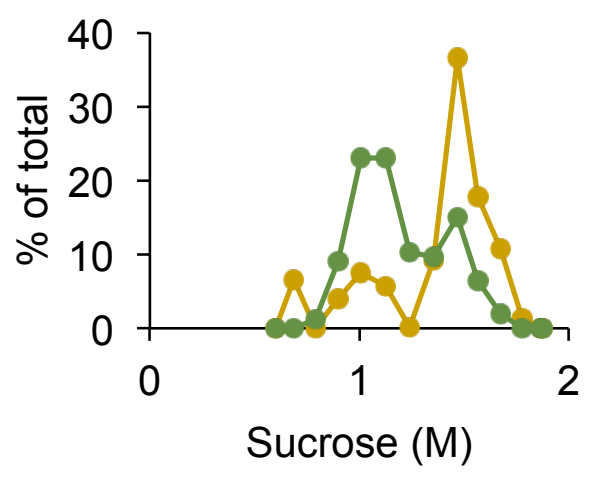


Figure 6 under aCC-BY 4.0 International license.

\section{WT}

$\int \mathrm{CPD}$

- Proinsulin

- Insulin

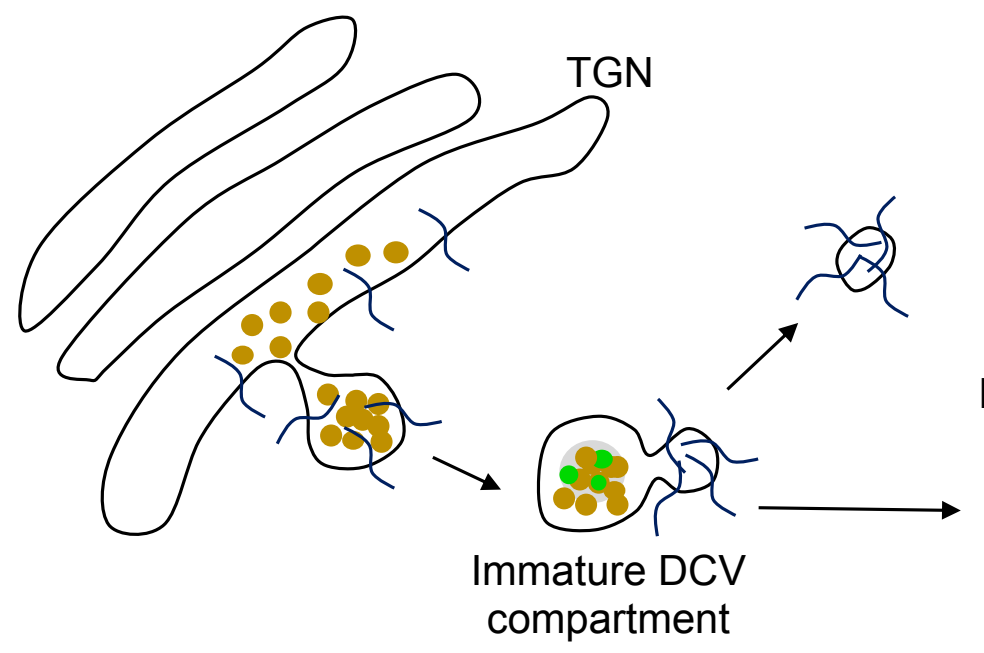

Plasma membrane

Ccdc186 KO

Eipr1 KO
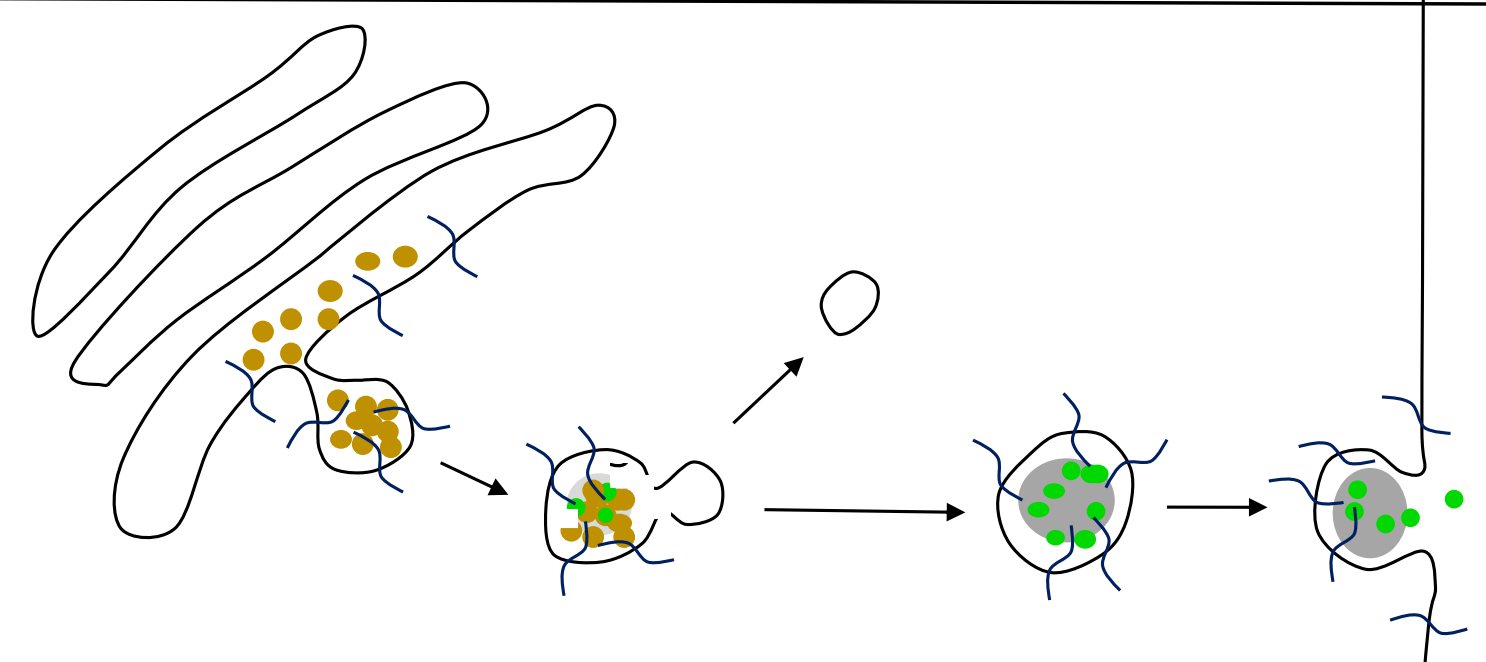
A

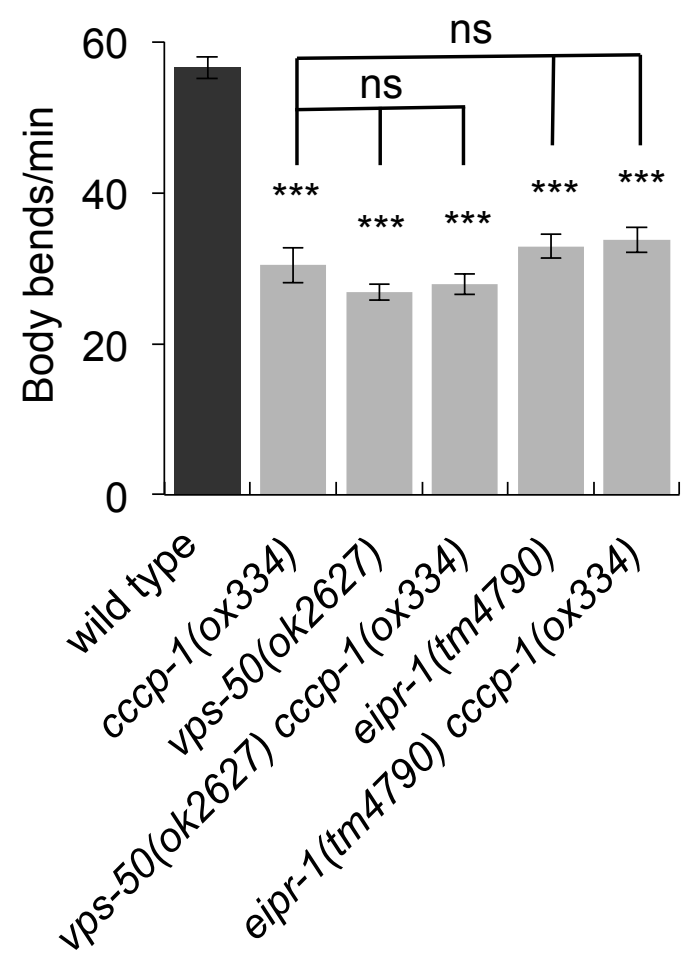

B
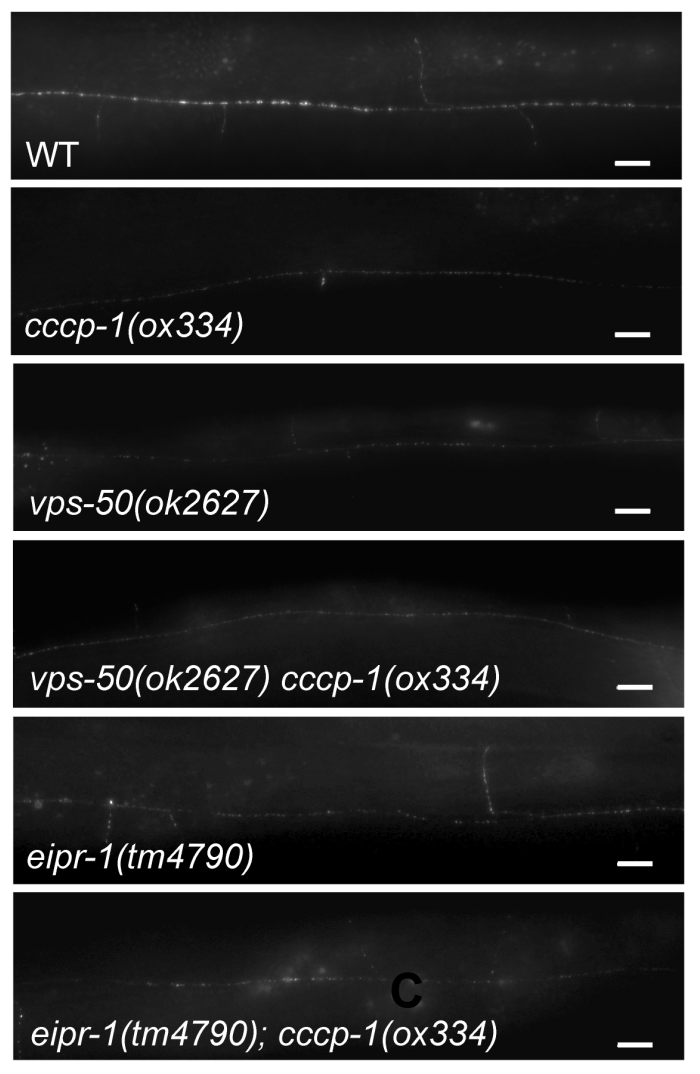

C

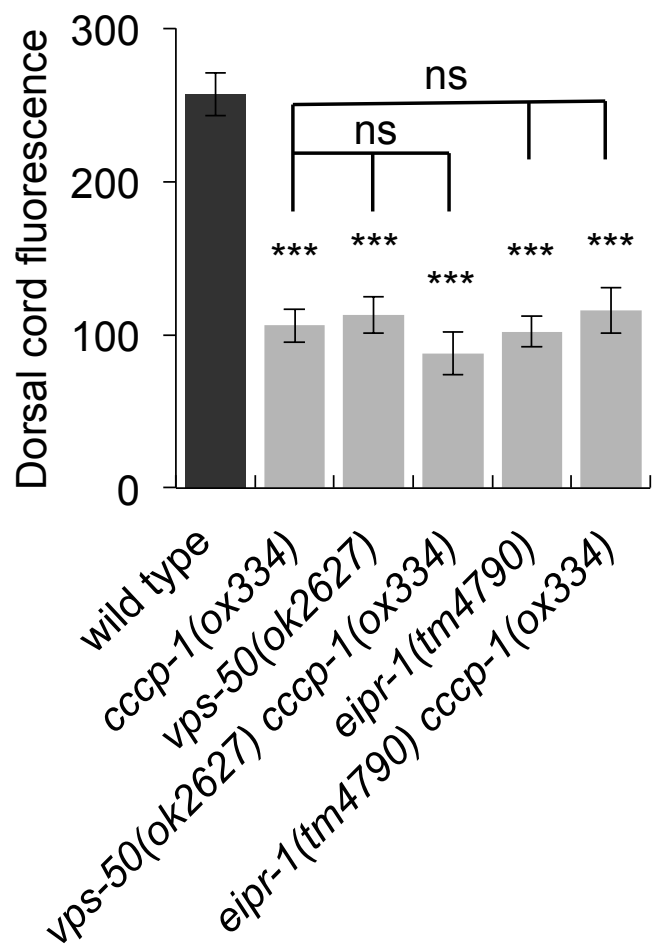




\section{Figure S2} under aCC-BY 4.0 International license.

A

Heart Liver Brain Kidney Spleen 832/13

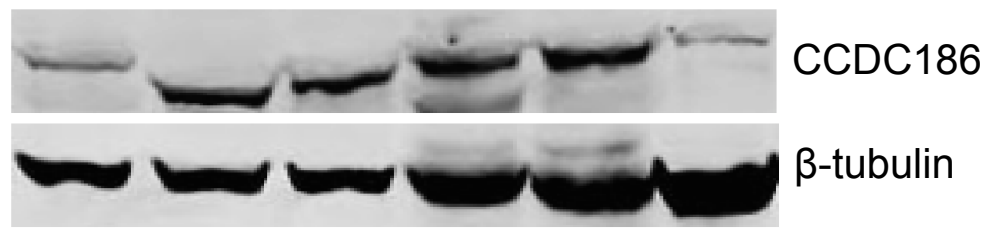

C
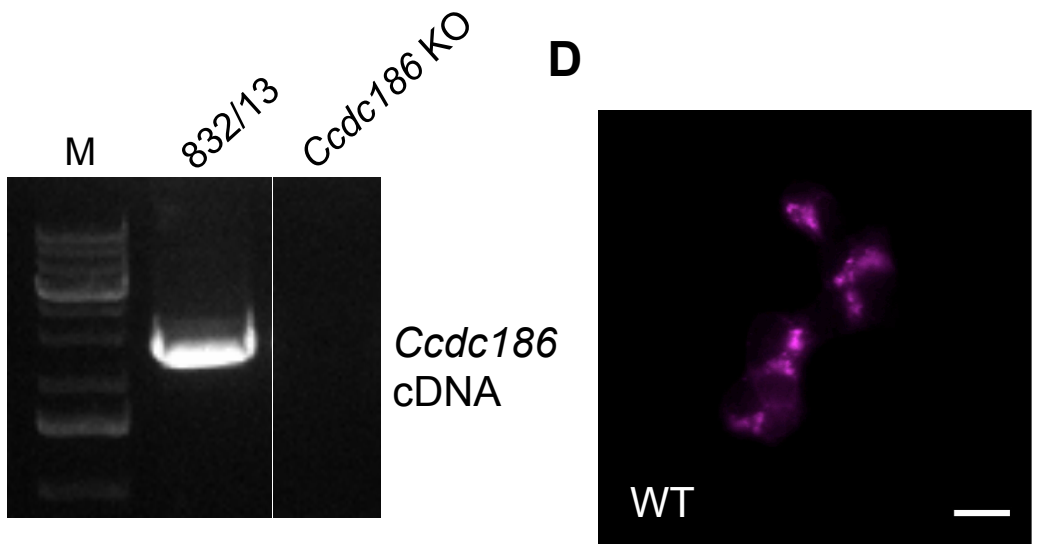

B

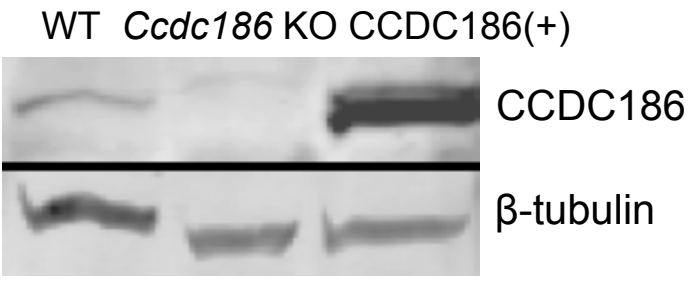

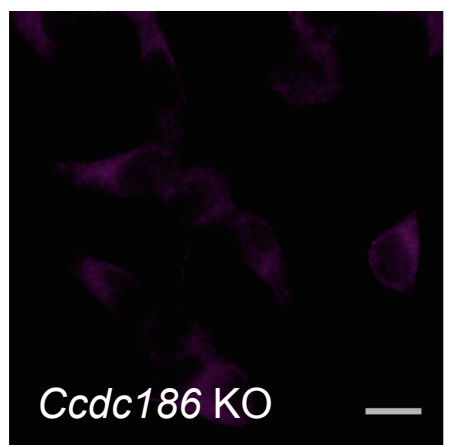

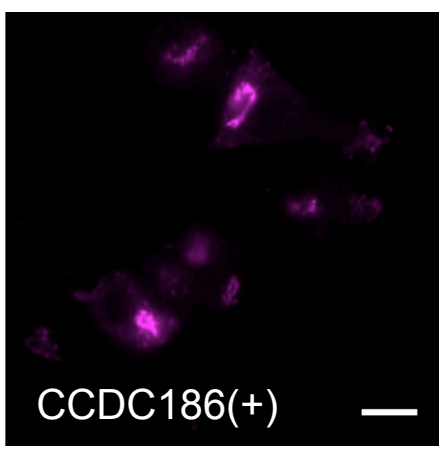


Figure S3

A

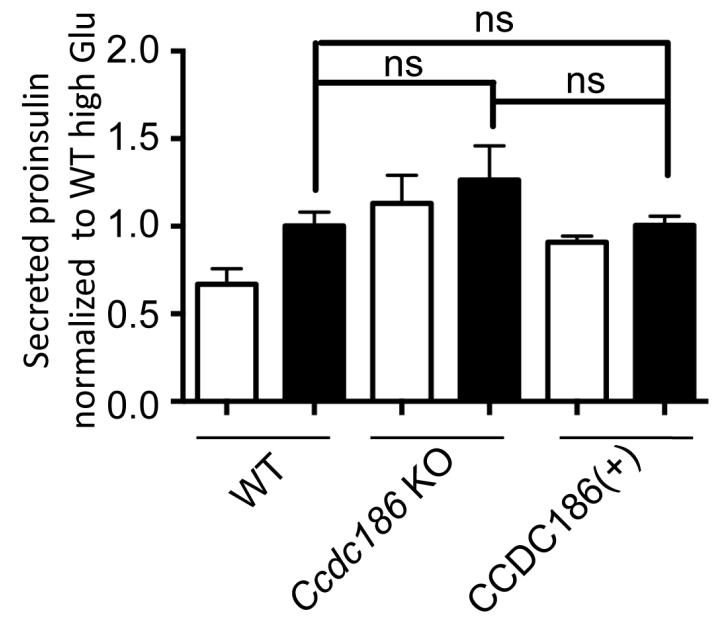

$\square 5 \mathrm{mM} \mathrm{KCl}, 0 \mathrm{mM}$ Glucose

- $55 \mathrm{mM} \mathrm{KCl}, 25 \mathrm{mM}$ Glucose

C

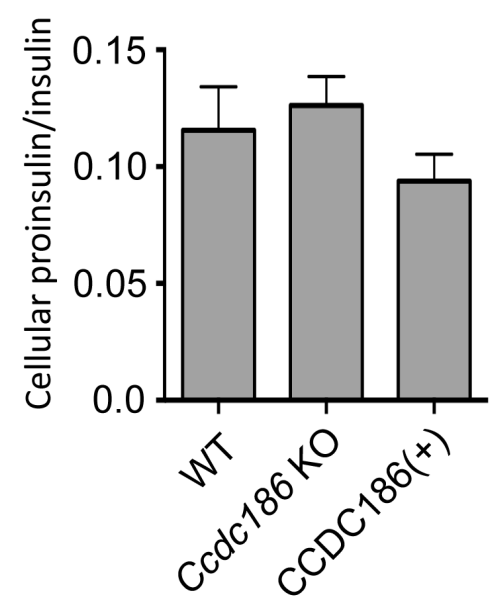

B

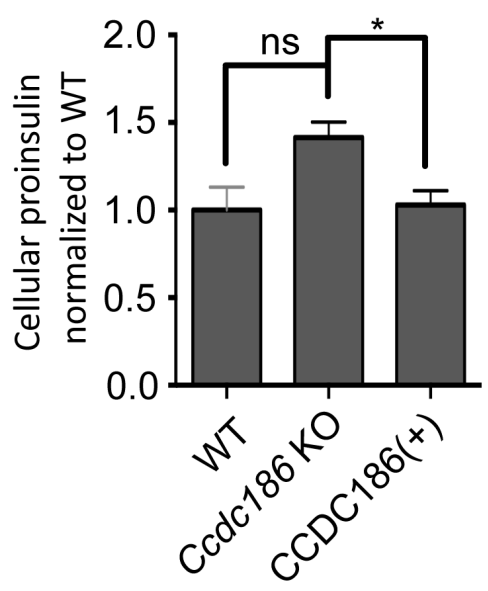

D

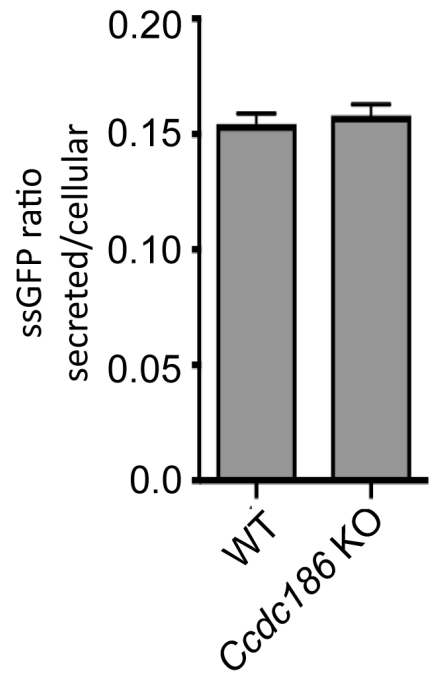


bioRxiv preprint doi: https://doi.org/10.1101/616458; this version posted November 6,2019 . The copyright holder for this preprint (which was not certified by peer review) is the author/funder, who has granted bioRxiv a license to display the preprint in perpetuity. It is made available Figure $\mathrm{S} 4$ under aCC-BY 4.0 International license.

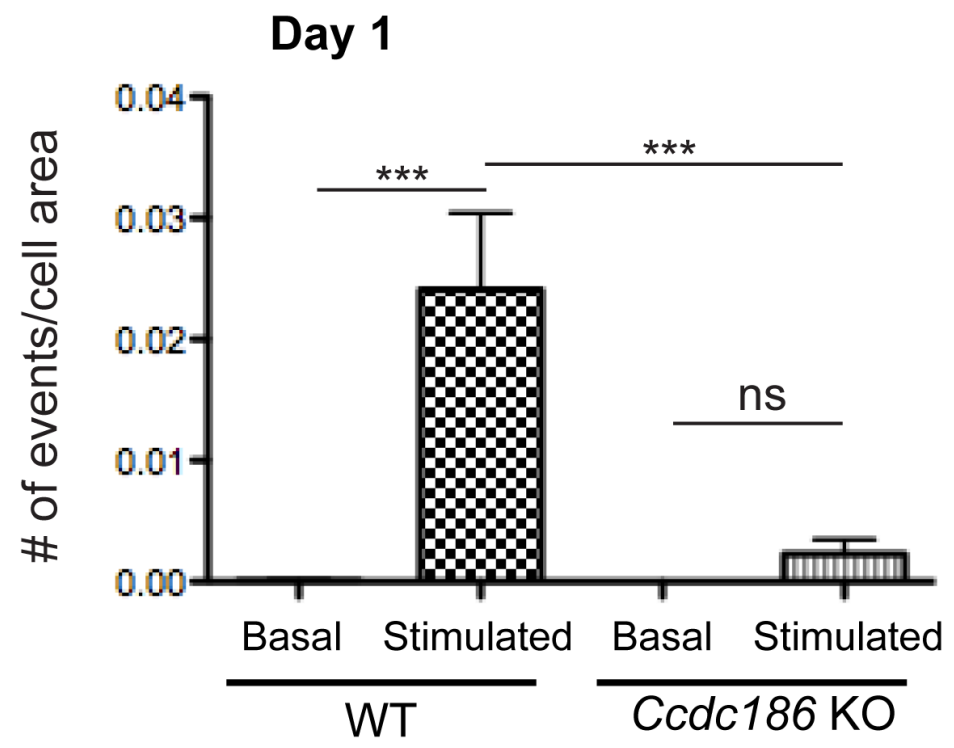

Day 2

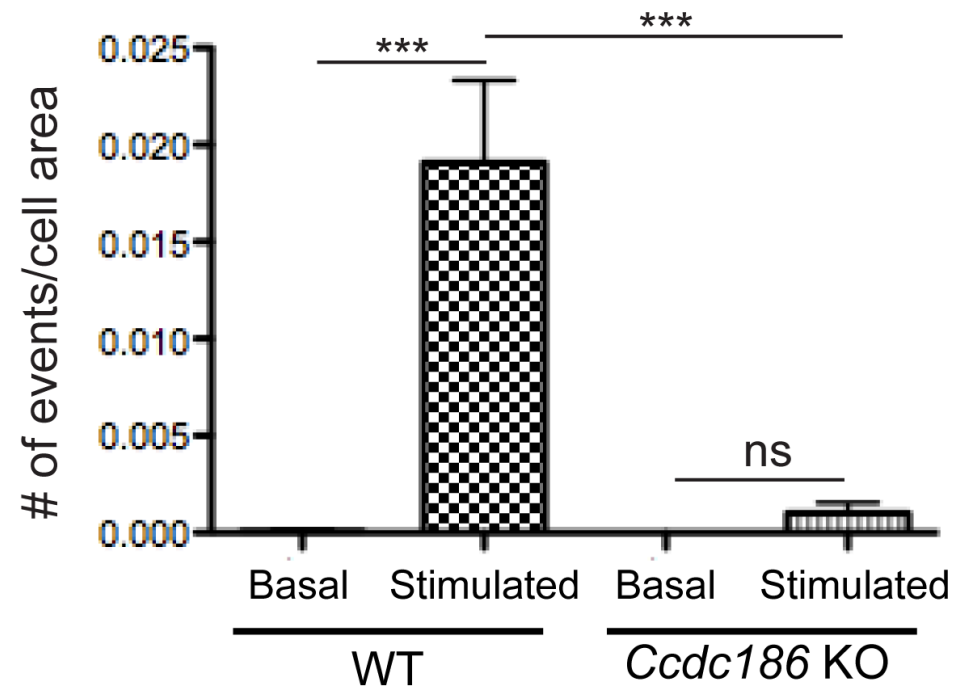

Day 3

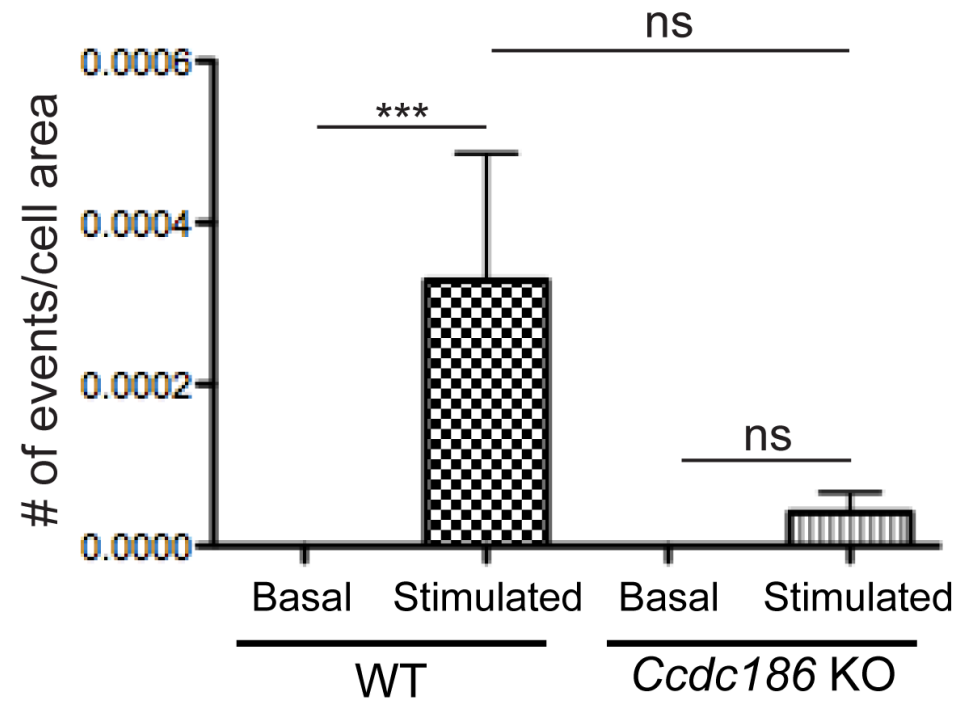


Figure S5

A

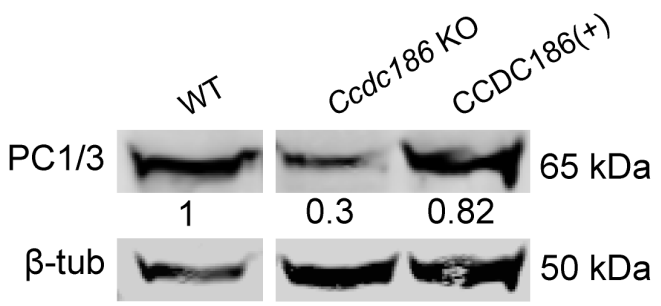

B

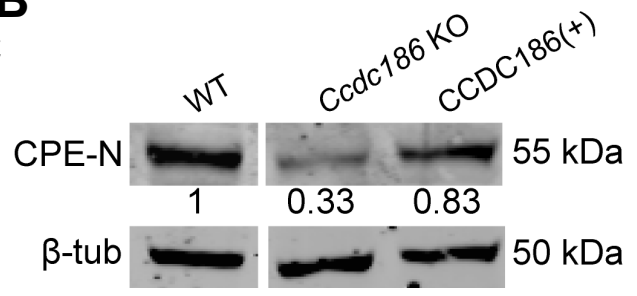

C

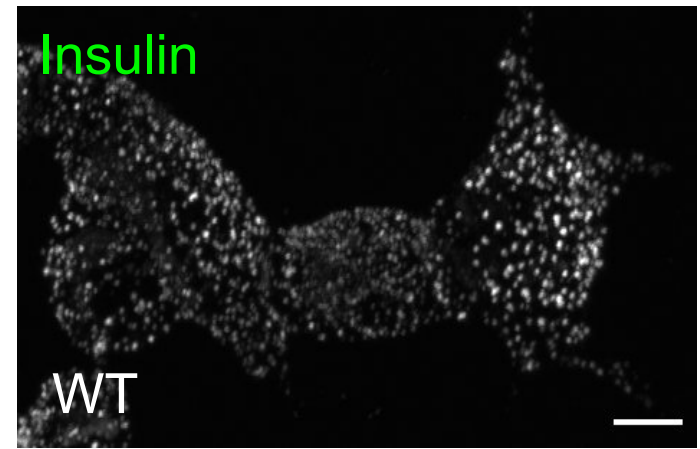

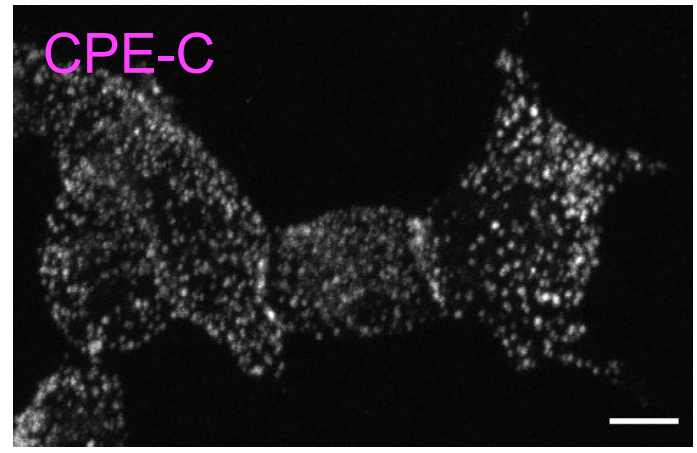

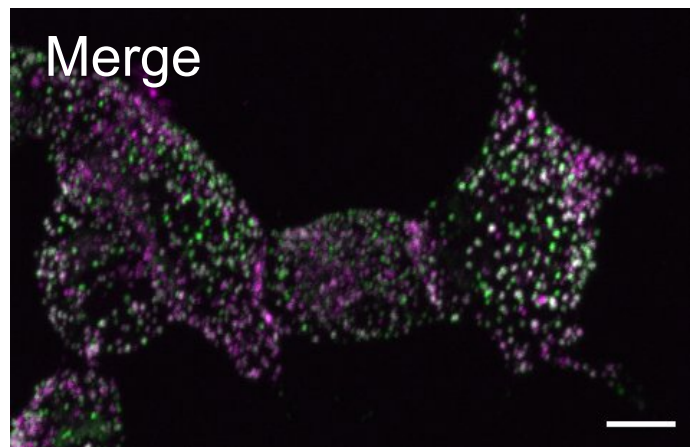


Figure $\mathbf{6} 6$ under aCC-BY 4.0 International license.

A
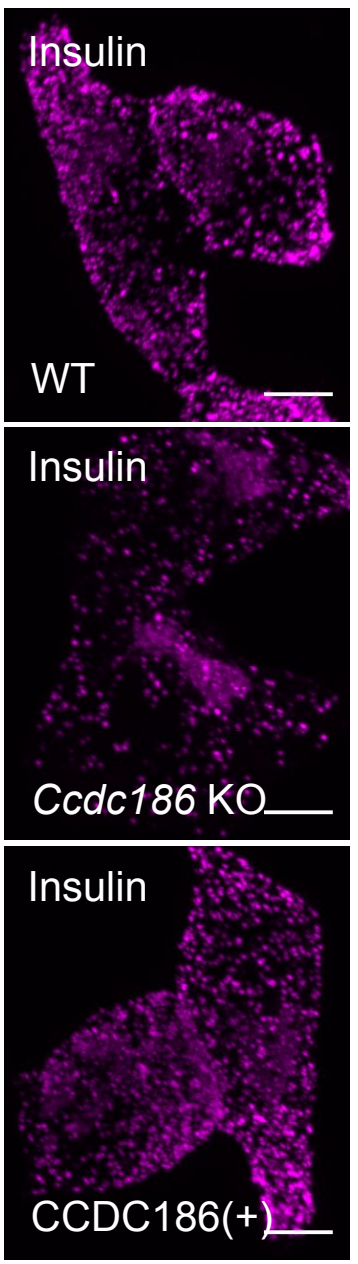
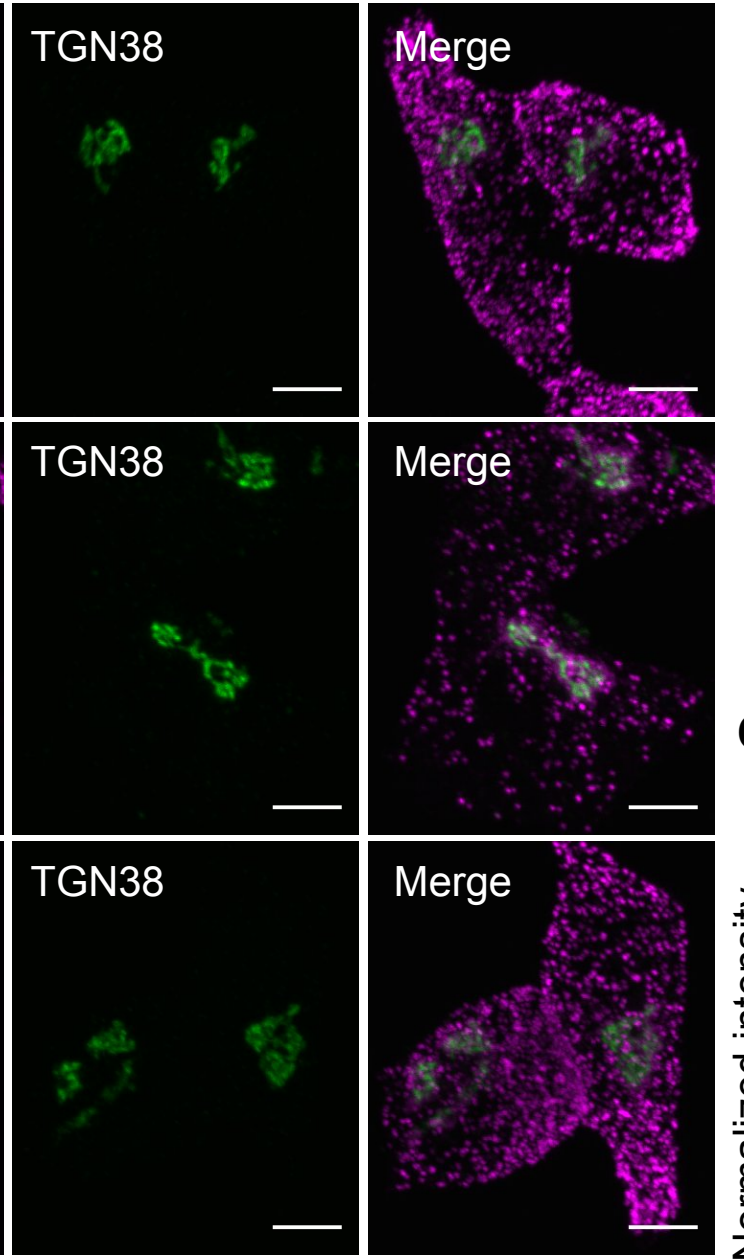

B Total insulin-TGN38

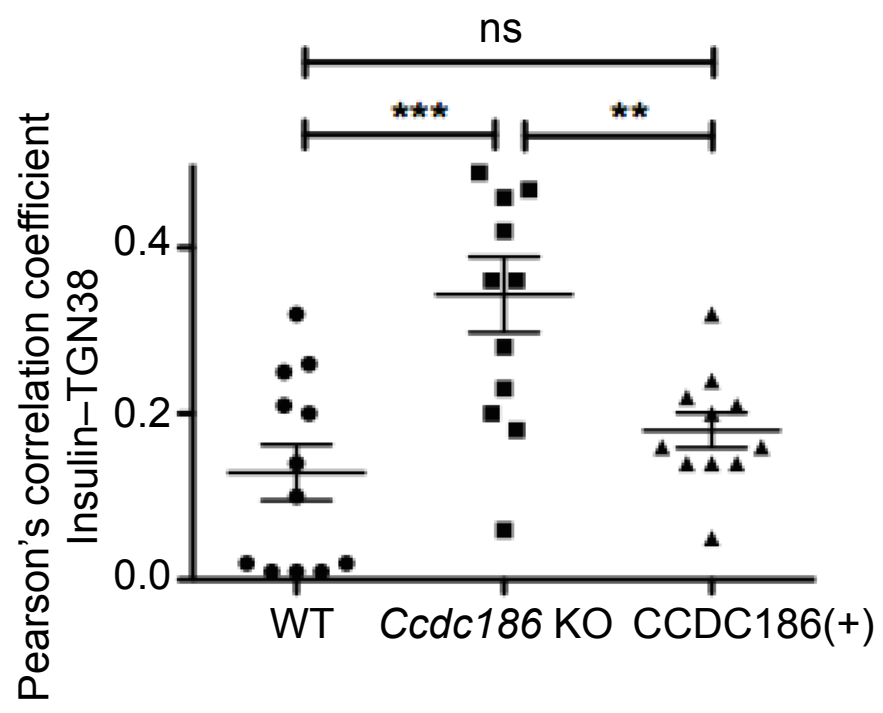

C
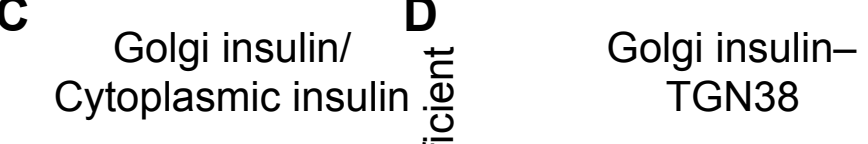

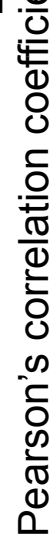

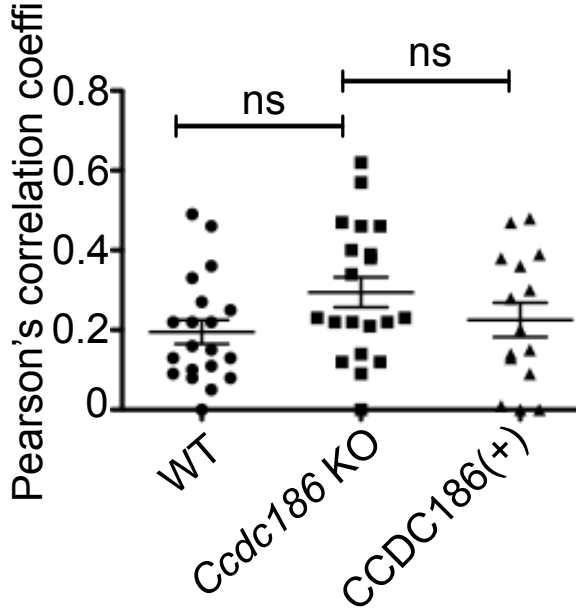


Figure S7 under aCC-BY 4.0 International license.

A
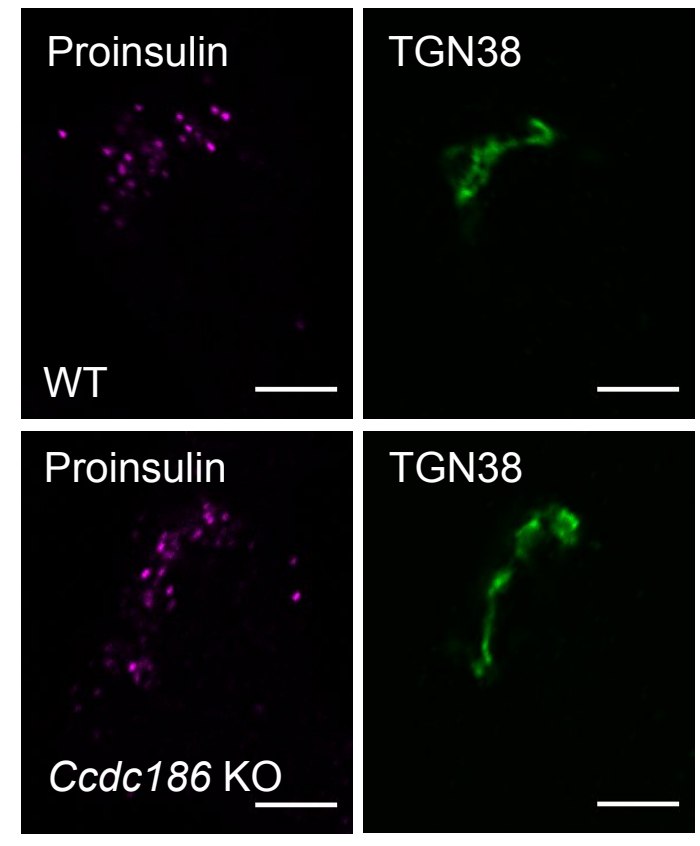

C
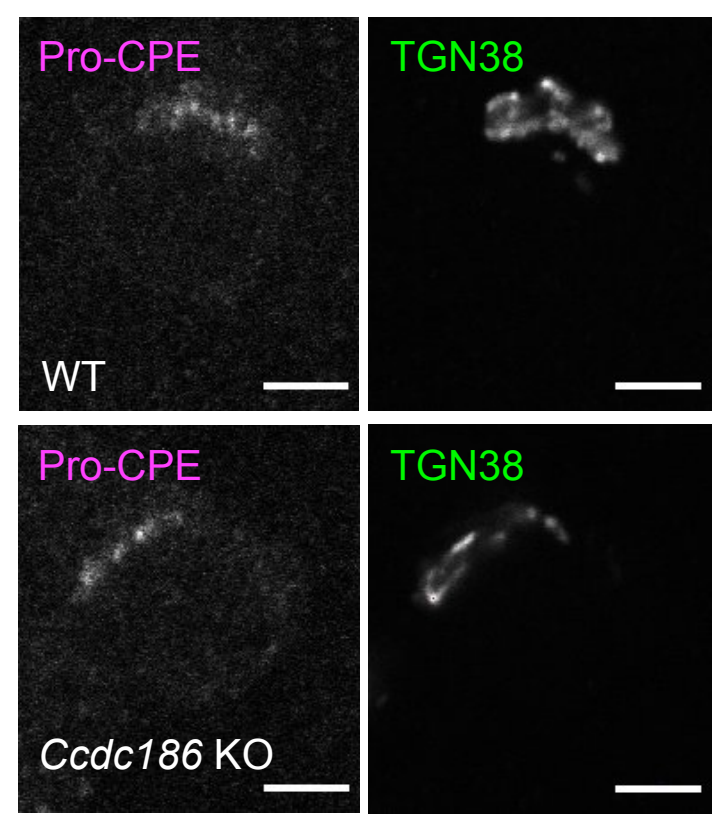

B
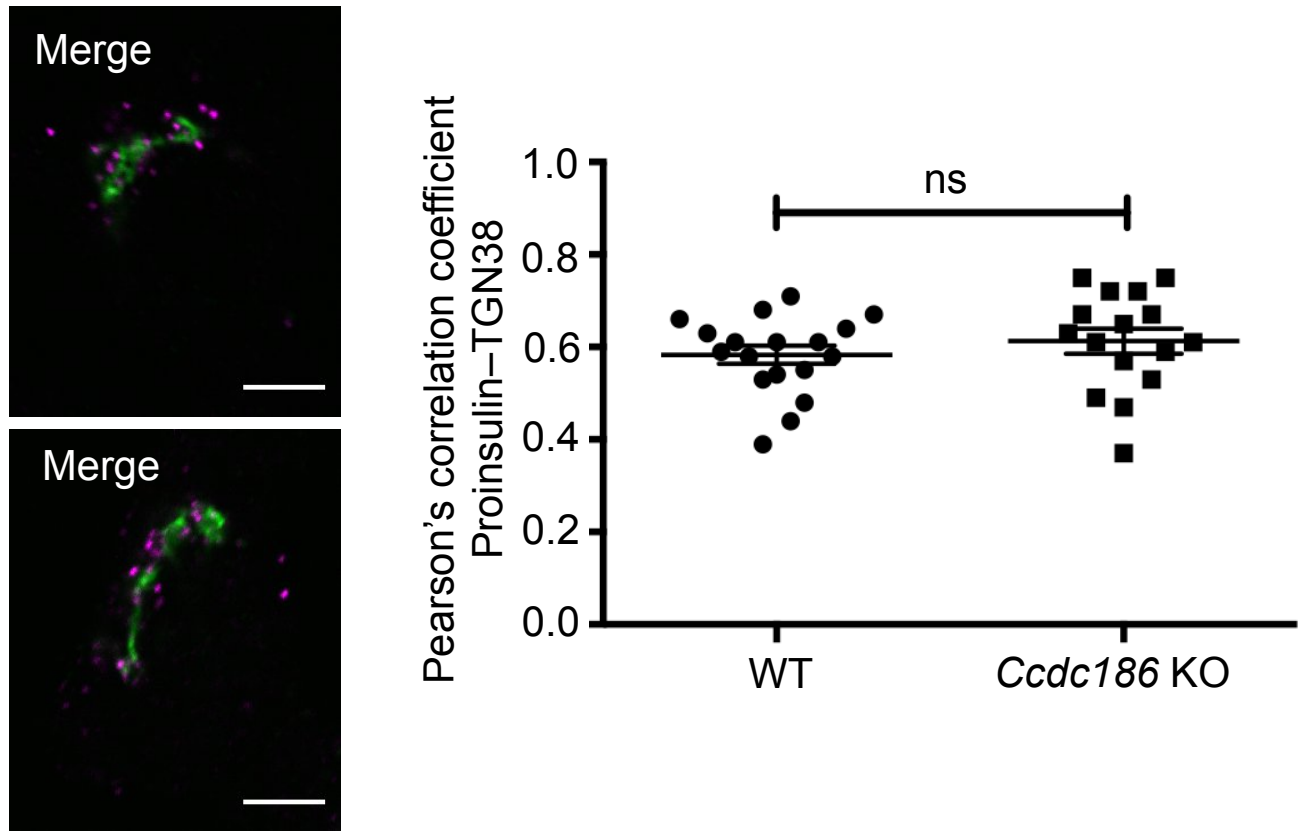

D
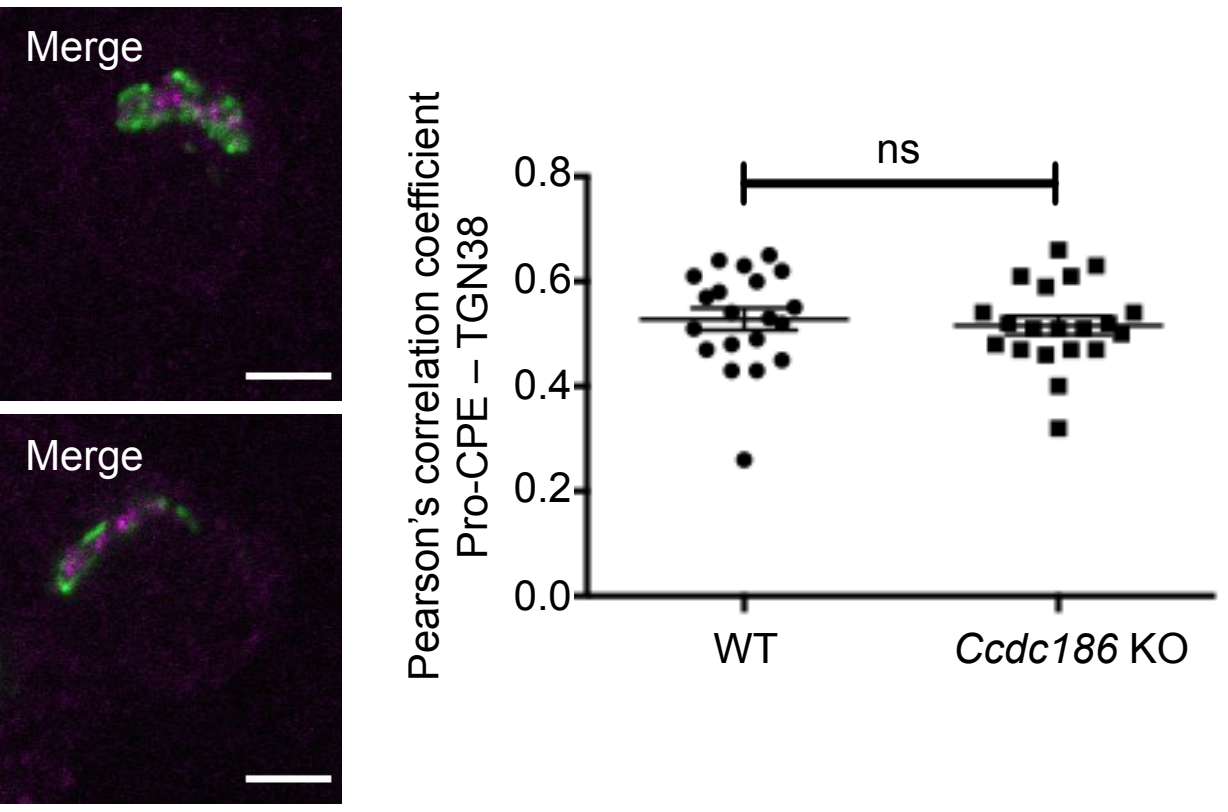
Figure S8

A

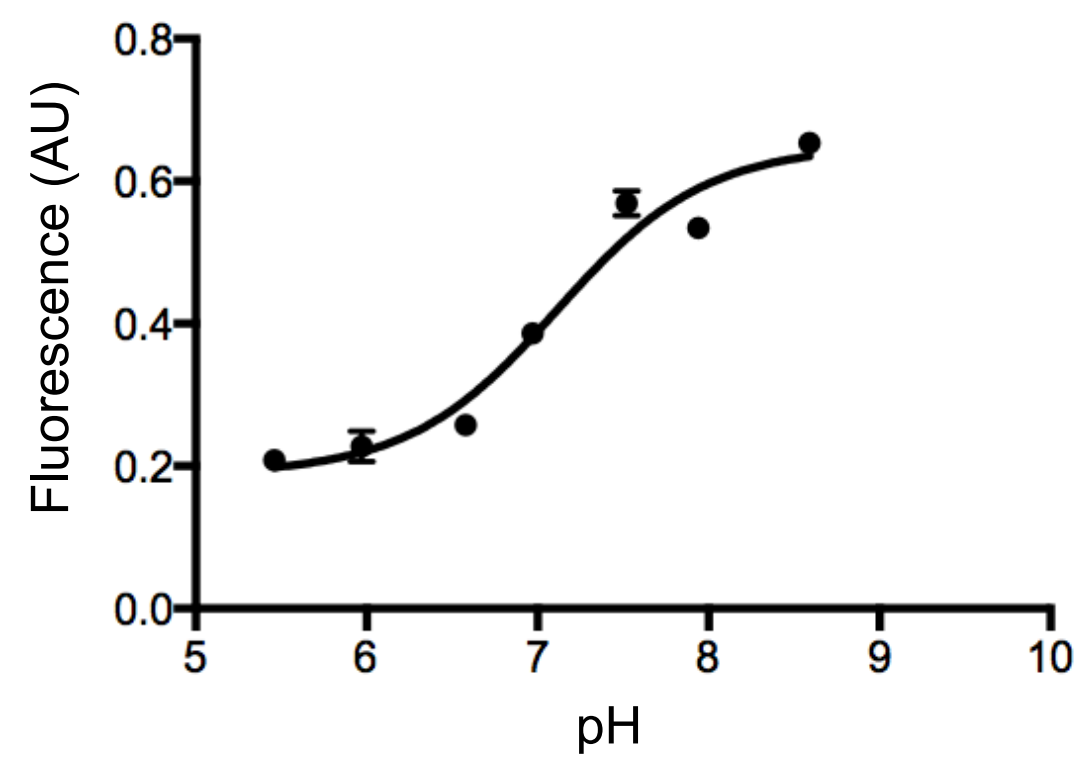

B

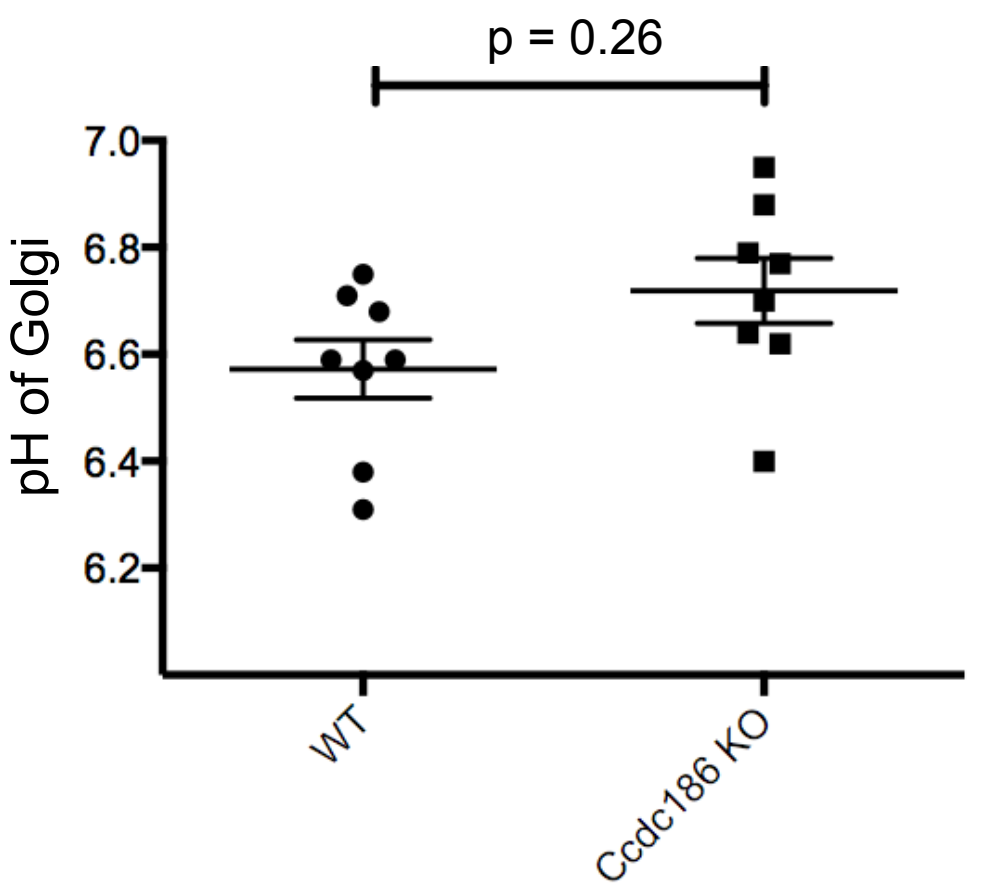




\section{Figure S9}

A

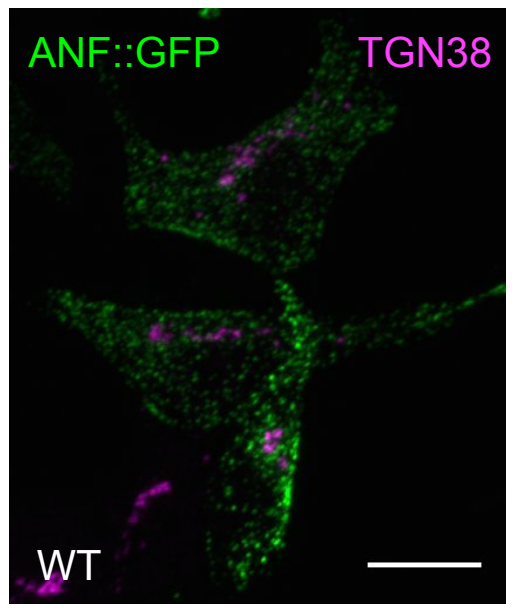

B

C

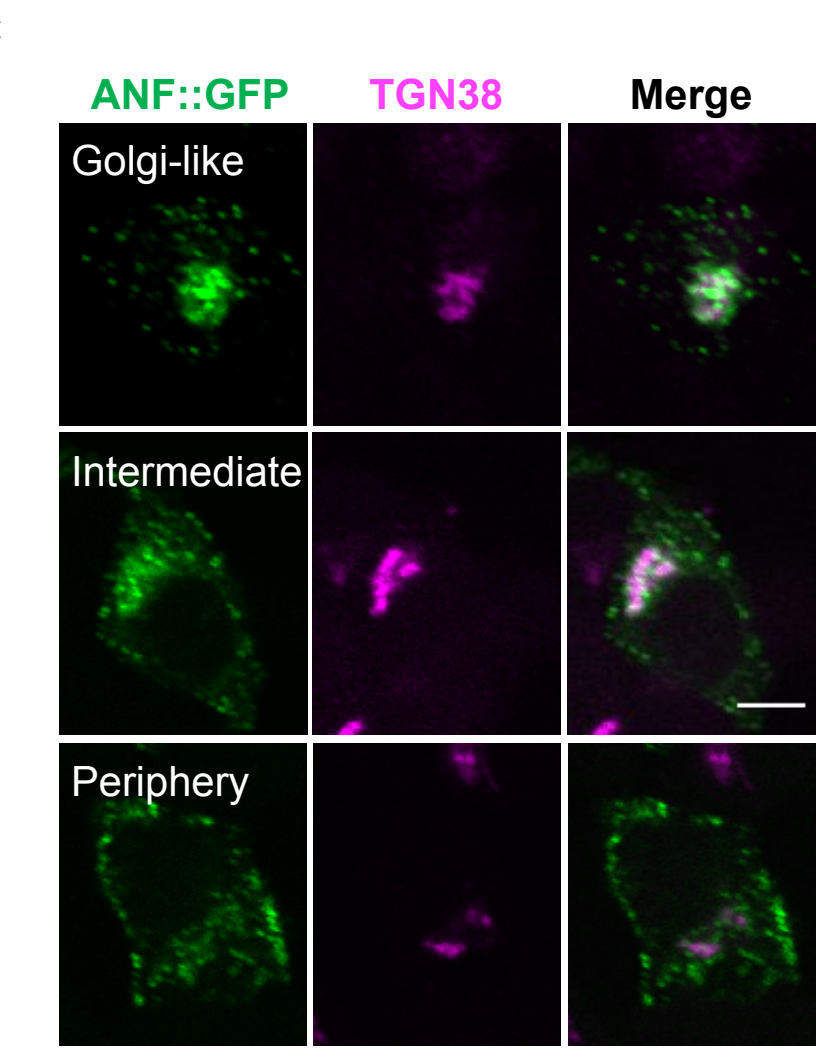

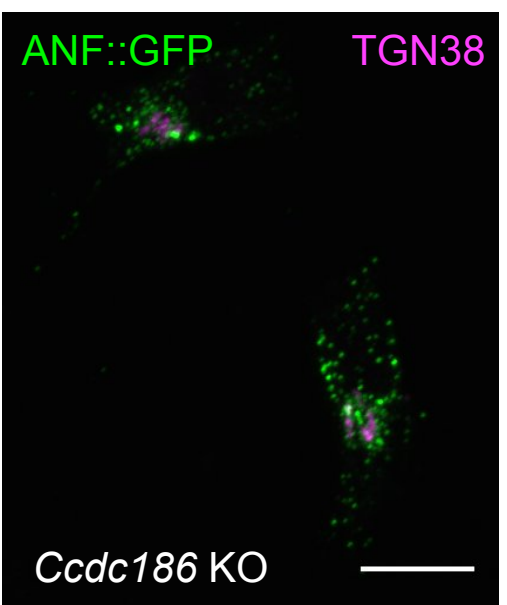

cycloheximide

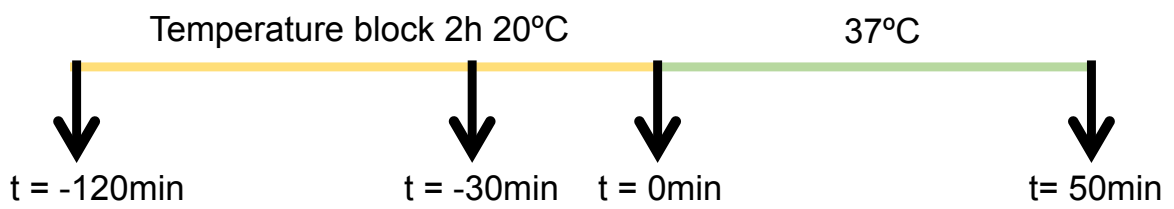

D

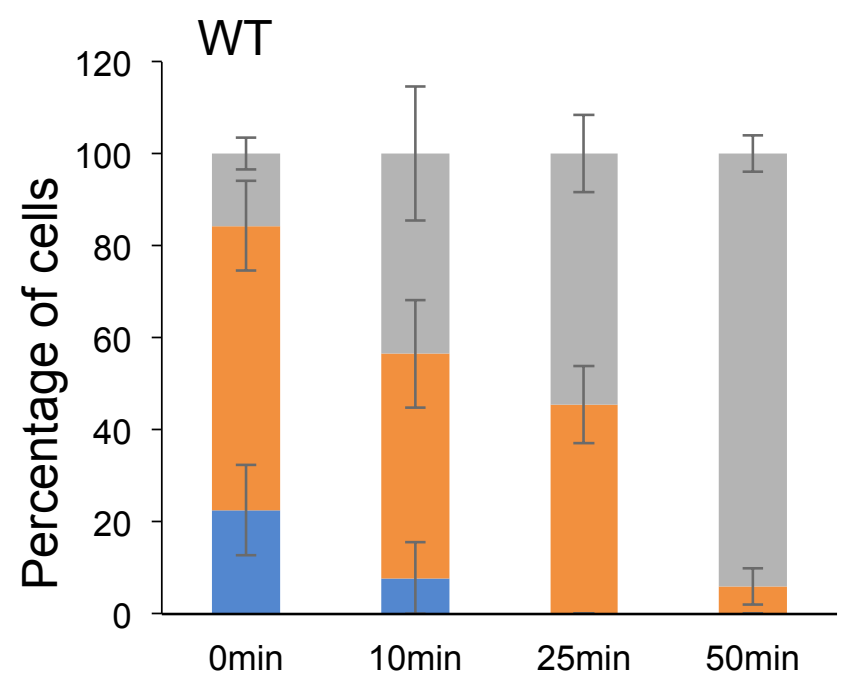

Ccdc186 KO

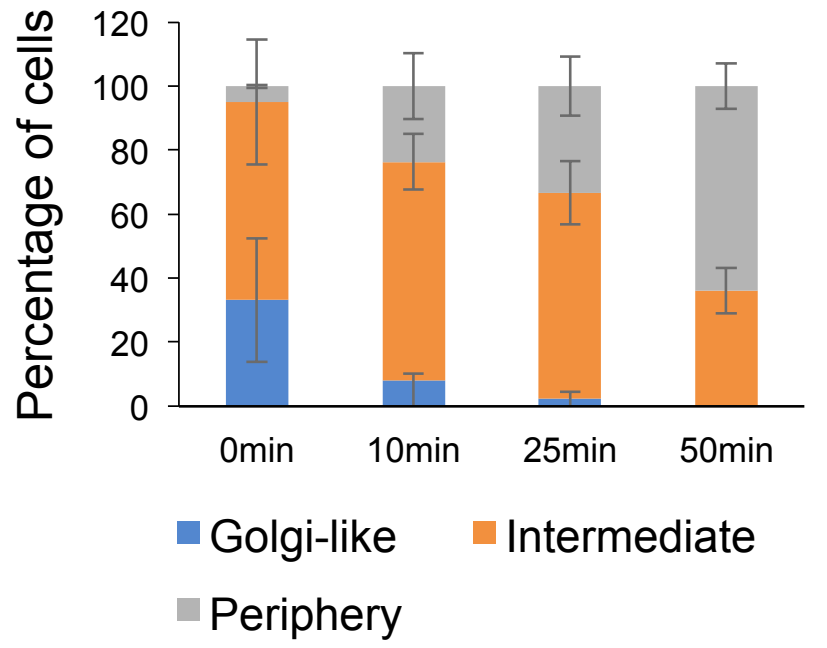




\section{Figure S10} under aCC-BY 4.0 International license.
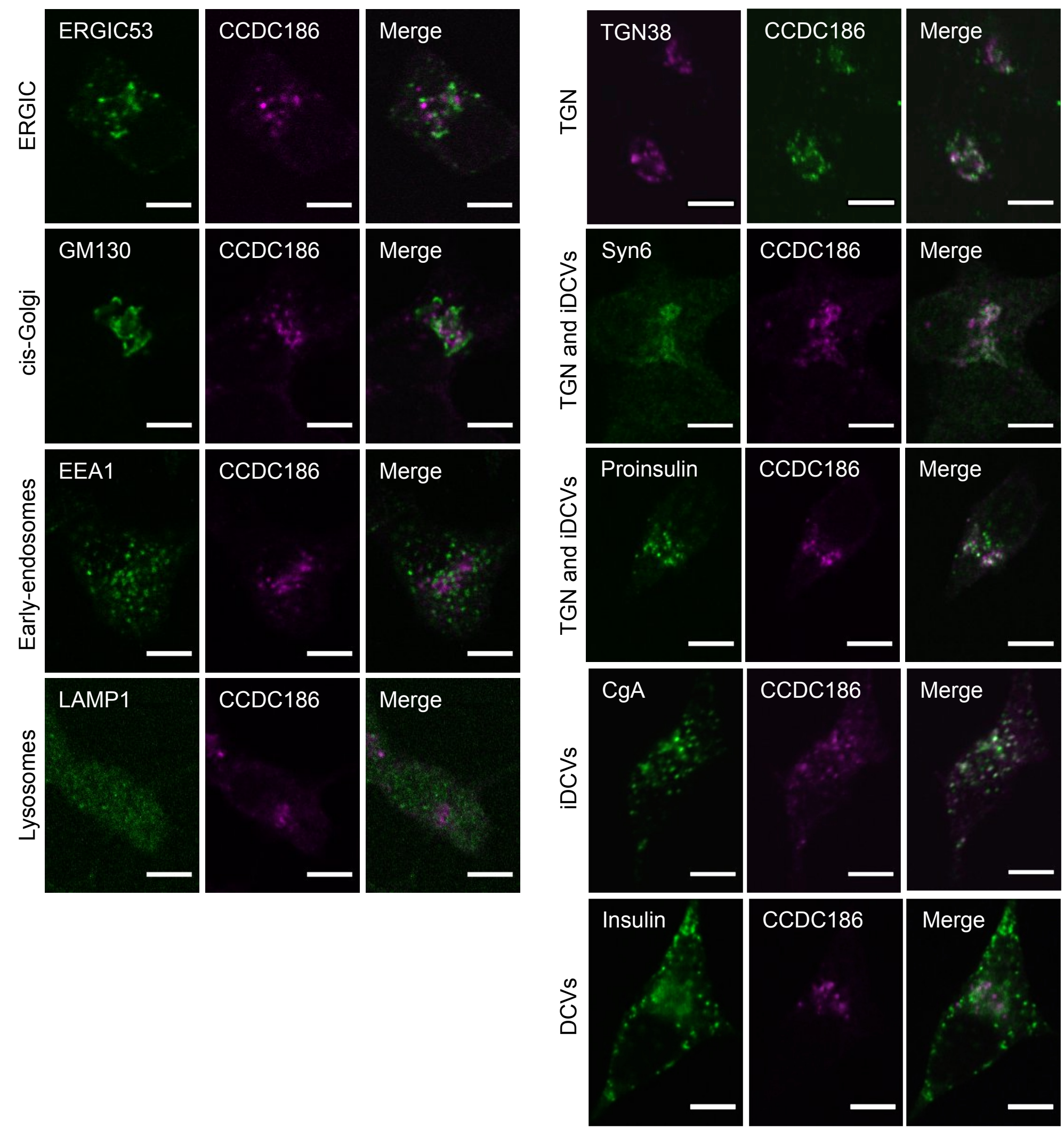
bioRxiv preprint doi: https://doi.org/10.1101/616458; this version posted November 6, 2019. The copyright holder for this preprint (which was not certified by peer review) is the author/funder, who has granted bioRxiv a license to display the preprint in perpetuity. It is made available under aCC-BY 4.0 International license.

Figure S11
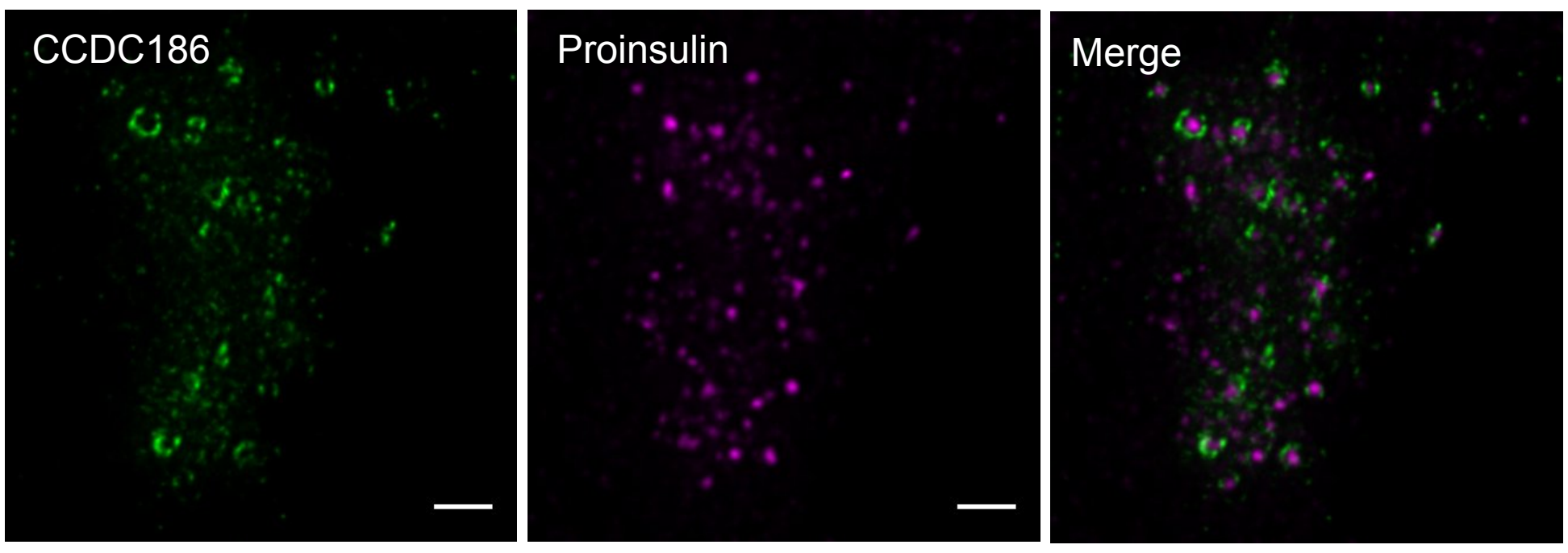


\section{Figure S12}

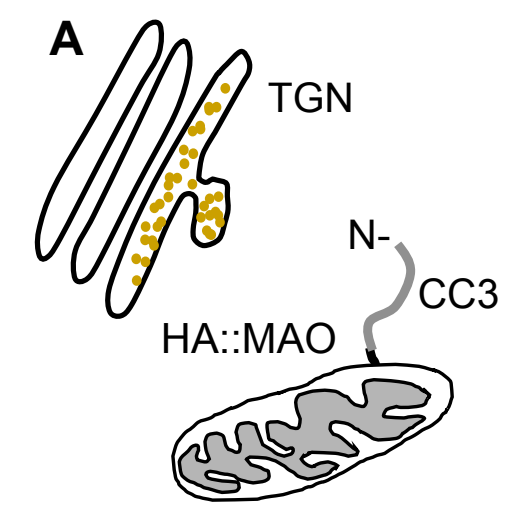

B

CCDC186, aa 1-922

$\mathrm{CC}$

$\mathrm{CC}$ CC

CC3::HA::MAO, aa 750-922

$\mathrm{CC}=$ coiled-coil

Mitochondria

C
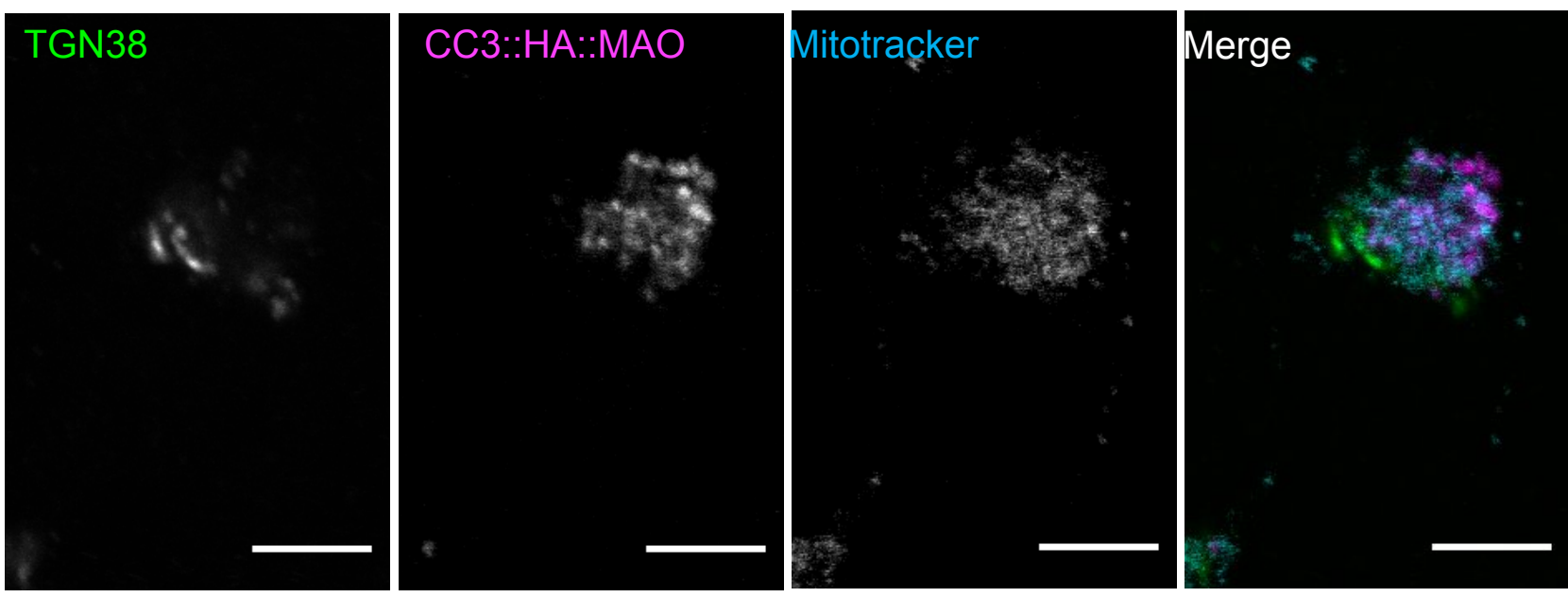

D
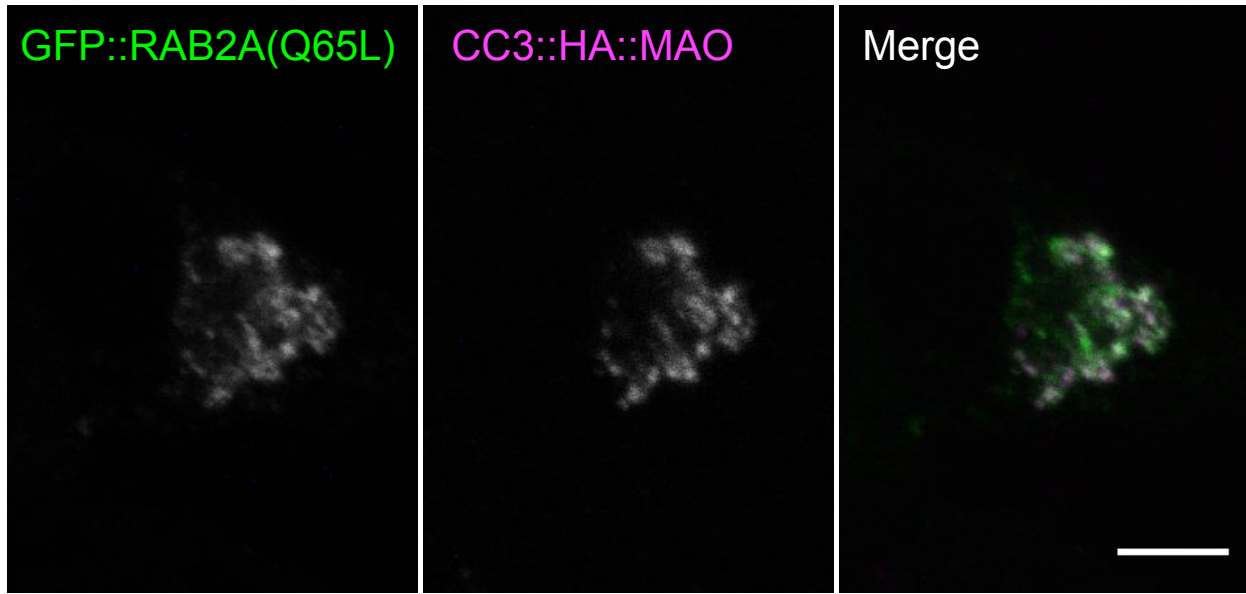

E
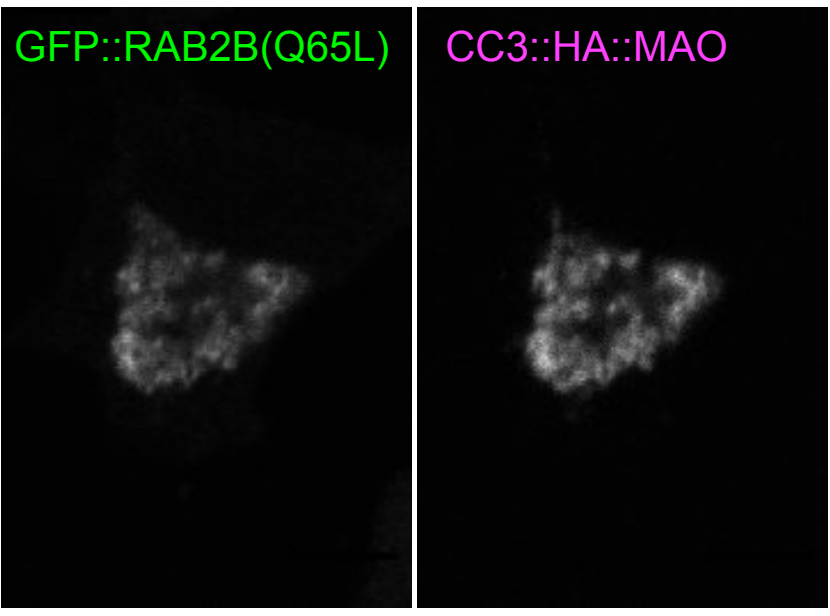

Merge 
bioRxiv preprint doi: https://doi.org/10.1101/616458; this version posted November 6,2019 . The copyright holder for this preprint (which was not certified by peer review) is the author/funder, who has granted bioRxiv a license to display the preprint in perpetuity. It is made available under aCC-BY 4.0 International license.

\section{Figure S13}

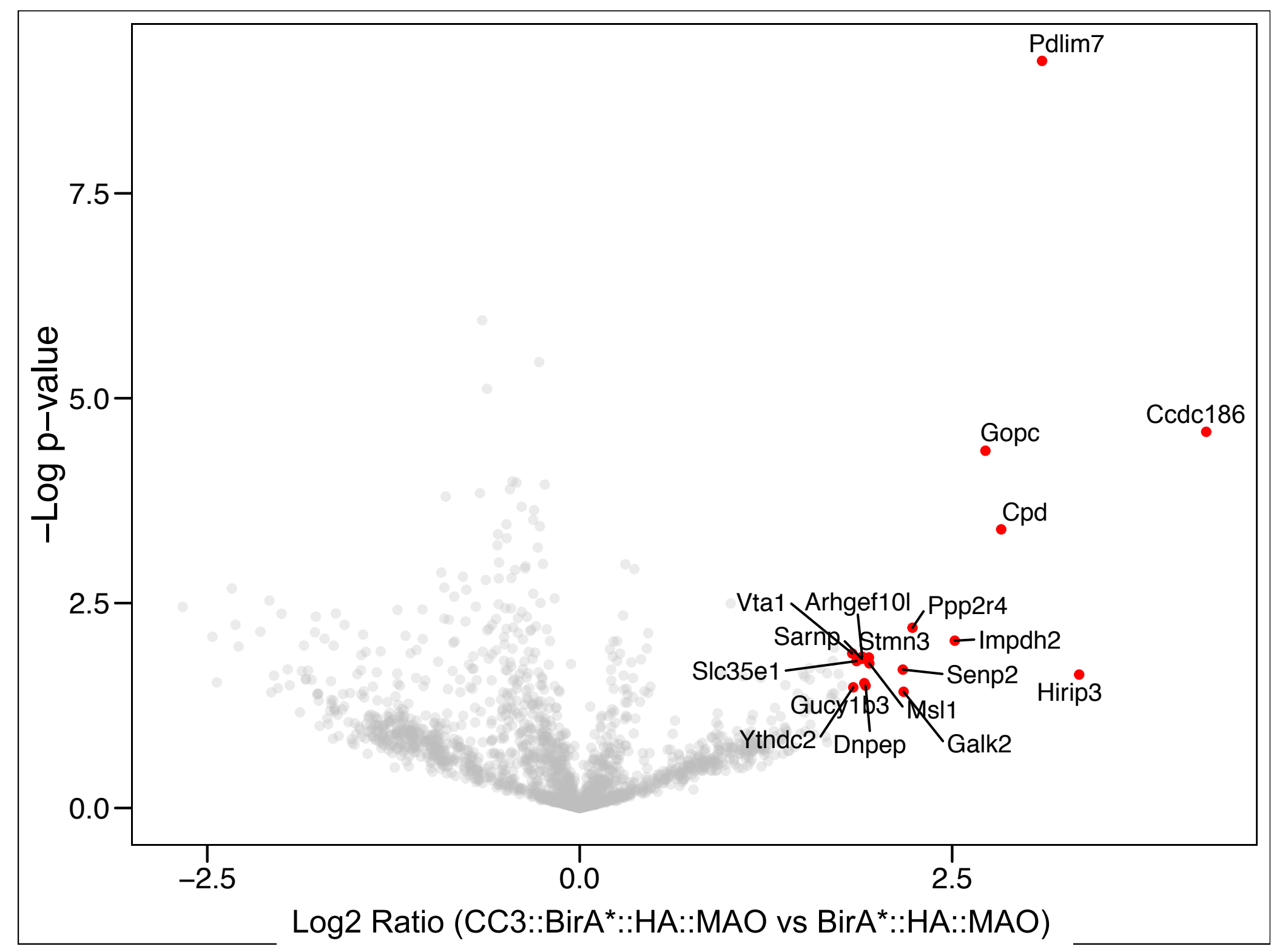


bioRxiv preprint doi: https://doi.org/10.1101/616458; this version posted November 6, 2019. The copyright holder for this preprint (which was not certified by peer review) is the author/funder, who has granted bioRxiv a license to display the preprint in perpetuity. It is made available under ACC-BY 4.0 International license.

\section{Figure S14}
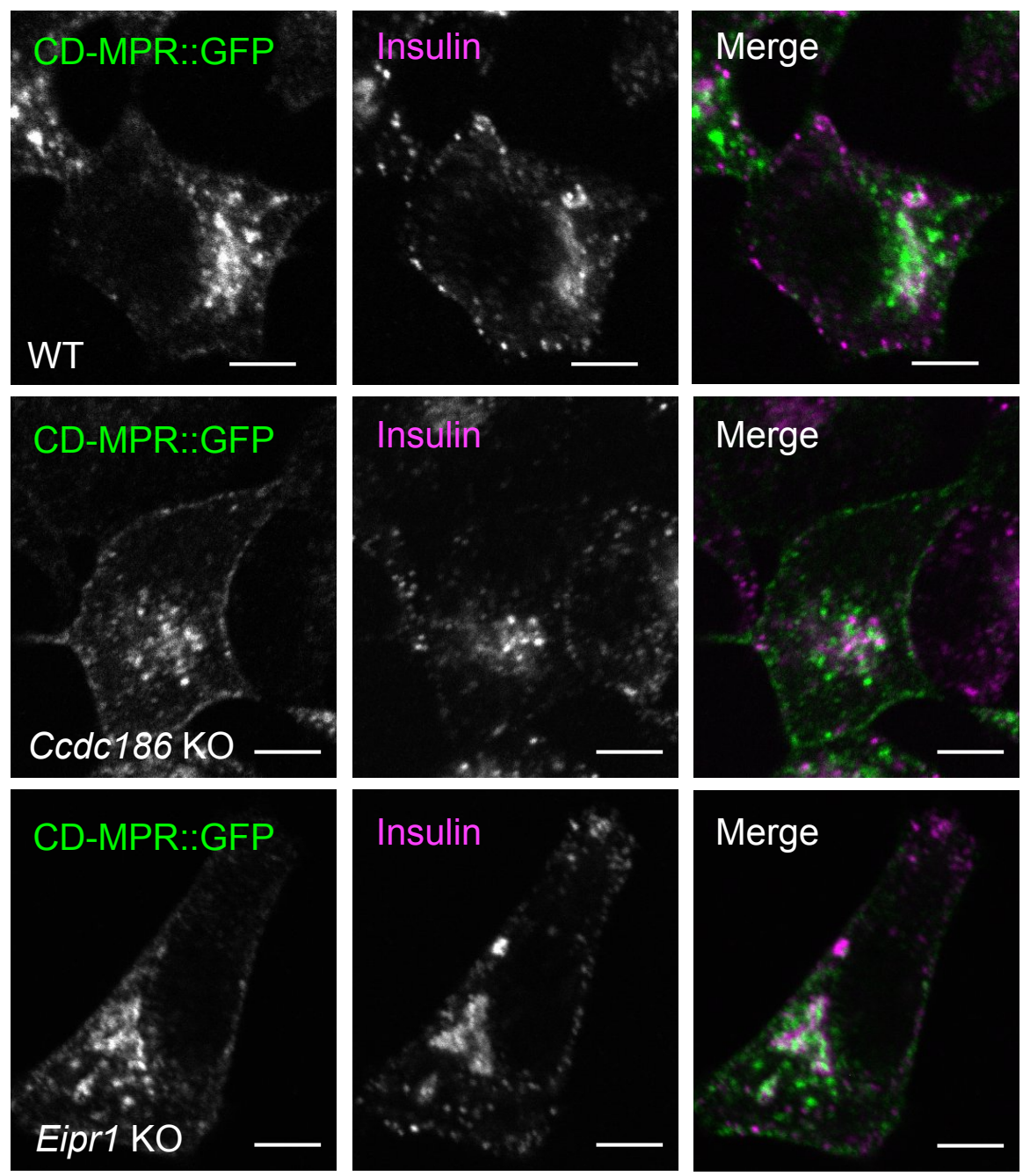


\section{TABLES}

Table S1. Top hits from CC3 BiolD experiment.

Unique peptide count organized in the descending order of the difference in number of unique peptides from CC3::BirA*::HA::MAO and the negative control BirA*::HA::MAO. The table shows the hits where the difference was 3 or greater. These data are from the BiolD experiment that showed the largest amount of enrichment for CPD. For raw data, see Table S6. 


\section{Table S1}

\begin{tabular}{|c|c|c|c|c|}
\hline Protein IDs & Gene names & $\begin{array}{c}\text { Peptides } \\
\text { BirA*::HA::MAO } \\
\text { (control) } \\
\end{array}$ & $\begin{array}{c}\text { Peptides } \\
\text { CC3::BirA* ::HA::MA } \\
0 \\
\end{array}$ & $\begin{array}{c}\text { Peptides } \\
\text { CC3::BirA*::HA::MAO } \\
\text { minus peptides } \\
\text { BirA*::HA::MAO }\end{array}$ \\
\hline Q9JHW1 & Cpd & 1 & 16 & 15 \\
\hline A0A0G2K8K1 & Ccdc186 & 2 & 15 & 13 \\
\hline P52873 & $\mathrm{PC}$ & 85 & 94 & 9 \\
\hline F1M9D0;B5DF98 & Map3k2 & 3 & 9 & 6 \\
\hline G3V6W7 & Cpsf3 & 5 & 11 & 6 \\
\hline 008722 & Unc5b & 3 & 9 & 6 \\
\hline B1WBW7 & Traf7 & 0 & 5 & 5 \\
\hline G3V6B0;F1M024 & Pdxdc1 & 9 & 14 & 5 \\
\hline $\begin{array}{c}\text { Q9QYF3;P70569; } \\
\text { F1M111 }\end{array}$ & Myo5a & 35 & 39 & 4 \\
\hline $\mathrm{P} 11960$ & Bckdha & 6 & 10 & 4 \\
\hline Q510C3 & Mccc1 & 32 & 36 & 4 \\
\hline Q63347 & Psmc2 & 13 & 17 & 4 \\
\hline D3ZFX4 & Pgm3 & 2 & 6 & 4 \\
\hline Q9EQH1 & Gab2 & 11 & 15 & 4 \\
\hline Q62807 & Syt17 & 3 & 7 & 4 \\
\hline F1LM47 & Sucla2 & 7 & 11 & 4 \\
\hline B4F775 & Gopc & 0 & 4 & 4 \\
\hline Q62673 & Plk1 & 2 & 6 & 4 \\
\hline D4ACS3 & $\mathrm{Mb} 21 \mathrm{~d} 2$ & 0 & 4 & 4 \\
\hline Q99P39 & Nfs1 & 3 & 6 & 3 \\
\hline E9PSQ0 & Acacb & 11 & 14 & 3 \\
\hline Q6QDP7;Q66HA2 & Creb3l2 & 4 & 7 & 3 \\
\hline $\mathrm{P} 13437$ & Acaa2 & 10 & 13 & 3 \\
\hline Q501R9 & Nbr1 & 6 & 9 & 3 \\
\hline B5DEJ5 & Eefsec & 1 & 4 & 3 \\
\hline $\mathrm{P} 14882$ & Pcca & 28 & 31 & 3 \\
\hline F1LT49 & Lrrc47 & 11 & 14 & 3 \\
\hline $\begin{array}{c}\text { P68136;P68035;P } \\
\text { 63269;P62738 } \\
\end{array}$ & $\begin{array}{c}\text { Acta1;Actc1;A } \\
\text { ctg2;Acta2 }\end{array}$ & 12 & 15 & 3 \\
\hline D3ZJ50 & Pkp3 & 2 & 5 & 3 \\
\hline P63045;P63025 & Vamp2;Vamp3 & 1 & 4 & 3 \\
\hline $\mathrm{D} 4 \mathrm{~A} 017$ & Tmem87a & 1 & 4 & 3 \\
\hline
\end{tabular}


Table S2. C. elegans strain list

N2 Bristol wild-type

EG334 cccp-1(ox334) III

EG6007 vps-50(ok2627) III

EG6939 eipr-1(tm4790) I

XZ1924 vps-50(ok2627) III cccp-1(ox334) III

XZ2108 eipr-1(tm4790) I ; cccp-1(ox334) III

KG1395 nuls183[Punc-129::NLP-21-Venus, Pmyo-2::GFP] III

EG5258 nuls183[Punc-129::NLP-21-Venus, Pmyo-2::GFP] III cccp-1(ox334) III

XZ1055 eipr-1(tm4790) I ; nuls183[Punc-129::NLP-21-Venus, Pmyo-2::GFP] III

XZ1607 nuls183[Punc-129::NLP-21-Venus, Pmyo-2::GFP] III vps-50(ok2627) III

XZ1918 nuls183[Punc-129::NLP-21-Venus, Pmyo-2::GFP] III vps-50(ok2627) III cccp-1(ox334)

III

XZ2109 eipr-1(tm4790) I ; nuls183[Punc-129::NLP-21-Venus, Pmyo-2::GFP] III cccp-1(ox334)

III 
Table S3. Plasmid list

\begin{tabular}{|c|c|c|}
\hline Plasmid name & Vector backbone & Description \\
\hline pEGFP-N1 & & $\begin{array}{l}\text { GFP expression vector, a gift from Suzanne } \\
\text { Hoppins }\end{array}$ \\
\hline pET50 & pEGFP-N1 & $\begin{array}{l}\text { CCDC186::GFP full length, rat CCDC186 } \\
\text { CDNA }\end{array}$ \\
\hline ANF::GFP & pEGFP-N1 & $\begin{array}{l}\text { ANF::GFP (rat atrial natriuretic factor fused to } \\
\text { GFP, (Hummer et al., 2017) }\end{array}$ \\
\hline ssGFP & pCAGGS & $\begin{array}{l}\text { signal sequence of rat ANF fused to GFP in the } \\
\text { chicken actin-based vector pCAGGS } \\
\text { (Hummer et al., 2017) }\end{array}$ \\
\hline pET55 & pEGFP-N1 & $\begin{array}{l}\text { GFP::RAB2A, RAB2A cDNA was PCR } \\
\text { amplified from } 832 / 13 \text { cDNA library }\end{array}$ \\
\hline pET54 & pEGFP-N1 & $\begin{array}{l}\text { GFP::RAB2B, RAB2B cDNA was PCR } \\
\text { amplified from } 832 / 13 \text { cDNA library }\end{array}$ \\
\hline pJC239 & pCMV-Myc & Myc::CCDC186 \\
\hline pJC271 & pCDNA3.1 & CC3::CCDC186(750-922)::HA::MAO \\
\hline pJC280 & pCDNA3.1 & CC3::CCDC186(759-922)::BirA*::HA::MAO \\
\hline pJJS112 & pCDNA3.1 & BirA*::HA::MAO, a gift from Sean Munro \\
\hline pJC279 & pEGFP-N1 & $\begin{array}{l}\text { CD-MPR::GFP, CD-MPR cDNA was PCR } \\
\text { amplified from } 832 / 13 \text { cDNA library }\end{array}$ \\
\hline pPUR & & A gift from Richard Palmiter \\
\hline pBABE-hygro & & A gift from Suzanne Hoppins \\
\hline $\begin{array}{l}\text { pSpCas9(BB)-2A- } \\
\text { GFP }\end{array}$ & & PX458 (Addgene) \\
\hline pET221 & pBABE-hygro & CCDC186 in pBABE-hygro \\
\hline pET64 & pSpCas9(BB)-2A-GFP & CCDC186 guide RNA in pSpCas9(BB) \\
\hline pET70 & pPUR & $\begin{array}{l}\text { CCDC186 HR (homologous recombination } \\
\text { cassette) in pPUR backbone }\end{array}$ \\
\hline FUGW & & $\begin{array}{l}\text { 3rd generation lentiviral plasmid with hUbC- } \\
\text { driven EGFP; can be used for cDNA } \\
\text { expression (Addgene \#14883) }\end{array}$ \\
\hline psPAX2 & & $\begin{array}{l}\text { 2nd generation lentiviral packaging plasmid. } \\
\text { Can be used with } 2 \text { nd or } 3 \text { rd generation } \\
\text { lentiviral vectors and envelope expressing } \\
\text { plasmid (Addgene \#12259) }\end{array}$ \\
\hline pVSVG & & $\begin{array}{l}\text { Envelope protein for producing lentiviral and } \\
\text { MuLV retroviral particles. Use in conjunction } \\
\text { with a packaging vector such as pCMV-dR8.2 } \\
\text { dvpr (lentiviral) or pUMVC (MuLV retroviral). } \\
\text { (Addgene \#8454) }\end{array}$ \\
\hline St6Gal1::pHluorin & FUGW & $\begin{array}{l}\text { 17-residue transmembrane domain of beta- } \\
\text { galactoside alpha } 2,6 \text {-sialyltransferase fused to } \\
\text { pHluorin. }\end{array}$ \\
\hline
\end{tabular}


Table S4. Primary antibody list

\begin{tabular}{|c|c|c|}
\hline $\begin{array}{l}\text { Antibody } \\
\text { target }\end{array}$ & $\begin{array}{l}\text { Manufacturer and } \\
\text { catalog number }\end{array}$ & Notes \\
\hline CCDC186 & Novus \#NBP1-90440 & $\begin{array}{l}\text { Rabbit polyclonal, 1:150 for IF and 1:1,000 for } \\
\text { WB }\end{array}$ \\
\hline TGN38 & Sigma \#T9826 & Rabbit polyclonal, 1:350 for IF \\
\hline EEA1 & BD Biosciences \#610456 & Mouse monoclonal, 1:100 for IF \\
\hline GM130 & BD Biosciences \#610822 & $\begin{array}{l}\text { Mouse monoclonal, } 1: 100 \text { for IF, but works at } \\
1: 300\end{array}$ \\
\hline ERGIC53 & Santa Cruz \#sc-398893 & Mouse monoclonal, 1:50 for IF \\
\hline LAMP1 & DHSB & Mouse monoclonal, 1:50 for IF \\
\hline GFP & Santa Cruz \#sc-9996 & $\begin{array}{l}\text { Mouse monoclonal, } 1: 200 \text { to } 1: 400 \text { for IF, } 1: 1,000 \\
\text { for WB }\end{array}$ \\
\hline GFP & Santa Cruz \#sc-8334 & $\begin{array}{l}\text { Rabbit polyclonal, 1:200 to } 1: 400 \text { for IF, 1:1,000 } \\
\text { for WB }\end{array}$ \\
\hline Insulin & Sigma \#|2018 & Mouse monoclonal, 1:400 for IF \\
\hline Proinsulin & Abcam \#ab8301 & Mouse monoclonal, 1:200 for IF \\
\hline Syntaxin 6 & Abcam \#ab12370 & Mouse monoclonal, 1:100 for IF \\
\hline TGN38 & Novus \#NB300-575S & Mouse monoclonal, 1:500 for IF \\
\hline $\mathrm{CgA}$ & Santa Cruz \#sc-393941 & Mouse monoclonal, 1:200 for IF \\
\hline Myc & Santa Cruz sc-40 & Mouse monoclonal, 1:200 for IF, 1:1,000 for WB \\
\hline GFP & Roche \#11814460001 & Mouse monoclonal, 1:1,000 for WB \\
\hline Beta-tubulin & DHSB E7 & Mouse monoclonal, 1:1,000 for WB \\
\hline Beta-tubulin & $\begin{array}{l}\text { ThermoFisher, BT7R, } \\
\text { \#MA5-16308 }\end{array}$ & Mouse monoclonal, 1:1,000 for WB \\
\hline $\mathrm{HA}$ & Roche \#11867423001 & Rat monoclonal, 1:150 for IF and 1:1,000 for WB \\
\hline CPD* $^{*}$ & $\begin{array}{l}\text { A gift from Lloyd Fricker } \\
\text { AE160 }\end{array}$ & $\begin{array}{l}\text { Rabbit polyclonal, 1:200 for IF and 1:1,000 for } \\
\text { WB }\end{array}$ \\
\hline PCSK1 (PC1/3) & Sigma SAB1100415 & Rabbit polyclonal, 1:1,000 for WB \\
\hline $\begin{array}{l}\text { CPE-N } \\
\text { terminus** }\end{array}$ & A gift from Lloyd Fricker & Rabbit polyclonal, 1:1,000 for WB, 1:100 for IF \\
\hline $\begin{array}{l}\text { Pro-CPE } \\
\text { form }\end{array}$ & A gift from Lloyd Fricker & Rabbit polyclonal, $1: 1,000$ for $\mathrm{WB}, 1: 100$ for IF \\
\hline $\begin{array}{l}\text { CPE-C } \\
\text { terminus }\end{array}$ & A gift from Lloyd Fricker & Rabbit polyclonal, 1:1,000 for WB, 1:100 for IF \\
\hline
\end{tabular}

* Antiserum was generated to the C-terminal 57 amino acids of mammalian CPD (cytosolic tail, (Song and Fricker, 1996).

** Antiserum was raised to the N-terminal 15 amino acids of bovine CPE (Fricker et al., 1990).

${ }^{* * *}$ Antiserum to pro-CPE was generated to the peptide QEPGAPAAGMRRC coupled to maleimide-activated keyhole limpet hemocyanin $(\mathrm{KLH})$. This peptide corresponds to the 12 residues of mouse/rat/human pro-CPE with an added Cys on the C-term (for coupling to the carrier protein, $\mathrm{KLH})$. 
bioRxiv preprint doi: https://doi.org/10.1101/616458; this version posted November 6 , 2019. The copyright holder for this preprint (which was not certified by peer review) is the author/funder, who has granted bioRxiv a license to display the preprint in perpetuity. It is made available under aCC-BY 4.0 International license.

${ }^{* * * *}$ Antiserum was raised against the 9-residue peptide KMMSETLNF corresponding to the C terminus of mouse CPE (Fricker et al., 1996). 
Table S5. Secondary antibody list

\begin{tabular}{|c|c|c|}
\hline Antibody target & $\begin{array}{l}\text { Manufacturer and } \\
\text { catalog number }\end{array}$ & Notes \\
\hline $\begin{array}{l}\text { Anti-mouse } \\
\text { Alexa488 }\end{array}$ & $\begin{array}{l}\text { Jackson } \\
\text { immunoresearch \#115- } \\
545-146\end{array}$ & 1:1000 for IF \\
\hline $\begin{array}{l}\text { Anti-mouse } \\
\text { Rhodamine Rex-X }\end{array}$ & $\begin{array}{l}\text { Jackson } \\
\text { immunoresearch \#715- } \\
295-150\end{array}$ & $1: 1000$ for IF \\
\hline $\begin{array}{l}\text { Anti-rabbit } \\
\text { Alexa488 }\end{array}$ & $\begin{array}{l}\text { Jackson } \\
\text { immunoresearch } \\
\# 711-545-152\end{array}$ & 1:1000 for IF, (1:100 for STED microscopy) \\
\hline $\begin{array}{l}\text { Anti-rabbit } \\
\text { Rhodamine TRITC }\end{array}$ & $\begin{array}{l}\text { Jackson } \\
\text { immunoresearch \#111- } \\
\text { 025-144 }\end{array}$ & $1: 1000$ for IF \\
\hline Anti-rat Dylight550 & $\begin{array}{l}\text { ThermoFisher \#SA5- } \\
10027\end{array}$ & $\begin{array}{l}\text { Highly cross-adsorbed, 1:200 to } 1: 500 \text { for } \\
\text { IF }\end{array}$ \\
\hline Anti-rabbit Atto647 & $\begin{array}{l}\text { A gift from Joshua } \\
\text { Vaughan's lab }\end{array}$ & $1: 200$ for IF \\
\hline $\begin{array}{l}\text { Anti-mouse } \\
\text { Dylight488 }\end{array}$ & $\begin{array}{l}\text { ThermoFisher \#SA5- } \\
10166\end{array}$ & $\begin{array}{l}\text { Highly cross-adsorbed, used at 1:200 to } \\
1: 500\end{array}$ \\
\hline $\begin{array}{l}\text { Anti-mouse } \\
\text { Alexa555 }\end{array}$ & $\begin{array}{l}\text { A gift from Joshua } \\
\text { Vaughan's lab }\end{array}$ & Used at 1:10 for STED microscopy \\
\hline $\begin{array}{l}\text { Goat anti-rabbit } \\
\text { Alexa680 }\end{array}$ & $\begin{array}{l}\text { Jackson } \\
\text { immunoresearch \#111- } \\
625-144\end{array}$ & $1: 20,000$ for western \\
\hline $\begin{array}{l}\text { Goat anti-mouse } \\
\text { Alexa680 }\end{array}$ & $\begin{array}{l}\text { Jackson } \\
\text { immunoresearch } \\
\# 115-625-166\end{array}$ & $1: 20,000$ for western \\
\hline $\begin{array}{l}\text { Donkey anti-mouse } \\
\text { Alexa790 }\end{array}$ & $\begin{array}{l}\text { Jackson } \\
\text { immunoresearch \#715- } \\
655-150\end{array}$ & $1: 20,000$ for western \\
\hline $\begin{array}{l}\text { Alexa790 } \\
\text { Streptavidin }\end{array}$ & $\begin{array}{l}\text { Jackson } \\
\text { immunoresearch \#016- } \\
650-084\end{array}$ & $1: 10,000$ for western \\
\hline
\end{tabular}


Table S6. Raw mass-spec data for CC3 BiolD experiment.

The table contains all the data for the experiment shown in Table S1.

Table S7. LFQ intensities for CC3 BiolD experiment.

The table contains Z-score normalized log2 LFQ intensities from MaxQuant output, Student's ttest $p$-values and ratios (CC3::BirA*::HA::MAO vs BirA*::HA::MAO). For calculation of $p$-values and ratios, see Materials and Methods. 